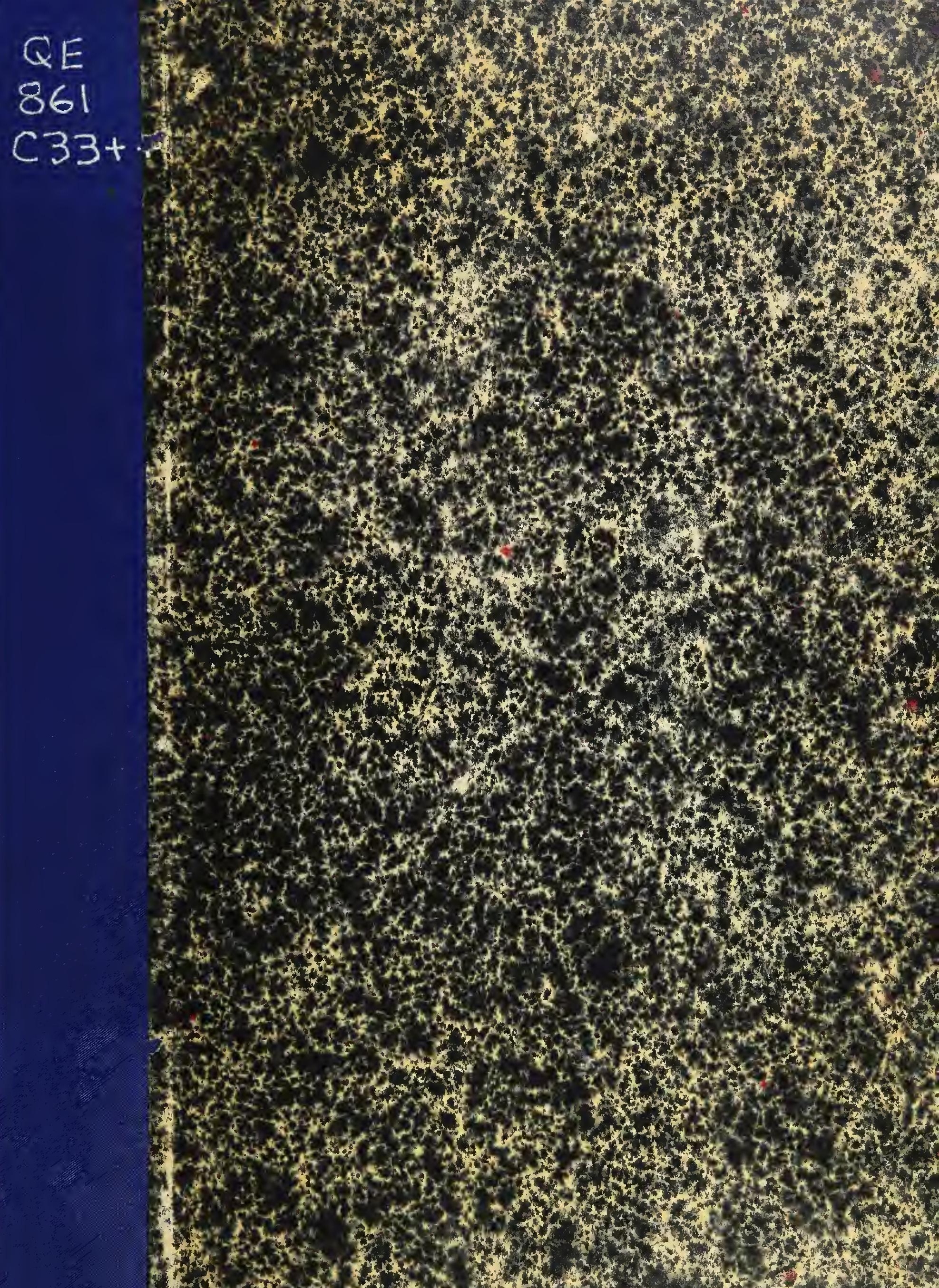




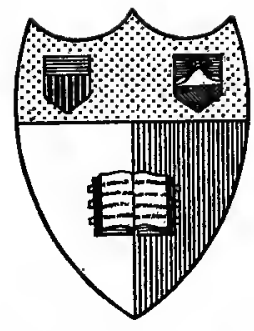

\section{Gurnell Inineraity Jibrary}

3thara. Nem york

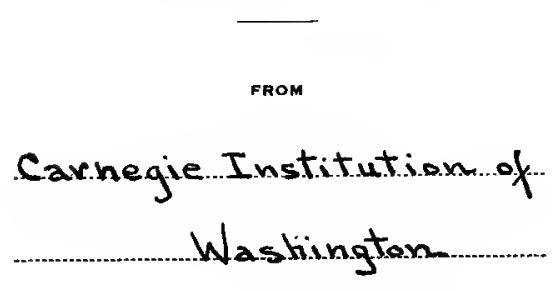


QE 861. Cornell University Library $^{\text {C33 }}$

New reptiles and stegocephalians from th

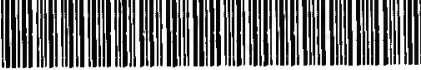

31924003885666 



\section{NEW REPTILES AND STEGOCEPHALIANS FROII THE UPPER}

TRIASSIC OF WESTERN TEXAS.

BY

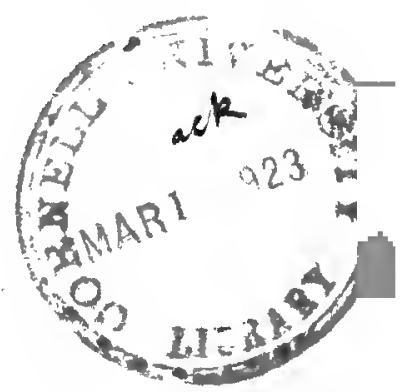

E. C. CASE

Professor of Historical Geology and Paloeontology in the University of Michigan

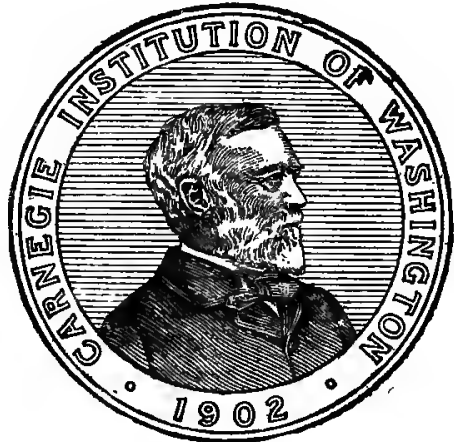





\title{
NEW REPTILES AND STEGOCEPHALIANS FROII THE UPPER TRIASSIC OF WESTERN TEXAS.
}

\author{
BY \\ E. C. CASE \\ Professor of Historical Geology and Palcoontology in the University of Michigan
}

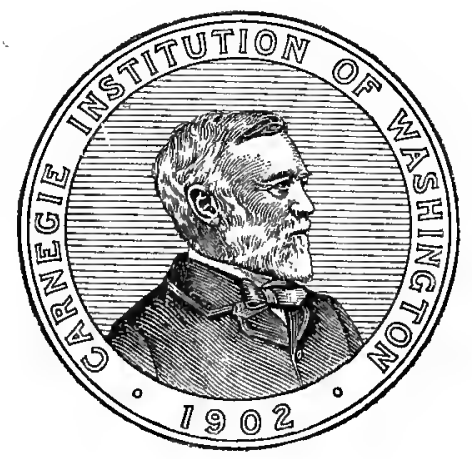

Published by the Carnegie Institution of Washington

Washington, OCtOBER, 1922. 


$$
\text { A520881 }
$$

CARNEGIE INSTITUTION OF WASHINGTON , Publication No. 321

Copies of this book Ama ins? OCT 191922

TECHNICAL PRESS

WASHINGTON, D. C. 


\section{CONTENTS.}

Introduction. PAgE

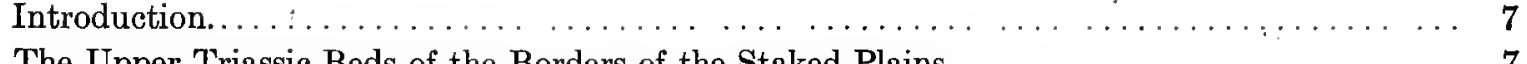

The Upper Triassic Beds of the Borders of the Staked Plains. $\ldots \ldots \ldots \ldots \ldots \ldots \ldots \ldots$

The Literature of the Triassic Vertebrates of Sith America. . . . . . . . . . . . . . . 12

A New Genus of the Stegocephalia, Buettneria perfecta . . . . . . . . . . . . . . 13

Description of Desmatosuchus spurensis and the New Suborder Desmatosuchia. . . . . . . . . 26

A New Parasuchian, Promystriosuchus ehlersi. . . . . . . . . . . . . . . . . . . . . 49

New Parasuchians, Leptosuchus crosbiensis and Leptosuchus imperfecta, from Crosby County,

Texas.........................................61

Description of Isolated Bones of Parasuchians. $\ldots \ldots \ldots \ldots \ldots \ldots \ldots$

Description of the Remains of Dinosaurs $\ldots \ldots \ldots \ldots \ldots \ldots$

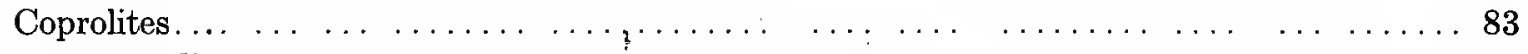

Incertæ sedis $\ldots \ldots \ldots \ldots \ldots \ldots \ldots \ldots \ldots \ldots \ldots \ldots \ldots \ldots \ldots \ldots \ldots$ 


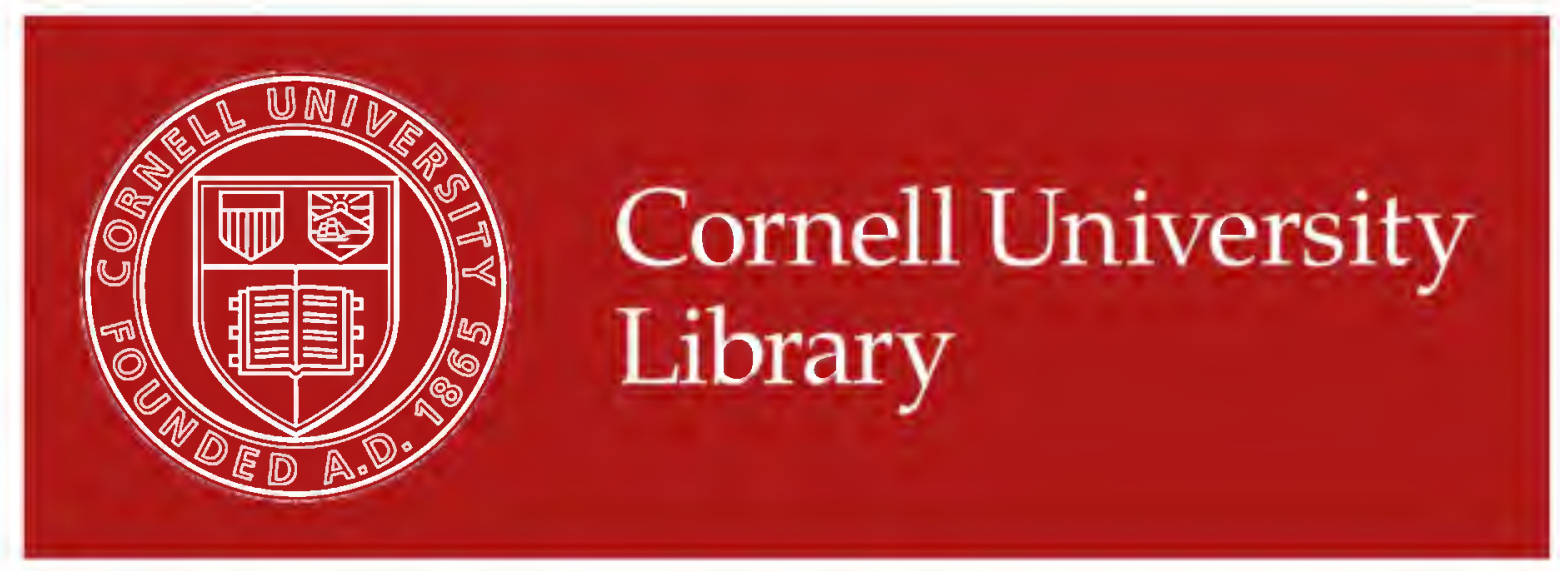

\section{The original of this book is in the Cornell University Library.}

There are no known copyright restrictions in the United States on the use of the text. 


\title{
NEW REPTILES AND STEGOCEPHALIANS FROM THE UPPER TRIASSIC OF WESTERN TEXAS
}

\author{
By E. C. CASE
}

\section{ERRATA.}

Page 21, Fig. 3, in place of $\mathrm{x}^{\prime}$ read $\mathrm{x}$, and in place of $\mathrm{x}$ read $\mathrm{x}^{\prime}$.

Page 28, line 24, in place of $7 \mathrm{~A}$ read $7 \mathrm{~B}$.

Page 44, fifteenth line from bottom, in place of "shown in figure 16A and B", read "shown in figure $16 \mathrm{E}$ and $\mathrm{F} . "$

Page 46 , line 5 , in place of $18 \mathrm{C}$ read figure $18 \mathrm{~A}$.

Page 61 , about middle of page, in place of $25 \mathrm{~A}$ read $25 \mathrm{~B}$.

Plate $7, \mathrm{~K}$ and $\mathrm{L}$, in place of anterior dorsals, read anterior caudals. 



\title{
NEW REPTILES AND STEGOCEPIIALIANS FROM THE UPPER TRIASSIC OF WESTERN TEXAS
}

\author{
By E. C. CASE
}





\title{
NEW REPTILES AND STEGOCEPHALIANS FRONI THE UPPER TRIASSIC OF WESTERN TEXAS.
}

\author{
By E. C. Case.
}

\section{INTRODUCTION.}

By aid of grants from the Carnegie Institution of Washington, the author has been for a number of years continuously at work upon the investigation of the vertebrate fauna of the Permo-Carboniferous beds of North America. The sudden and complete disappearance of this fauna (followed, after an interval represented by barren beds, by a highly specialized Upper Triassic fauna) has always been a tantalizing problem-the more so as the barren beds between the two widely different faunæ are practically the same, in all the implications as to climate, mode of deposition, and terrestrial conditions, as the fossiliferous beds above and below.

The interval of time represented by the barren beds is just the interval in which was developed the wonderful Permian and Triassic reptilian life of South Africa, Russia, and western Europe. A few very uncertain remains, briefly discussed in the section of this paper dealing with the Upper Triassic beds of western Texas, suggest the possibility that something of the Lower Triassic life of the Eastern Hemisphere reached North America. For these reasons the barren beds have been followed and searched with extreme care wherever they occur, but so far no trace of vertebrate life has been found in them. While engaged in such a search, the author learned of a small area in Crosby County, Texas, which has yielded a considerable amount of Upper Triassic vertebrate material, most of which is new. The present paper contains descriptions of this new and interesting fauna.

The author takes this opportunity to thank the Carnegie Institution of Washington and its officers for the continued support which has made the work possible. Also, he wishes to acknowledge his obligation to Mr. Clifford Jones, manager of the Spur Farm Lands Company, and the other officers of the Swenson properties, for permission to go upon the lands under their control and for many acts of kindness and courtesy which rendered the task of collection much easier and contributed largely to the success of the work.

\section{THE UPPER TRIASSIC BEDS OF THE BORDERS OF THE STAKED PLAINS.}

The Upper Triassic beds exposed on the borders of the Staked Plains in Texas and New Mexico present the same puzzling complex of terrestrial and fresh-water deposits that they do wherever they appear in the other Plains and Rocky Mountain States. No definite determination of continuous horizons is possible, as the sequence alters rapidly within a short distance and there are many 
lenses and intercalated beds of small extent. Invertebrate fossils are few, limited to Unios, which are generally so poorly preserved as to be indeterminate specifically; frequently there is an abundance of fossil wood in the form of larger or smaller fragments, but none has been determined. An attempt to determine the wood revealed that it was badly rotted before fossilization and so deeply impregnated with gypsum as to destroy the cell structure. Knowlton's catalogue of the Mesozoic and Cenozoic plants of North America mentions no Triassic plants from Texas, and those listed from New Mexico are from the central and southern portions. The age of the beds must be determined by the vertebrate fossils, and these indicate an Upper Triassic stage, approximately equivalent to the Keuper of Europe.

On the borders of the Staked Plains, as in the other regions of the United States where the Triassic is exposed, there seems to be no possibility of determining the boundary between the Permo-Carboniferous beds and the Triassic. The Red Beds are apparently continuous across the interval, and the connecting beds are, so far as known, entirely devoid of any evidence of life. It is in this connecting series of beds, representing the period of the great development of reptilian life in the late Permo-Carboniferous and the early Triassic in South Africa, that some representation of that life should appear if it were present in North America. Because of this fact the transition beds have been repeatedly searched with the greatest care, but as yet nothing has been found. The only remains that suggest the presence of anything like the South African forms in North America are the problematical fossil found in West Virginia, 200 feet below the base of the Pittsburgh coal bed and the base of the Monongahela Series, in Braxton County, West Virginia, named Pareiasaurus(?) henningi by I. C. White, and the forms described by Williston, from a few poorly preserved bones, as Eubrachiosaurus and Brachybrachium, from the Popo Agie beds near Landor, Wyoming. The first of these Williston² regarded as belonging near to Tapinocephalus or Phocosaurus, and Dr. Broom, in conversation with the author, stated his opinion that it was Deinocephalian in its affinities. Here, also, should be mentioned the humerus, described by Lucas as Placerias hesternus, from the Triassic near Tanner's Crossing, Little Colorado River, Arizona. ${ }^{3}$ These remains are far too little known to permit of any conclusion being drawn from them, and they do not occur in the transition beds, but below and above them.

The Triassic beds of the borders of the Staked Plains have been divided by Drake $e^{4}$ into three parts, and his divisions are recognizable in a broad way, but rarely can any definite boundaries be assigned to the divisions, nor can the provisional separation made in one place be carried satisfactorily for any distance. Drake described his three divisions as follows:

\footnotetext{
${ }^{1}$ Case, E. C., Notes on the Possible Evidenee of a I'treiasaur-like Reptile in the Conemaugh Series of West Virginia, West Virginia Geologieal Survey, Braxton and Clay County Report, p. 803, 1917.

${ }^{2}$ Williston, S. W., Notiee of Some New Reptiles from the Upper Triassic of Wyoming, Journal of Geology,
vol. XII, p. 690, 1904 .

${ }^{3}$ Lueas, F. B., Proceedings U. S. National Museum, vol. 27, p. 194, pl. 1r, 1904. ${ }^{4}$ Drake, N. F., Stratigraphy of the Triassie Formation of Northwest Texas, Third Annual Report Texas'
Geological Survey, p. 227, 1892.
} 
"Stratigraphy.-The following classification or grouping is not intended as a correlation with any other Triassic beds, but only to apply to the Dockum beds over the area examined. The Dockum may be divided into three beds, though some localities show more, that are more or less well marked. $*^{*} *$ These three main beds are as follows: A lower bed of sandy clay, which is from 0 to 150 feet thick; a central bed or beds of sandstone, conglomerate, and some sandy clay, which is from 0 to 235 feet thick; an upper bed of sandy clay and some sandstone, which is from 0 to 300 feet thick. While these groups represent the different geological horizons over most of the Triassic area, there is nevertheless at some places a thinning out of the one, and a thickening of another, which shows that at the same time the conditions of deposition were somewhat different at different localities. The same geological horizon is, therefore, more or less represented in other beds than that which generally represents it. Then, while these beds do not absolutely represent geological horizons, they do so approximately and are so well marked as to be of stratigraphical value."

On the east side of the Staked Plains the lower beds are red sandy shales which may be traced from the Canadian River southward to where they disappear beneath the Cretaceous and younger deposits south of Big Springs, in Howard County. These beds shade downward indefinitely into the Double Mountain beds of the Permo-Carboniferous. The author has repeatedly crossed the line, in every county of Texas where it lies, from the Canadian River on the north as far south as the Triassic appears, and has been unable to draw any line that can be used to separate the two formations. In passing from the towns Seymour, Vernon, Haskell, Anson, and Abilene westward to the Triassic at the base of the Plains, the same indefinite boundary is crossed. The red beds grow more shaly, and in general there is an increase in the amount of gypsum, which may occur in beds from a few inches to as much as 3 feet thick, or may be in fine seams running in all directions through the red sandy clay. The same condition is found in the breaks of the Canadian River and in the great canyons which penetrate into the Plains in Randall, Armstrong, Swisher, and Briscoe Counties. Similar conditions prevail wherever these two formations come together in New Mexico, Arizona, or Wyoming and the adjacent States.

In the vicinity of Dickens, in Dickens County, where the transition beds are beautifully exposed in the Croton Breaks, 2 miles directly east of the town, the intermediate series is terminated above by a few feet of yellowish and bluish clay which is overlain by a considerable thickness of grit and conglomerate, such as is described by Drake in his middle division of the Dockum beds. The conglomerate and the resulting gravel, which in many places covers the surface, are generally very easily distinguished from the grits and gravel derived from the overlying Tertiary beds of the Plains by the large amount of brownish, semiangular, indurated clay as opposed to the dominant whitish, well-rounded quartzite of the upper beds. The Triassic conglomerate is typically shown at Dickens, but can be traced from that point as far as the Canadian River on the north and beyond Big Springs on the south. At Dickens in Dickens County, Roaring Springs and Matador in Motley County, and on the section through Quitaque to Tulia in Hall, Briscoe, and Swisher Counties, this grit and conglomerate lies directly beneath the Tertiary 
cap-rock. At Spur, a few miles south of Dickens, it has the same position, forming the hill, in the north part of the town, upon which the water-tower is located, and is easily traceable in the small elevations which can be seen in all directions for miles from that point. West of Spur it is the surface rock, appearing at intervals through the surficial clays and sands to within a few miles of the Blanco or Catfish River, where the lower formations are again visible in the breaks. On the east side of the river the Triassic is much obscured by the accumulation of wind-blown sand, but on the western side the bluffs are prominent and stand out as conspicuous features similar to the bluffs at Dickens. Such a prominence is Cedar Mountain, between the forks of Sand Creek. From the summit of these bluffs the handlevel shows that the tops of the hills are approximately on the same level. The beds below the conglomerate cap in this region are decidedly different from those shown in the Croton Breaks east of Dickens; there is much less of the deep-red clay and relatively little gypsum. The beds are composed of light-red or yellowish clay in most of the exposures. Though there is considerable continuity in the beds, there is a decided irregularity of deposition exposed in the breaks of Holmes, Sand, and Davidson Creeks near Cedar Mountain; here there are frequently lenses and intercalated beds of light cream-colored clay, light-bluish clay, and light-red clay, with abundant irregular concretions and nodules. By far the greater number of the beds, and uniformly those which are at all regular in their deposition, are totally barren of fossils. It is only in the irregular beds which were evidently deposited in stream-channels and local pools that any remains are found. It is evident that this area, which is so different from that of the Croton Breaks, is the site of some great stream-channel and flood-plain.

Unfortunately, only a small area is exposed in the breaks, and a careful search of the whole eastern side of the Plains has revealed no similar locality. Waterworn fragments of bone frequently appear in the conglomerate; some were collected as far south as the vicinity of Slaughter's Ranch, 18 miles southwest of Post City in Garza County, and traces of bone were found east of Big Springs, but it is evident that the areas where vertebrate fossils may be collected in any quantity and in a usable state of preservation are very limited on the eastern side of the Plains.

The exposures of the Triassic in the breaks of the Canadian River, in the northern part of the Plains, show a more or less uniform series of red beds, clays, and sandy shales, with occasional bands and veins of gypsum beneath the conglomerate. These beds can not be exactly located in Drake's series, but appear to be the ones located in his upper division, though Permo-Carboniferous vertebrates have been reported from the vicinity of Plemons in Hutchins County, and the Texas Geological Survey has mapped Permo-Carboniferous in the western part of Oldham County.

On the western side of the Staked Plains a splendid view of the exposures of the Triassic can be had from the edge of the cap just west of Adrian in Oldham County. From this point it is possible to see a large area of the breaks in the upper part of the Canadian Valley and much of the area to the south, almost to Glen Rio on the Texas-New Mexico line. The land is roughly rolling and much 
of it is grassed, so the exposures are limited in extent; but they are uniformly of red clay and red sandy shale, with occasional layers of more or less heavy brown sandstone and thin beds of grit or conglomerate. Throughout this area fragmentary remains of Phytosaurs and Stegocephalians occur in small quantity. The rolling country continues westward to and beyond Tucumcari in Quay County. About 5 miles west of San Jon, in Quay County, there is an area of river deposits with beds of conglomerate, heavy sandstone, loose gravel, and clay; the change in the character of the beds is reflected in the nature of the surface, for the region is locally known as the Bad Lands. In this limited area remains of Phytosaurs and Stegocephalians occur, similar to those found in Crosby County, Texas, but in far smaller number and in a poorly preserved condition. ${ }^{1}$ Beyond San Jon the surface of the country again becomes more regular, reflecting the more uniform character of the beds beneath.

At Mount Tucumcari and along the west front of the Plains there is, in general, a more uniform sequence of the beds than on the east side. A heavy mass of red clay and red sandy shales is overlain by a second heavy bed of sandstone which may be white, as directly west of Montoya, or brownish farther to the west and south, typically exposed at Cuervo, in Guadalupe County. These dominant heavy beds of clay and sandstone are frequently interrupted by locally developed beds of lighter-colored clays and sands, white, yellow, or blue, in which poorly preserved fragments of bones occur in limited amount. The same character of the beds is found as far west as Santa Rosa, in Guadalupe County, and as far south as beyond Roswell. East of Roswell the red beds contain much more gypsum than those farther north, and no remains of vertebrates have been found in them.

A reconnaissance from Montoya westward through Isidor, Buxton, and Cabre Springs and up the Conchas Canyon to Las Vegas showed that the beds retained a similar character until they disappeared beneath the Cretaceous. It is evident that the great bulk of the Triassic beds revealed on the borders of the Staked Plains and in eastern and central New Mexico were deposited under conditions unfavorable to the preservation of vertebrate fossils. The more uniformly deposited beds of clay and shale were apparently laid down in deep water or in water far from the shores; it is only in the disturbed beds, which bear evidence of having been deposited by great flood washes, that the remains of animals and plants are found. Such remains are usually badly broken and water-worn; occasionally good specimens will turn up, as evidenced by the presence of a skull of a Phytosaur preserved in the University of Chicago, which was obtained from the School of Mines at Socorro, New Mexico, and said to come from near Santa Rosa, ${ }^{2}$ and from some remains secured by the author near Carthage, Socorro County. It is only in such rare occurrences as the section of some large river flood-plain, such as occurs in eastern Crosby County, Texas, that good material will be found. The rarity of such occurrences is shown by the experience of the author, who, in four trips in the regions mentioned, has found only the single exposure.

${ }^{1}$ For a more detailed description of the Bad Lands west of San Jon, see an article by the author in the Journal of Geology, vol. xII, No. 3, 1914.

2 Mehl, M. G., A New Phytosaur from the Trias of Arizona, Journal of Geology, vol. xxx, p. 144, 1922. 


\section{THE LITERATURE OF THE TRIASSIC VERTEBRATES OF NORTH AMERICA.}

Our knowledge of the Triassic vertebrate life of North America is so limited that it is not yet time to attempt a summary statement of the material at hand, but it will not be amiss, as a step in progress, to list the main articles which have from time to time partially reviewed the work done up to the time of their appearance. The bibliographies in these articles will lead to the original publications.

1902. $\mathrm{H}_{A Y}$, O. P. Bibliography and catalogue of the fossil vertebrates of North America. Bullctin No. 179, United States Geol. Survey.

1905. Branson, E. B. Structure and relationships of American Labyrinthodontidx. Journal of Geology, vol. XIII, No. 7.

Contains critical review of known Triassic Stegocephalians from North America and description of a new genus, Anaschisma.

1906. McGregor, J. H. The Phytosauria, with especial reference to Mystriosuchus and Rhytidodon. Memoirs American Mus. Nat. Hist., vol. Ix, pt. 11.

Contains a list and critical review of genera and species of North American Phytosauria, and a bibliography.

1906. Huene, F. v. Ueber die Dinosaurier des Aussereuropaeischen Trias. Geologische und paleontologische Abhandlungen, N. F., Bd. virI, Hft. 2.

Contains a critical review of the genera and species of the Triassic Dinosaurs of North America, with a bibliography.

1911. Huene, F. v. Beiträge zur Kenntnis und Beurtheilung der Parasuchier. Geologische und paleontologisch є Abhandlungen, N. F., Bd. x, Hft. 1.

1911. Eastman, C. H. Triassic fishes of Connecticut. Bulletin 18, Geological and Natural History Survey, State of Connecticut.

Contains a critical revision of the Triassic fishes of the northeastern United States.

1915. Merl, M. G. The Phytosauria of the Trias. Journal of Geology, vol. xxIII, Feb.-Mar.

Contains a description of new forms, a review of known genera and species, and a bibliography.

1915. Luld, R. S. Triassic life of the Connecticut Valley. Bulletin 24, Geological and Natural History Survey, State of Connecticut.

Contains a critical discussion of the vertebrate fossils of the Triassic of the northeastern United States, and a bibliography.

1920. CASE, E. C. Preliminary description of a new suborder of phytosaurian reptiles, witl a description of a new species of Phytosaurus. Journal of Geology, vol. xxviı, Sept.-Oct.

Contains a description of the new suborder Desmatosuchia, the genus and species Desmatosuchus spurensis and Phytosaurus doughtyi.

1920. CAsE, E. C. On a very perfect thoracic shield of a large labyrinthodont in the geological collections of the University of Michigan. Occasional Papers of the Museum of Zoology, University of Michigan, Ann Arbor, Mich. No. 82.

Contains a description of the clavicles and interclavicle of Metoposaurus jonesi.

1921. Case, E. C. A new species of Ceratodus from the upper Triassic of western Texas. Occasional Papers of the Museum of Zoology, University of Michigan, Ann Arbor, Mich. No. 101. Contains a description of a tooth of a new species of Ceratodus, C. dorothea.

1922. MenL, M. G. A new Phytosaur from the Trias of Arizona. Journal of Geology, vol. xxx, p. 144, 1922

Contains a description of a new form Phytosaurus, Macharoprosopus andersoni.

The few papers published in 1920, 1921, and 1922 are later than any summary

papers and are inserted to bring the literature up to date. 

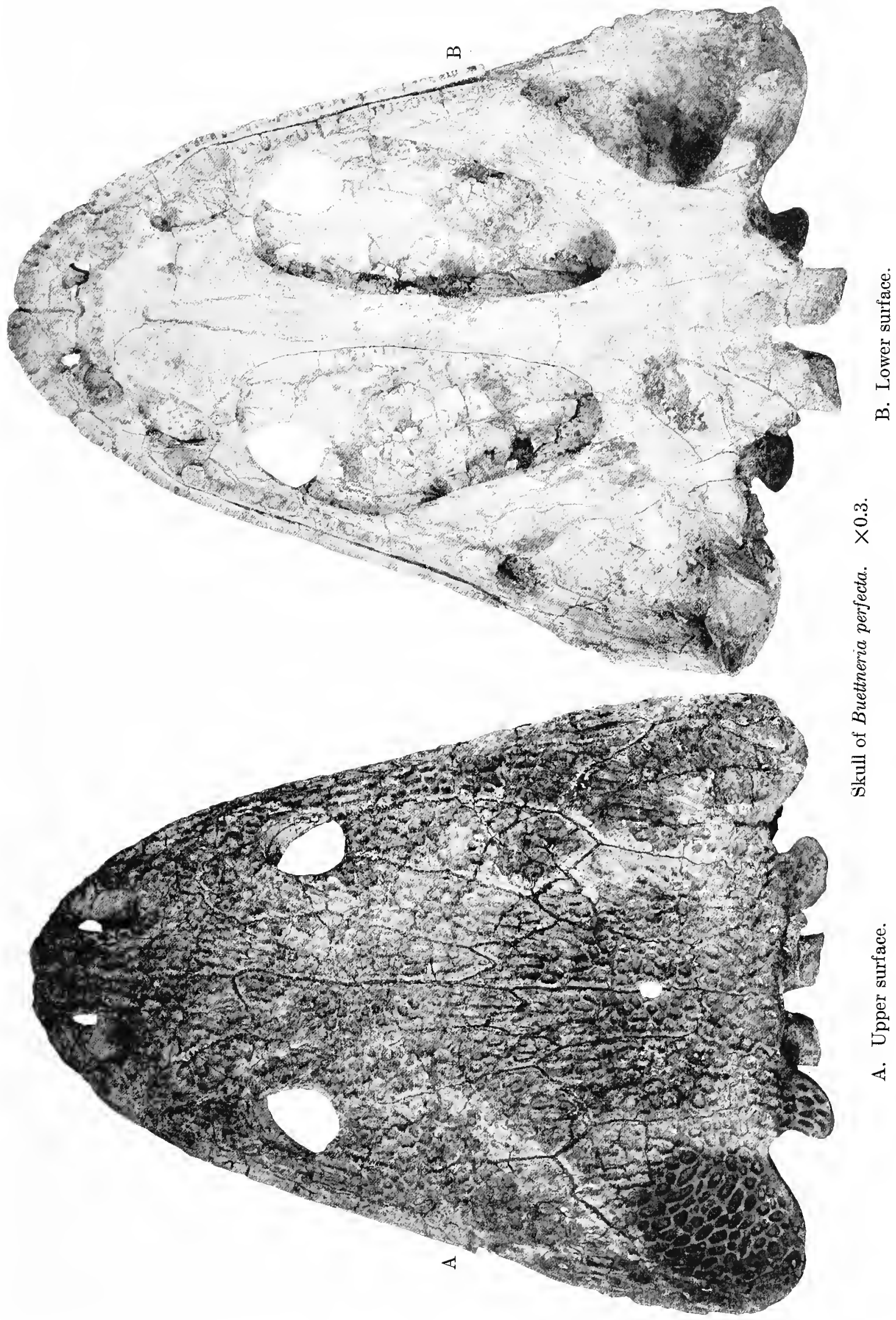

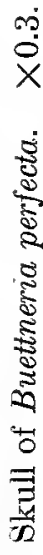





\section{A NEW GENUS OF THE STEGOCEPHALIA, BUETTNERIA PERFECTA.}

The specimen here described, No. 7475, University of Michigan, was found in the breaks of Sand Creek just south of Cedar Mountain, in Crosby County. It lay in a dark-red, mud-lump conglomerate with some finer material, the deposit of an old riverwash. The undistorted skull is unique in the perfect preservation of the bones and the minutiæ with which the osteological details may be traced. The matrix was readily removed from the bones of the lower surface, leaving them clean and white, except where stained red or brown by iron. The rugose upper surface was less readily freed, but the matrix came away very clean, revealing the pits and ridges and all the details of the sutures and the slime-canals. There is no distortion of the bones of the upper and lower surfaces, but the edges of some of the slender bones which form the walls of the brain-case are slightly crumpled and injured by decay. No parts are missing from the upper surface except the major part of the left squamosal, the extremities of the tabulare, and the extreme posterior tip of the right maxillary. On the lower surface a part of the distal end of the left pterygoid is missing, there is no trace of the stapes, and the otic opening is extremely large; for reasons given in the body of the paper it is believed that this region was largely cartilaginous.

The upper surface of the skull.-The form and arrangement of the various elements, the position of the slime-canals, and the character of the sculpture are shown in figure $1 \mathrm{~A}$, and plate 1, fig. $\mathrm{A}$, and do not need extended discussion. The general resemblance to the skull of Anaschisma from the Popo Agie beds of Wyoming is apparent, but the arrangement of the teeth and the bones of the lower surface show that the two forms can not be placed in the same genus, and render it doubtful whether they should be placed in the same family. A comparison with Branson's figures ${ }^{1}$ shows that the skull was a little broader, proportionately, than in Anaschisma and that the orbits were a little farther forward. Branson was unable to trace all the sutures on the upper surface of his specimen, but, so far as he was able to determine them, the position and relations of the bones correspond as well as could be expected in animals in which there was so much of individual variation. A comparison of his figures with figure $1, \mathrm{~A}$ and $\mathrm{B}$, of this paper will show the position of the sutures he was unable to follow, outlining in whole or in part the lachrymals, the quadratojugals, the jugals, and the maxillaries. In Buettneria the lachrymals are small elements not reaching to the nares; the maxillaries extend inward anterior to the orbits and form a part of the posterior and lateral boundaries of the nares; posteriorly they lie upon the sides of the skull, and the postorbital portions are only visible from above as narrow bands. The premaxillaries, nasals, frontals, and parietals exhibit a decided asymmetry. In both the figures and the plates it will be seen that the extremities of the tabulare have been restored; it may easily be that these have been made too large, as the projections are very slight in Anaschisma.

Not only the sutures but the slime-canals are very perfectly shown in the specimen. (See fig. 1 A. The course of the sutures and the canals shown in the figures was traced with a camera lucida and the lines are almost exactly as they appear in the specimen; the figures have not been diagrammatized to any extent. The edges of the slime-canals have been traced as straight lines to distinguish them from the sutures.) The course of the slime-canals is similar to that in Anaschisma, but differs in one or two important particulars. Adopting the nomenclature proposed by Moodie, ${ }^{2}$ the anterior commissure and the occipital cross-commissure are absent: the course of the supraorbital canals between the orbits and nares is quite different (compare fig. 14 of Moodie's paper).

${ }^{1}$ Branson, E. B., Journal of Geology, vol. XIII, figs. 1 and 7, 1905.

2 Moodie, R. L., Journal of Morphology, vol. xIx, No. 2, p. 513, 1908. 
The infraorbital canal turns sharply inward across the short lachrymal bone and joins the supraorbital; the single canal thus formed runs forward for a short distance and then bifurcates on the anterior part of the maxillary just posterior to the narial opening. The outer branch runs forward for a short distance and terminates in an irregular expansion. The inner branch follows the normal course of the supraorbital canal; there is no antorbital commissure. Posterior to the orbit the supraorbital canal is complete and runs backward to join the temporal canal. It will be observed that the supraorbital canal on the left side lies for a short distance on the frontal; on the right side it does not
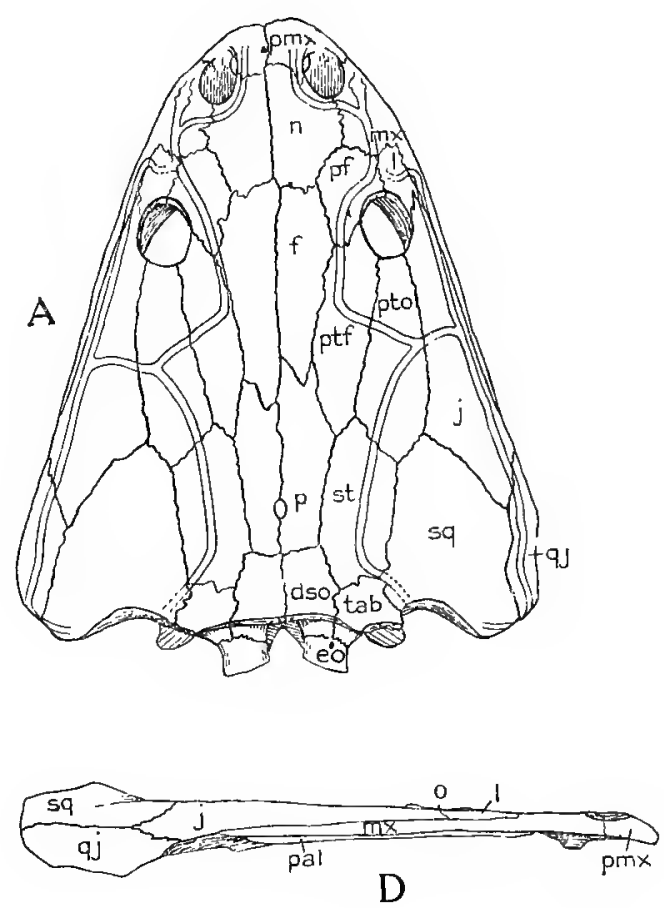
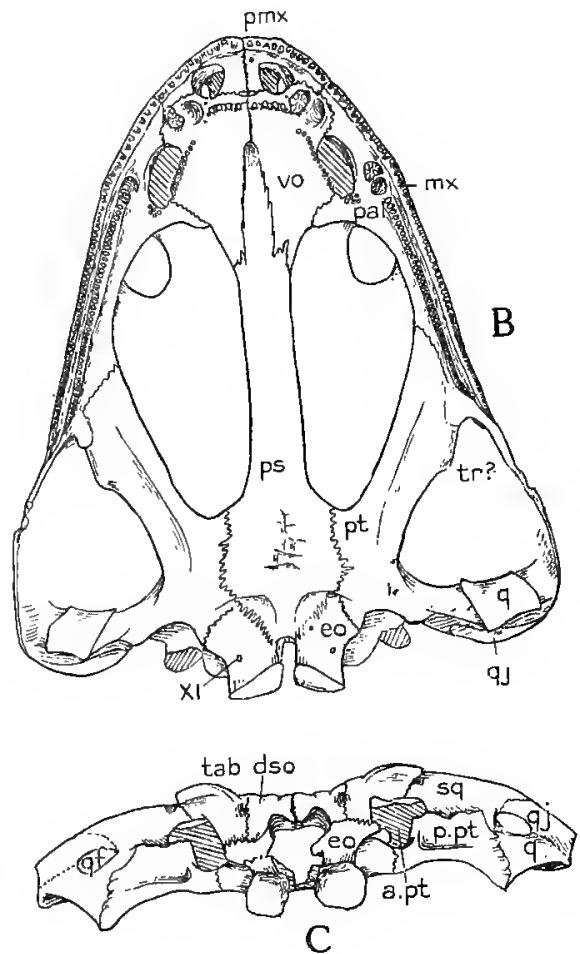

Fig. 1.-Buettneria perfecta, skull of, No. 7475, University of Michigan.

A. Upper surface.

C. Posterior surface.

Cremaxillary; $m r$, maxillary $n$. Lateral surface. orbital; ptf., postfrontal; j., jugal; st., supratemporal; p., parietal; $s q .$, squamosal; $q j$. , quadratojugal; tab., tabulare; dso., dermsupraoccipital; eo., exoccipital; vo., vomer; ps., parasphenoid; tr?, transverse; pal., palatine; q., quadrate; $x l$, outlet for eleventh nerve; a.pt., anterior rising process of pterygoid; p.pt., posterior rising proeess of pterygoid; $q f$. quadrate foramen; 0. , orbit.

touch that element. The supraorbital and the temporal canals meet at a sharp angle, and there is a canal connecting them with the infraorbital. Continuing backward, the temporal canals lie upon the supratemporal bones and turn sharply outward at their posterior ends; on the left side the canal touches the anterior outer corner of the tabulare; on the right side it clears that bone. The jugal canal continues backward to the extremity of the quadratojugal and, with a slight interruption, turns inward for a short distance near the posterior edge of the squamosal.

The edges of the canals are irregular and the sculpture is continued on the bottom of the grooves. It is evident that in this specimen there is a departure from the usual and (according to Moodie) morphologically important position of the canals; that is, 
they do not lie upon definite bones so certainly as to be entirely dependable criteria for the determination of the homology of the bones with those of the fish skull. This is particularly noticeable in the posterior part of the course of the temporal canals and their relation to the tabulare. In comparison with the course of the canals in Metoposaurus, as given by Moodie, the differences are quite similar to those noted in comparison with Anaschisma.

The lower surface of the skull.-In this region the skull shows very decided differences from Anaschisma. Branson states that in Anaschisma each palatine bone bears only a single tooth, and this has been confirmed by a reexamination of the skull by Mr. Paul Miller. It is also stated by Branson that there are four teeth on the anterior edge of each prevomer (vomer), but no mention is made of a row of teeth on the inner edges of the narial openings. It may be that these rows are obscured by the condition of the specimen in the University of Chicago. The vomers are shown in Anaschisma as terminating behind in long points which extend down the side of the parasphenoid. The transverse bones are shown as large elements. The character of the articulation of the parasphenoids with the exoccipitals is very different in the two forms. Mr. Miller has reexamined this region and assures the author that there is a median suture as shown by Branson and interpreted by him as the meeting of the exoccipitals and that there is a large union of the parasphenoid with the pterygoids. The parasphenoid-exoccipital suture is reported as uncertain, but it could not be far from the position given it by Branson. The long median suture shown by Branson is one of the most interesting points about the skull of Anaschisma; if it is formed by the meeting of the exoccipitals for any considerable distance (the posterior portion of the skull is restored in plaster), it is unique among the Stegocephalia, for in no other form is there a meeting of the posterior ends of the exoccipitals for any considerable distance, if at all.

In Buettneria the premaxillaries are short, with large openings through which a small part of the external nares can be seen from below. At the point of the union of the premaxillaries with the vomers there is a small irregular depression in the median line which may be significant or may be due only to imperfect ossification at the meetingpoint of the four bones. There are 13-13 teeth on the premaxillaries.

The vomers are large flat plates; the anterior outer part forms the floor of the external narial opening when seen directly from above. The anterior outer corners support large tusks on each side; these were placed in pairs in which the tusks were alternately functional; on the left side the anterior one was in use and on the right the posterior one at the time of the death of the animal. On the anterior edges of the bones between the tusks there is a nearly straight row of fairly large teeth. There are 5 teeth on each side, the outer one smaller than the others. On the inner edge of the internal narial openings there is a row of small teeth, 18 to 20 in number; the rows terminate posteriorly at the palatine-vomer suture; anteriorly they are separated from the tusks by a short vacant space. Within the inner edge of the internal nares there is a small cluster of very small teeth; these point toward the center of the opening in the specimen.

The palatines are separated from the maxillaries by a long, straight suture, and from the premaxillaries and the vomers by clearly defined sutures, as shown in figure $1 \mathrm{~B}$, and plate 1, fig. B. External to the posterior half of the internal nares there are large paired tusks; as in the vomerine tusks, the functional teeth of the pairs are alternate in position. Just posterior to the internal nares is a small cluster of irregular teeth, 5 to 6 in number. The long row of teeth on the outer edge begins just posterior to the tusks and is continuous to the extreme posterior end. The teeth are very closely set and diminish to exceedingly small size towards the rear; many of the teeth are represented by empty spaces and were apparently not functional at the time of death. There are 36 to 38 teeth on each side. The palatine joins the pterygoid by an oblique suture. 
The transverse bone, if present, is a small element. On each side there is an uncertain line, indicated in figure $1 \mathrm{~B}$, which seems to mark the separation of a distinct element from the pterygoid. On the right side the small element is slightly displaced, indicating its distinct character.

The maxillaries appear on the lower surface as a tooth-bearing edge only. There are no tusks. The bone of the right side, which is complete, carries 97 teeth and spaces; allowing for the small part missing on the left side there would be 98 on that side. These numbers were certainly not a fixed quantity in the individual or species.

The parasphenoid has a broad, flat processus cultriformis, which terminates at the anterior end in a sharp point extending far forward between the vomers. In the specimen the anterior end is raised, so that there is a decided elongate pit on the roof of the mouth. This seems to be entirely natural, but may be due, in part, to slight postmortem changes. The posterior end is moderately expanded and meets the pterygoids in long, clearly marked sutures. The central part of this expanded portion is marked by low but distinct rugosities. Near the posterior end there is a low elevation on each side, which runs from the pterygoids out upon the parasphenoid and then turns sharply to the rear near the median line. The sutures with the exoccipital run obliquely backward and inward and almost, but not quite, meet at the bottom of the notch between the exoccipitals. These sutures are very complex and sharply and finely interdigitating.

No trace of a basioccipital or basisphenoid could be made out on the specimen, on either the upper or the lower side of the floor of the brain-case, or by a careful examination of the edges of broken pieces in the process of preparation.

The pterygoids.- There are two strong rami of the pterygoids visible on the lower surface. The anterior runs forward and outward to join the palatines and the trans." verse (?) or maxillary. There is a slight median depression on this ramus, and near the anterior end there is a small prominence extending slightly downward and outward. The second ramus runs directly outward to the quadrate; its lower surface is rounded.

The quadrates. - The articular surface is concave from side to side and convex in its longest diameter, which runs obliquely from without, inward and forward. The inner and outer edges are raised into slender, sharp ridges. The suture between the quadrate and the quadratojugal is not clearly marked, but it was evidently at the extremity of a process extending inward from the quadratojugal. Anteriorly the quadrate sends a process forward and inward on the anterior face of the anterior rising process of the pterygoid. Posteriorly the quadrate is overlapped by the conjoined outer ends of the rising processes of the pterygoid. Between the quadrate and the quadratojugal there is a relatively large quadrate foramen. As shown in figure $2 \mathrm{~B}$, there is apparently a small, distinct element present between the anterior rising process of the pterygoid and the inner process of the quadrate. This may be a deceptive appearance, but it is present on both sides and the lines between the elements are distinct and filled with matrix. Its meaning is unknown; certainly it is not a part of a descending process from the skull-roof, as the lower side of the roofing bones at this point is perfectly smooth.

The exoccipitals carry the large, distinct condyles, which are separated by a deep notch extending forward to the parasphenoid bone. There is a good-sized foramen on the lower side of each, which probably transmitted the X and XI nerves and the jugular vein. On the middle of the outer side is the foramen for the XII (?) nerve. At the base of the rising process which articulates with the dermsupraoccipital and the tabulare there is a large foramen on the inner side which transmitted the $\mathrm{X}$ nerve.

The posterior face of the skull (fig. $1 \mathrm{c}$, and plate 2, fig. A).-The dermsupraoccipitals are visible in the median line and are separated by a distinct suture. They join the tabulare by straight vertical sutures. The space between the dermsupraoccipitals was filled in large part by a mass of cartilage in the absence of a supraoccipital. 


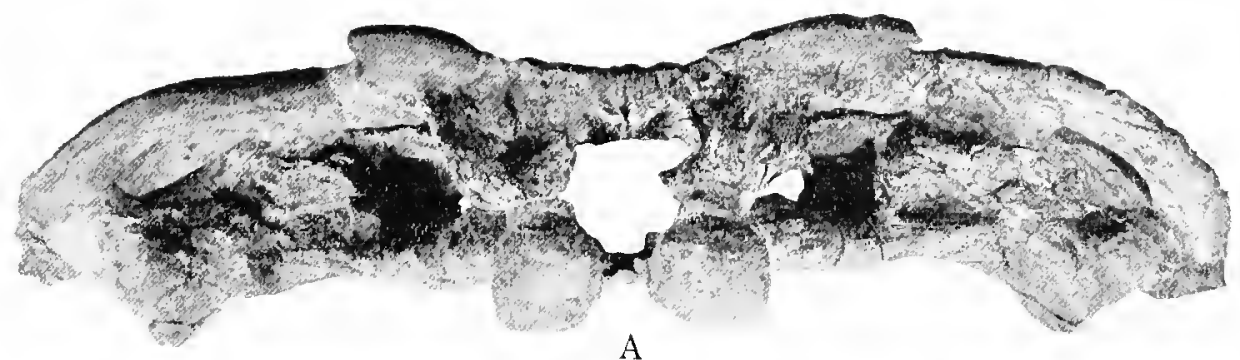

A
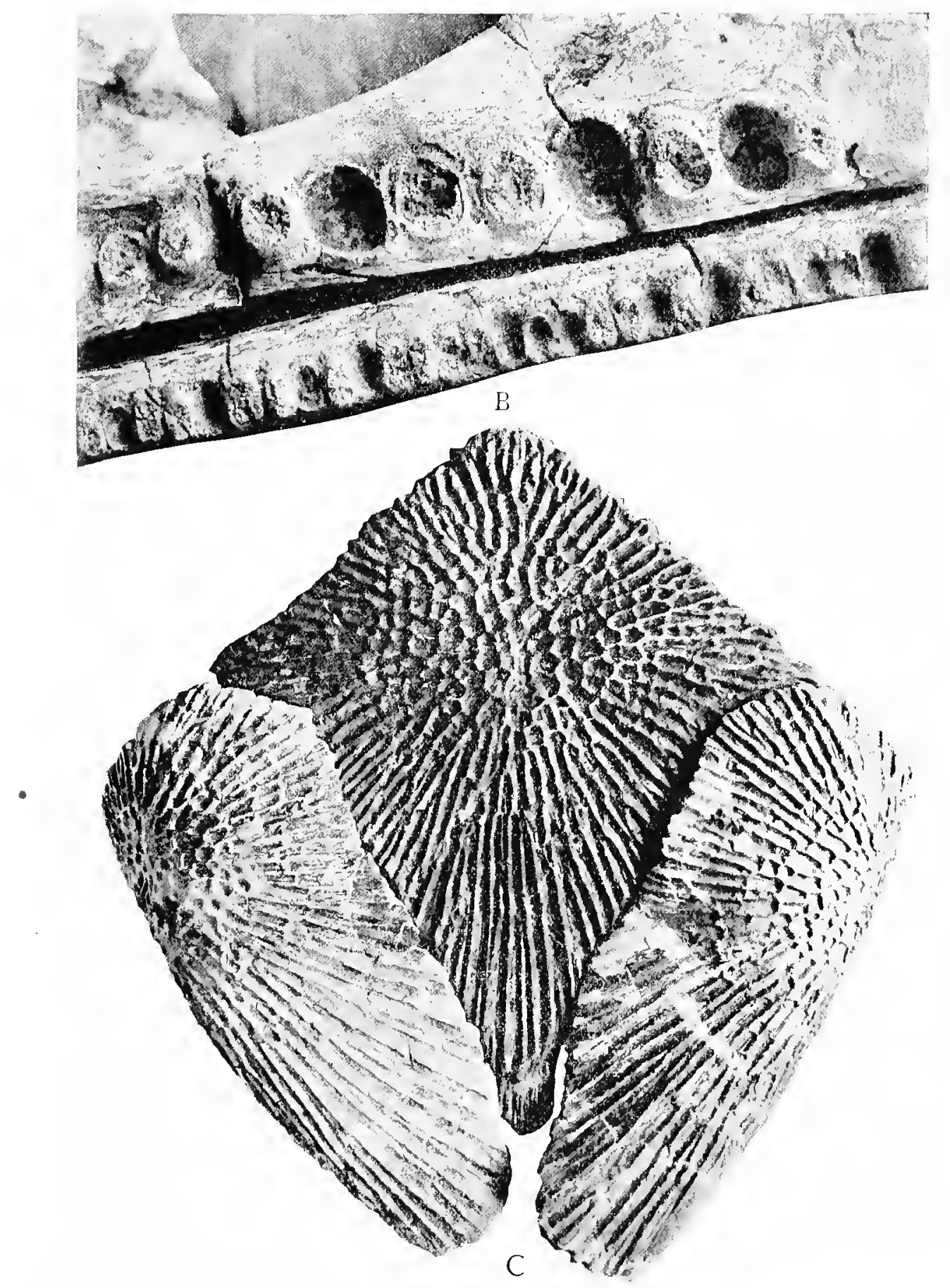

A. Posterior surface of skull of Buettneria perfecta. $\quad \times 0.3$.

B. Enlarged view of portion of the palatine and maxillary of same, showing the teeth opposite the internal nares. The labyrinthine structure is clearly seen. $\times 2$.

C. Metoposaurus(?) jonesi, No. 3814, U. of Mich. $\times 0.3$. Ventral surface of clavicles and interclavicles. 
The exoccipitals meet the tabulare and the dermsupraoccipitals by strong, finely interdigitating sutures. On the left side there is preserved a portion of a thin process extending inward, which, with its fellow of the opposite side, forms a more or less complete shelf dividing the foramen magnum from the space left by the disappearance of the supraoccipital cartilage. The articular surfaces of the condyles face backward and inward.

On either side of the exoccipitals the posterior rising processes of the pterygoids extend outward to the quadrates. The processes rise toward the upper edge of the squamosal, but do not reach to it in the specimen, ending in a thin and broken edge on both sides. Anterior to this process the posterior face of the anterior rising process may be seen through the great otic vacuity. Between the two rising processes is received the descending process of the squamosal. The otic vacuity lies between the exoccipital, the tabulare, the squamosal, and the posterior rising process of the pterygoid (fig. $1 \mathrm{c}$ ).

The quadrate foramen is relatively larger than in Anaschisma. ${ }^{1}$

The ophisthotic is completely covered by the descending process of the dermsupraoccipital and the tabulare. The general similarity between the posterior surfaces of the skulls in the two forms, Anaschisma and Buettneria, is obvious from a comparison of the figures, but it is equally obvious that there is one great difference: in the latter form there are no post-temporal fenestræ; the place of each fenestra is taken by a deep pit with an imperforate bottom. The resemblance is even greater to Metoposaurus diagnosticus as figured by Watson. ${ }^{2}$ It is probable that the part which he has called the epipterygoid ( $E$. Pt. ?) is a part of the descending process of the squamosal. In correspondence, Doctor Watson suggests that the space between the two ascending processes of the pterygoid was filled with a "persistent pterygo-quadrate cartilage that is essentially an epipterygoid," and suggests that the part described in this paper is an ossification of that cartilage; but it is clearly a process from the squamosal, as the broken edges in the specimen were clean and fitted perfectly. His figure shows but a slight development of the posterior rising process of the pterygoid, which in Anaschisma and Buettneria reaches nearly to the upper edge of the squamosal. In the place of a large post-temporal fenestra he shows a small foramen on the dermsupraoccipital-tabulare suture, a condition approaching very closely to that found in Buettneria.

The upper (inner) surface of the basicranial bones.-The condition of the specimen was such that it was possible to remove the matrix completely from the brain-case and the inner side of all the bones, leaving them as clean and intelligible as the outer side (fig. 2 A).

The anterior portion of the parasphenoid is marked by a deep, flat-bottomed groove with thin, abrupt borders; opposite the anterior edges of the palatine vacuities this groove is nearly equal to the width of the bone $(23 \mathrm{~mm}$.), but it contracts gradually and regularly to the rear, and opposite the posterior edges of the palatine vacuities it is not more than $5 \mathrm{~mm}$. in breadth; at the same time the groove becomes much shallower, due to the gradual thickening of the bone. The edges become more rounded and lower as they thicken to the rear, and finally disappear about opposite to the center of the broad posterior portion of the parasphenoid. On either side of the center of ossification and a little to the rear there are openings which extend obliquely outward and backward and are inclosed by a low arch of bone, so that they do not lie within the substance of the parasphenoid, but rather upon its surface, covered by the arch. The outer end of the arch is slightly wider than the inner and terminates in an irregular edge, as if it had been covered with cartilage during life. The length of the arch is $32 \mathrm{~mm}$. The meaning

${ }^{1}$ Branson, E. B., Journal of Geology, vol. xIrI, No. 7, fig. 3, 1905.

2 Watson, D. M. S., Transactions Royal Society of London, vol. 209, Series B, fig. 10, 1919. 
of these peculiar structures is not certain; a careful study of both the upper and lower surfaces and the broken edges revealed no indication of separate basioccipital or basisphenoid ossification. It is probable that the basisphenoid cartilage became much reduced and the internal carotid arteries were forced down upon the parasphenoid and passed for a short distance through the arches. This suggestion is supported by the position of the arches and the fact that the internal carotid arteries entered the brain-case through the posterior part of the palatine vacuities and then turned backward. Watson ${ }^{1}$ identified markings in the specimen of Laccocephalus in this position as the grooves of the internal carotids, though he interpreted the method of the arterial entrance into the skull in a different manner. On the surface of each arch, nearer to the inner than the outer end, there is a small foramen penetrating through the wall to the canal below. Just anterior to the inner ends of the arches there are slightly elongated rugosities; these are in the direct line of the continuation of the ridges on the upper side of the parasphenoid and of the ridges on the inner edges of the pterygoids. Anterior to these rugosities there are small foramina entering the skull from before backward; they are probably no more than openings for nutrient vessels. The sutures between the parasphenoid and the pterygoids can be easily traced; they run irregularly backward from a point at the center of the posterior edges of the palatine vacuities and pass beneath the outer edges of the arches just described, i. e., the arches are entirely upon the parasphenoid. Posterior to the arches the sutures appear again and continue backward, convex outwardly, and then converge to end very close together at the base of the deep notch between the exoccipitals.

The pterygoids.- The upper face of the anterior ramus of the pterygoid is marked by a wide, shallow groove which becomes more distinct posteriorly to a point about opposite the posterior edge of the palatine vacuity; the outer edge of the groove is distinct for its whole length, but the inner becomes definite only in its posterior portion. The outer edge of the ramus is raised into a slight prominence just at the origin of the anterior rising process of the quadrate ramus of the pterygoid. The pterygoid joins the parasphenoid, as is indicated in figure $1 \mathrm{~B}$, and connects with the exoccipital just posterior to the origin of the quadrate ramus. Just anterior to the junction of the pterygoid and the exoccipital there is a foramen near the inner edge of the pterygoid; on the left side the bone is broken around the foramen and shows that it enters into a considerable cavity in the body of the bone.

The upper surface of the quadrate ramus is most interesting. The perfection of the structures preserved has rendered it a little difficult to reconcile the conditions found with the descriptions of less perfect specimens, but, in the light cast by the study of this specimen, the previous descriptions can be brought into more or less harmony. There are two distinct rising processes, an anterior and a posterior (see figs. $2 \mathrm{~A}$ and $2 \mathrm{~B}$ ). These are directly continuous with the body of the bone and extend for nearly the full length of the ramus; there is no trace of a suture in the specimen, where every suture is revealed with almost diagrammatic clarity. The processes are inclined backward as they rise and are separated by a considerable space at their inner ends, but are very closely approximated, if not actually united, at their outer ends. The anterior process rises to the roof of the skull; its upper edge was thin, with the inner half attached to the lower surface of the parietal and squamosal by cartilage; this is demonstrated by the thinning and irregularity of the upper edge, by the line of low rugosities on the roof-bones mentioned, and by the fact that the bones were found in this position with a thin line of matrix between them (fig. 2 B).

\footnotetext{
${ }^{1}$ Watson, D. M. S., Transactions Philosophical Socicty of London, vol. 209, Series B, pl. 2, 1919.
} 
The inner end of the anterior process rises from a triangular base. From the center of the posterior end of the groove on the palatine ramus of the pterygoid a thin wall rises obliquely backward; beneath this there is a deep pit, with its mouth just anterior to the outer end of the arch described on the parasphenoid. This pit extends obliquely backward and its apex is perforated by two small foramina on the left side; the pit on the right side is perforated by a single foramen. Posterior to this pit the base of the process is thickened (fig. 2 B) just opposite the anterior edge of the outer

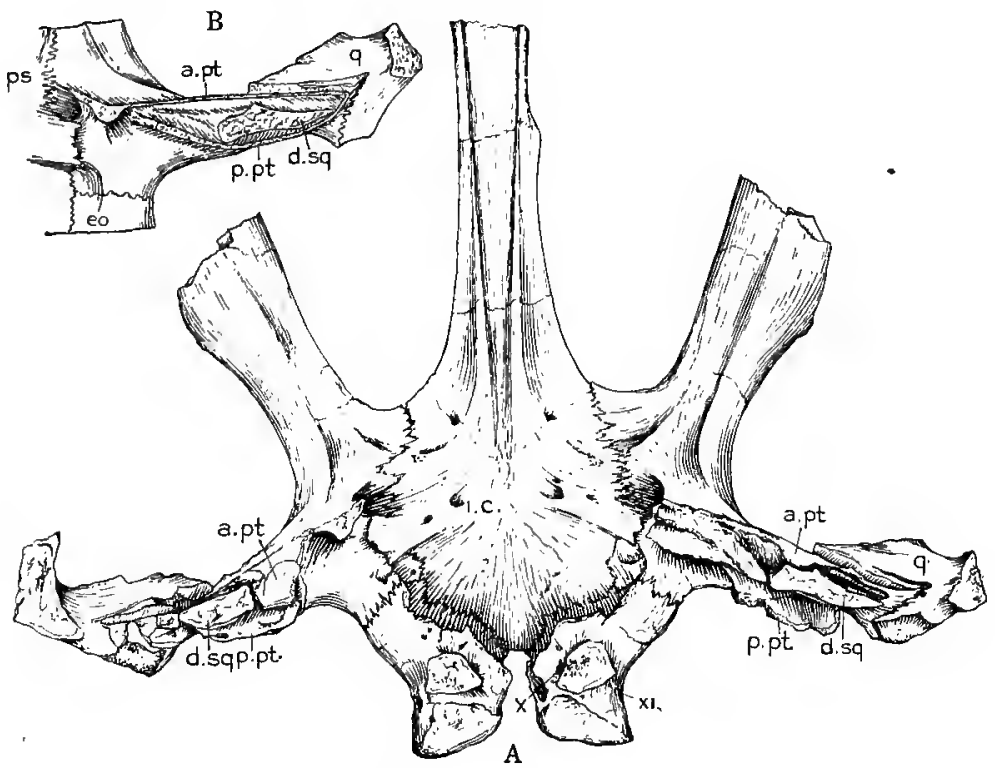

FIG. 2.-Buettneria perfecta.

A. Upper (inner) view of the bones of the basicranial region. d.sq., descending process of the squamosal; i.c., opening of cavity for the internal carotid artery; $x$. outlet for the tenth cranial nerve. Other lettering as in figure 1.

B. Upper view of the left quadrate ramus of the pterygoid. Lettering as in previous figures.

opening of the arch on the parasphenoid; beneath it a second pit passes forward and slightly inward and is imperforate. The apices of the two pits are separated by a thin wall. 'The third part of the triangular base is formed by the lower part of the anterior rising process. The upper part of this rising process is somewhat crumpled; it is impossible to interpret the appearance exactly, for the distortion gives the appearance of reduplication, as if the bone were made up of superimposed laminæ or, which seems very improbable, of separate thin bones.

On the posterior edge of the quadrate ramus is the posterior rising process. Its inner end originates just posterior and external to the second pit described above; it reaches nearly as great a height as the anterior one, but there is no indication that it was ever attached to the roof above; in the specimen there is quite a space between the two. This process is shown by Quenstedt ${ }^{1}$ as reaching up to the squamosal in Cyclotosaurus (Mastodonsaurus) robustus. Fraas, $^{2}$ however, shows the plate of much less height in Cyclotosaurus posthumus. Watson, in his figure after Fraas, draws it much higher. ${ }^{3}$

The outer ends of the two processes unite apparently without suture and clasp the inner and part of the posterior face of the quadrate. Into the deep cleft between the two processes descends the process from the squamosal. The relations of these processes

${ }^{1}$ Quenstedt, F. A., Die Mastodonsaurier im grünen Keupersandsteine Wurtemberg's sind Batrachier, Tubingen, 1850, pl. 3, fig. 16.

2 Fraas, E., Neue Labyrinthodonten aus der Schwabischen Trias, Paleontographica, Bd. Lx, pl. xvirı, fig. 2, 1913.

${ }^{3}$ Watson, D. M. S., loc. cit., fig. 30 c, p. 54. 
is very puzzling in places; towards the outer ends the three seem to be indistinguishably fused; this may be natural or may be due to the very close approximation of the elements, partly due to a very slight compression in fossilization. It is possible that the descending process was surrounded by cartilage and that the partial ossification of this cartilage may have produced the appearance of fusion of the bones. The thin outer edge formed by the united or approximated ends of the processes descends obliquely forward and disappears behind the quadrate; there is a small foramen between the bones at this point.

The quadrate.-The upper surface of the quadrate was seen in the specimen during preparation; it sends a shorter and heavier process backward and inward to articulate with the posterior process of the pterygoid, and a longer and more slender process forward which lies on the anterior face of the anterior process of the pterygoid. This anterior process is expanded vertically and in life was either applied closely to the pterygoid or attached to it loosely by cartilage. In the specimen it is separated from the pterygoid on both sides by a space of a millimeter or two, now filled with matrix.

The exoccipitals. - These join the pterygoids and the parasphenoids by finely interdigitating sutures. The edges of the parts of the exoccipitals, which form the walls of the brain-case, are broken away, but they did not rise to and connect with the roof, as is proven by the absolutely smooth surface of the under side of the roof-bones. Anterior to the rising process there is a foramen; a little farther forward and somewhat laterally there are two small foramina on the left side and a single foramen on the right side. At the base of the rising process on the posterior outer angle there is a small foramen. On the right side there is a second foramen on the posterior inner corner, but this is lacking on the left side.

The lower surface of the roof of the cranial area (fig. 3).-The dermsupraoccipitals and the tabulare send down processes which unite with the rising processes of the exoccipitals. On the inner side of these processes there is a thin plate of bone, evidently the very rudimentary opisthotic. On each dermsupraoccipital there is a small, elongate area with a rough surface and slightly raised edges; that of the left side reaches to and even crosses the dermsupraoccipital-squamosal suture; that of the right side is shorter. These are evidently points of cartilaginous attachment for some element of the brainwall, probably the prootic, but no trace of such an element was preserved. The tabulare has small presentation on the lower surface and the outline is nearly square. About the center of the bone there is a deep pit with the inner edges slightly elevated. These pits end blindly and do not penetrate more than halfway through the bone. Outside of the pits the remainder of the surface is rough and evidently afforded cartilaginous attachment; the rough area terminates sharply at the tabulare-squamosal suture, but the adjacent portions of the squamosal are marked with fine grooves, as if by a plexus of blood-vessels. There is no element which can be supposed to have attached to this area, unless it be the opisthotic, which has nearly disappeared in the genus; this suggestion seems the more unlikely, as, if it were attached, the opisthotic would appear on the posterior face of the skull, which it does not do in the Metoposauridæ. On the other hand, Watson ${ }^{1}$ shows an ascending plate on the inner edge of the exoccipital in Capitosaurus. The thin plate on the inner side of the rising process of the exoccipital of Buettneria may possibly be such a process, though it is apparently free from the exoccipital and has been interpreted as the opisthotic. The meaning of the large pits on the tabulare is not understood.

Attached to the inner edge of the anterior rising process of the pterygoid there was found, on the left side, a small plate of bone, somewhat constricted in the middle. This lay vertically in the matrix and extended horizontally inward, across the posterior end

1 Watson, D. M. S., loc. cit., fig. 11 A. 
of the groove on the upper face of the posterior end of the pterygoid. It is perhaps an ossification of the alispenoid or orbitosphenoid cartilage; no corresponding element was found on the other side.

One of the remarkable features of the skull is the evidently large amount of cartilage in the walls of the brain-case. The stapes were lost and the otic opening is very large, the bones around it terminating in smooth edges. There seems no escape from the conclusion that the whole of the area of the organ of hearing was cartilaginous. The whole of the lower surface of the bones in the area occupied by the brain is perfectly smooth, with the exceptions noted. There was no attachment of exoccipital, epiotic, or opisthotic to the upper wall, and the same condition in front shows that there was no ossification of the ethmoidal elements.

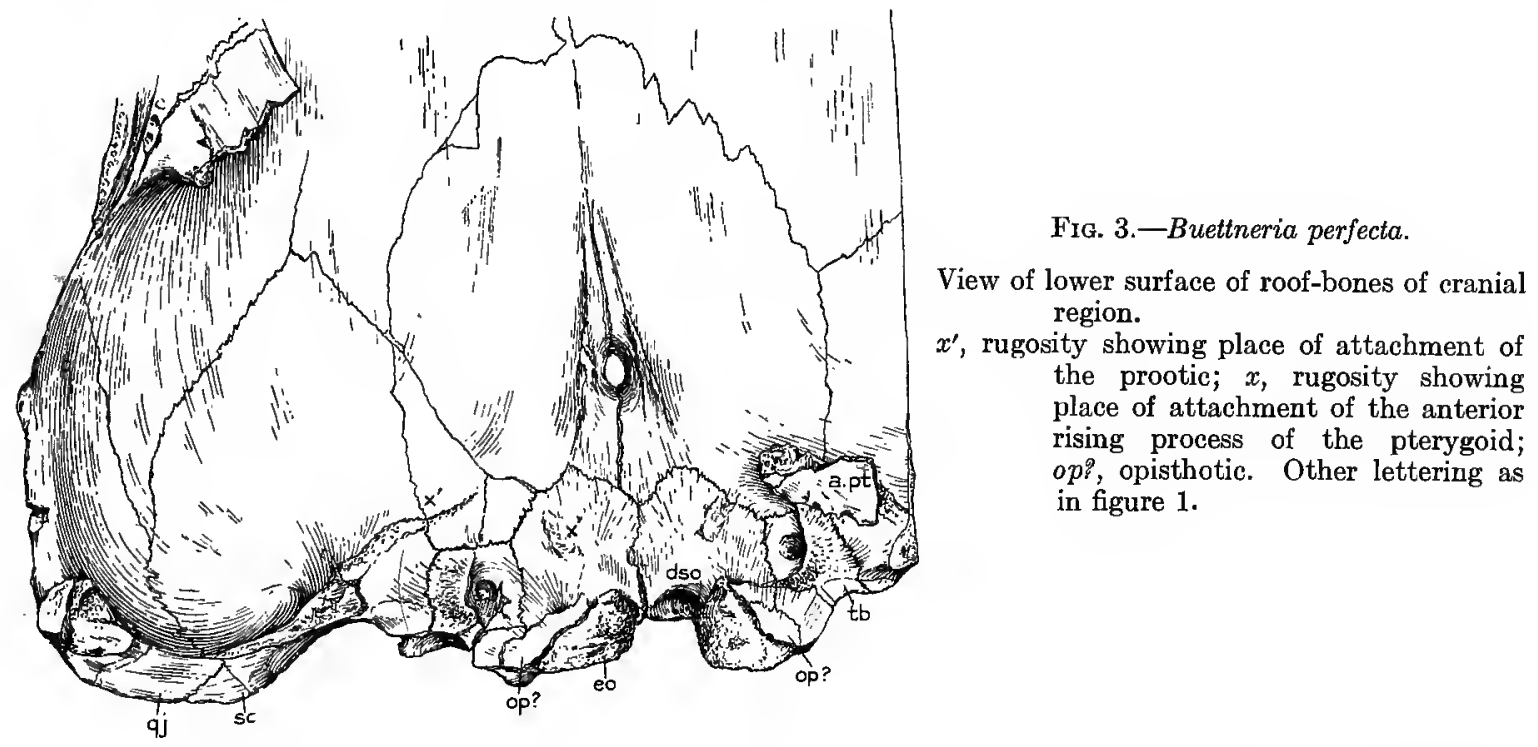

The teeth are imperfect, the tops having been broken away and the stubs worn as the skull was dragged, palatal side down, over the bottom. In even the smaller teeth the broken surfaces show the labyrinthine structure (plate 2 в).

It is evident that this genus has its nearest relations in Metoposaurus and belongs in the family Metoposauridæ of Watson, ${ }^{1}$ but it is very doubtful whether Anaschisma can be retained in the same family. From Metoposaurus the genus Buettneria differs in the narrower processus cultriformis and the shape of the posterior portion of the parasphenoid, in the smaller (or absent) transverse, in the shorter quadrate ramus of the pterygoid, in the loss of all trace of the post-temporal foramina, in the presence of a series of small teeth on the internal nares, etc.

Measurements.-Total length of skull, $443.2 \mathrm{~mm}$. Breadth of skull at posterior end, $344.2 \mathrm{~mm}$.

For this new form I take great pleasure in proposing the name Buettneria perfecta, in recognition of the interest, patience, and skill of Mr. William H. Buettner, who has prepared the skull and mounted it in all of its perfection.

A second skull of the same genus, but far less perfect, showing only the upper surface, was found in the same region. Many other isolated bones were found, indicating

${ }^{1}$ Watson, D. M. S., loc. cit., p. 67. See also v. Huene, Gonioglyptus, ein alttriasicher stegocephale aus Indien, Acta Zoologica, p. 456, 1920. In this paper v. Huene arrived, independently, at almost exactly the same arrangement of the families of the Stegocephalia as did Watson a year earlier. 
other parts of the skeleton, but of these the majority are vertebræ and bones of the pectoral girdle; remains of limb-bones are scarcely represented in the collection. Some of the isolated bones are described below.

A nearly perfect left ramus of a lower jaw, No. 7469, University of Michigan collection, was found by the author in the breaks of Sand Creek, just south of Cedar Mountain. The jaw lacks the extreme anterior end and the posterior end is somewhat crushed, but the greater portion is in good condition. The length of the jaw is, allowing for the missing anterior end, $43 \mathrm{~mm}$., somewhat shorter than the jaw of Busttneria as indicated by the skull. The jaw as preserved shows too great a curvature to be associated with the skull in the same genus. The jaw is illustrated in figure 4, A and B. On the inner
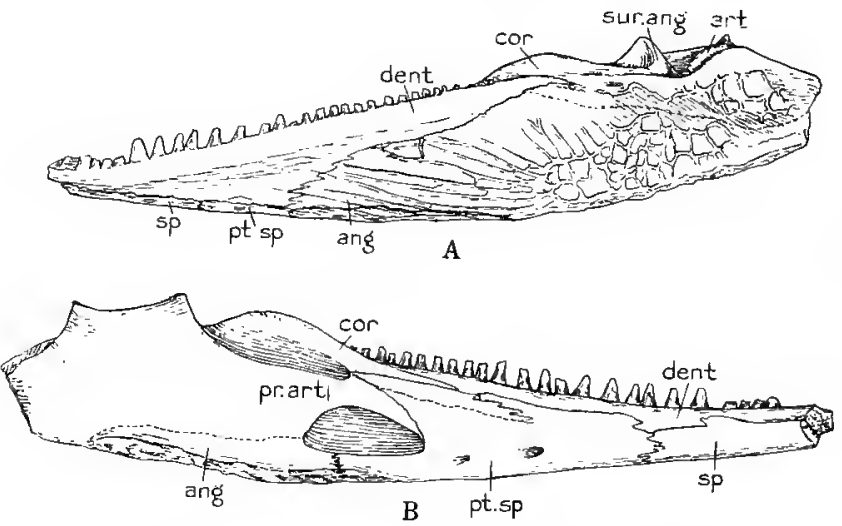

FIG. 4.

A. Outer surface of left ramus of jaw of a large Stegocephalian, No. 7469, U. of Mich. $\times 0.25$.

$B$. Inner surface of the same jaw shown in A. dent., dentary; cor., coronoid; sur. ang., surangular; art., articular; $s p$. , splenial; pt. sp., postsplenial; ang., angular; pr. art., prearticular.

side there is a relatively large supra-Meckalian foramen and below this a surprisingly large lower opening. The splenial is short and confined to the anterior fourth of the ramus; it appears on both the inner and the outer sides of the lower edge and evidently took part in the symphysis. The sutures marking the outlines of this bone are clear and distinct. Posterior to the splenial there is a postsplenial which forms the middle portion of the inner surface of the jaw; it appears on both the inner and outer sides of the lower edge, but on the inner side rises in a smooth plate to form the greater part of the inner surface. It is pierced by two good-sized foramina. The posterior edge of the postsplenial extends back to the middle of the lower edge of the lower Meckalian opening, where the suture is clear and distinct. From the middle of the upper edge there is apparently a suture of irregular outline extending downward, but it can be traced for only a short distance; the exact nature of this apparent suture can not be made out; it may indicate the presence of an intercoronoid bone, but no other indications of either an intercoronoid or a precoronoid can be detected. Posterior to the lower Meckalian opening the inner surface of the bone is badly crushed and covered with a multitude of small fracture lines which render it impossible to determine the course of any sutures. It is altogether probable that the greater part of this surface is formed by the prearticular. The anterior edge of the supra-Meckalian opening is formed by the coronoid and the prearticular; it is probable that the angular appears on the lower edge of the inner surface, but the suture can not be made out. The coronoid extends forward in a long process between the postsplenial and the inner edge of the dentary. The dentary ends posteriorly in a sharp process between the coronoid and the angular or surangular. Anteriorly it extends forward, forming the whole of the alveolar edge. The teeth are small at the posterior end, but rapidly increase in size forward until they reach the maximum size. Under the binocular microscope the structure of the teeth is seen to be labyrinthine at the base, becoming much more simple near the apex. No teeth appear upon the coronoid. 

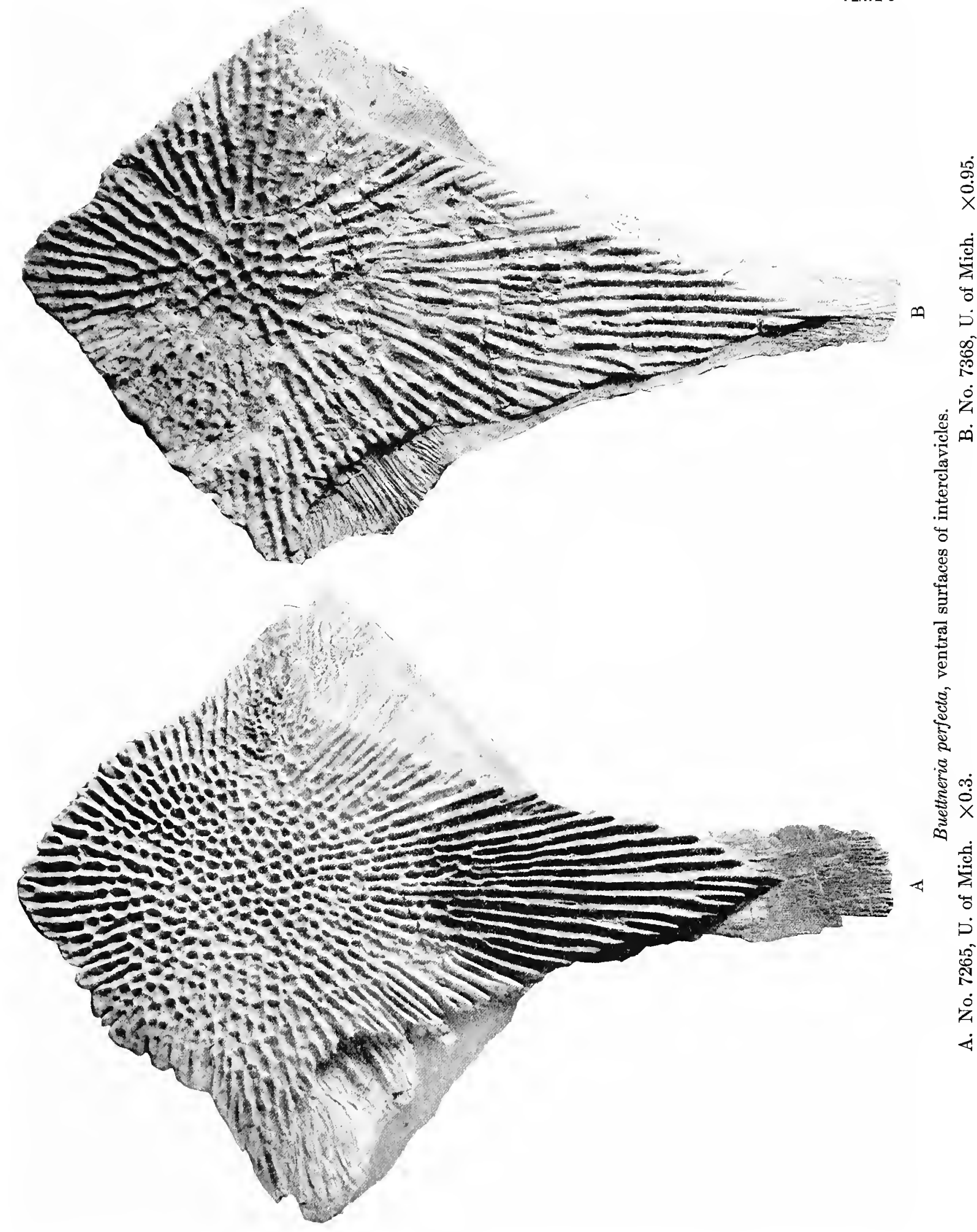

The posterior part of the outer surface of the jaw is largely formed by the angular; it is marked in its posterior portion by a very coarse sculpture, which changes to a coarse radiating pattern anteriorly and gradually dies out near the anterior third of the jaw. No suture can be made out between the angular and the surangular, and it is not certain that the surangular appears on the outer side, as it is figured in Eryops by Broom. The sutures between the angular, dentary, postsplenial, and splenial are all clear and distinct. Near the posterior end of the jaw there is a deep linear depression devoid of sculpture; this may mark the position of the suture between the angular and surangular, but no traces of the suture could be made out in or near the depression.
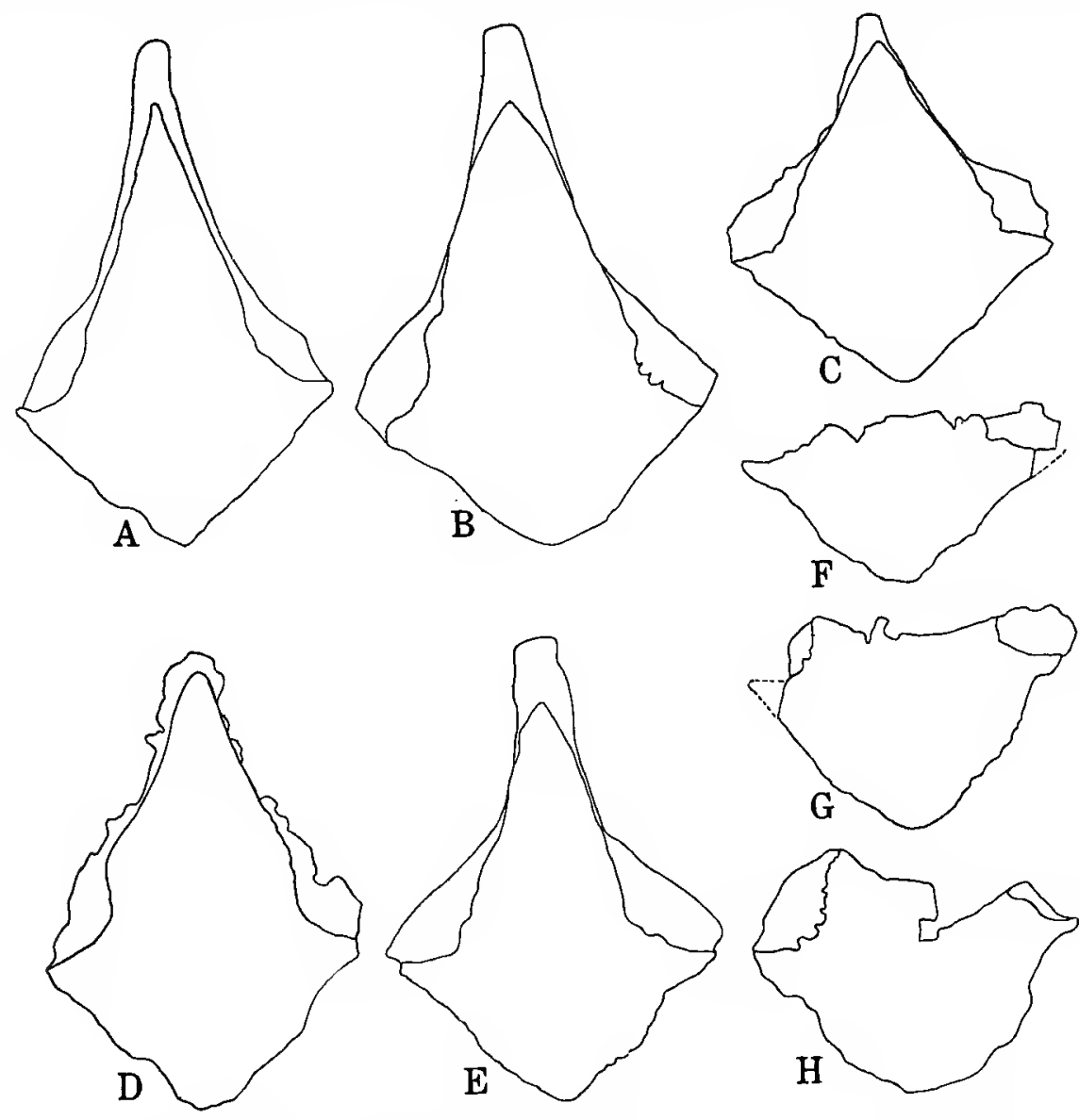

FIG. 5.-Outlines of interclavicles, all, except D, from University of Michigan.

A. No. 7368. B. No. 7448. C. No. 3814. D. Metoposaurus frassi Lucas. E. No. 7266. F. Posterior portion, No. 7367. G. Posterior portion, No. 7366. H. Posterior portion, No. 7374 .

Viewed from above, the posterior end of the jaw shows two distinct halves which seem to meet as distinct bones at the posterior end; these may be the angular and the surangular or the surangular and the prearticular. Just posterior to the elevation of the surangular on the posterior edge of the supra-Meckalian opening there is apparently a distinct element represented by an egg-like mass of bone between the two separate halves described above. This may be the articular, as no other trace of that bone can be found.

A second jaw (No. 7503, University of Michigan), also from Sand Creek, is complete, but badly rotted by gypsum. The sutures can not be traced, but the Meckalian 
openings are the same as in No. 7469 and there is the same meeting of two distinct bones at the posterior edge and the same distinct articular element.

Eight interclavicles were found in the same region as the skull of Buettneria. Five of these are nearly complete; three are accompanied by more or less complete clavicles; three are represented by the posterior portion only. These bones are shown in figure 5, and plates $2 \mathrm{c}, 3$, and 4 . It is evident that none of these forms is specifically identical with any of the described forms from the Upper Triassic of Europe, and it is probable that the difference is of generic value. Figure 6, copied from Fraas, ${ }^{1}$ shows the characteristic form of the interclavicles in Metoposaurus, Cyclotosaurus, and Mastodonsaurus. In comparing these with the interclavicles from the Texas Triassic, it is evident that there is a great difference in the proportions; in the American forms the posterior prolongation is much less in relation to the anterior. In the specimen previously described as Metoposaurus jonesi, No. 3814 of the University of Michigan collection, the form most closely approaches that figured by Fraas as Metoposaurus in the shortness of the anterior process and the breadth as compared with the length, but the posterior process is much sharper and the sculpture is very different. In all of Fraas's figures there is shown a strong posterior prolongation of the clavicles in the region of the articulation with the shoulder girdle, which is apparently absent in the Texas forms, though this is not absolutely certain, as all of the clavicles, except No. 3814, are imperfect in this region.
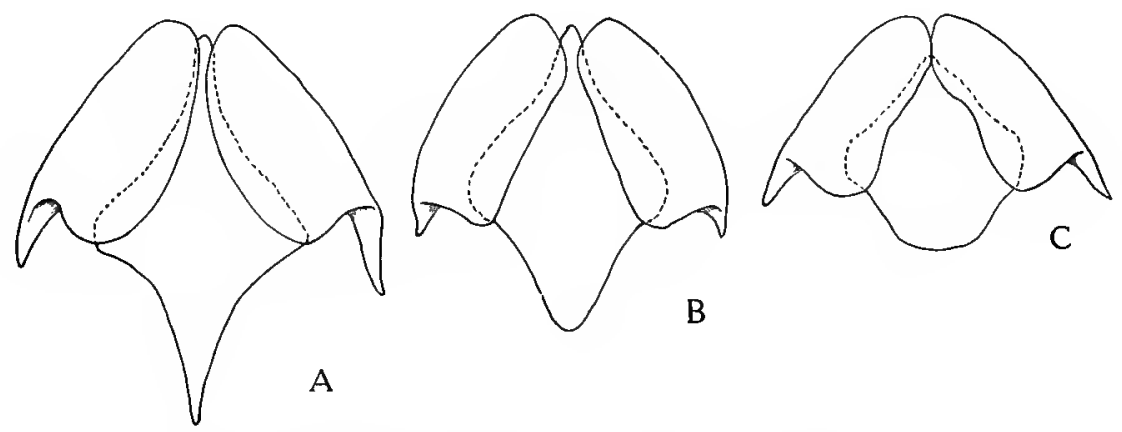

FIG. 6.-Outlines of interclavicles and clavicles.

A. Metoposaurus, after Fraas.

B. Cyclotosaurus, after Fraas. after Fraas.

The figures showing the outline of the interclavicles have all been reduced to the same scale on the single line which is comparable in all of the specimens, $i$. e., the breadth just at the posterior edge of the articular faces for the clavicles. The disproportion between the breadth of the interclavicles and the length of the posterior process posterior to this line is sufficiently striking in the different specimens to need no comment. Working out the proportion between these lines in all of the specimens results in an almost perfect series, with no break where a line can be drawn between groups. The varying outlines warrant the belief that there are several distinct species, but upon such incomplete material the author does not feel that new genera or even species should be founded. Future discoveries will undoubtedly associate the different interclavicles with more characteristic parts of the skeleton; and if the differences in outline and proportions are shown to be more than developmental or individual variations, new names may be based on such characters.

\footnotetext{
${ }^{1}$ Fraas, E., Neue Labyrinthodonten aus der Schwabischen Trias, Paleontographica, Bd. LX, p. 286, 1913.
} 


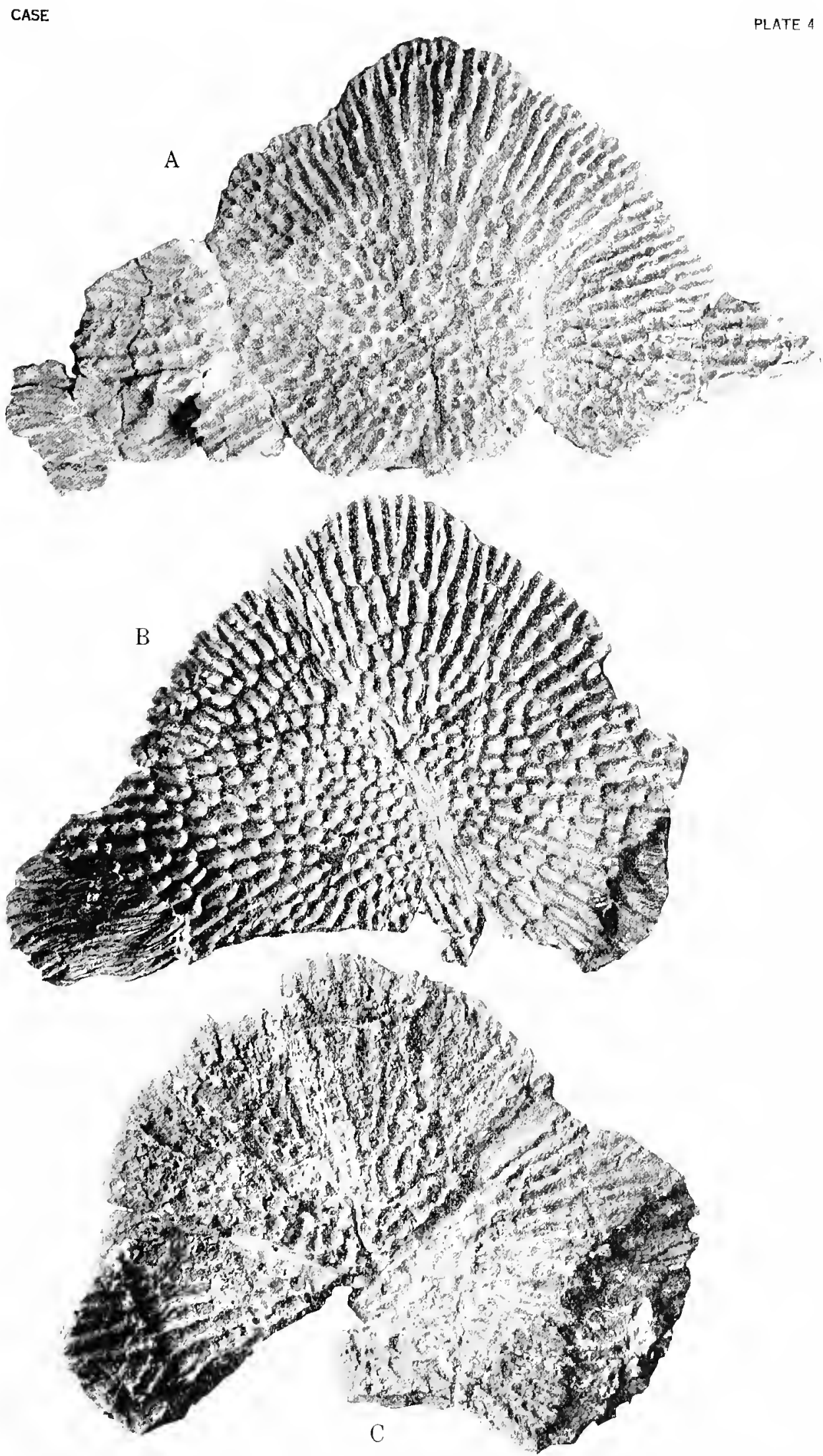

Buettneria perfecta, ventral surfaces of posterior halves of interclavicles.

A. No. 7367, U. of Mich. $\times 0.34 . \quad$ B. No. 7366, U. of Mich. $\times 0.48$. C. No. 7364 , U. of Mich. $\times 0.53$. 


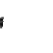


As the figures are reduced to the same scale, it is necessary to take the measurements into account to realize the difference in size. The measurements are given in the following table:

\begin{tabular}{|c|c|c|c|c|}
\hline Specimen. & $\begin{array}{c}1 \\
\text { Total } \\
\text { length. }\end{array}$ & $\begin{array}{c}2 \\
\text { Breadth at } \\
\text { posterior edge of } \\
\text { face for claviele. }\end{array}$ & $\begin{array}{l}3 \\
\text { Length posterior } \\
\text { to line indicated } \\
\text { in } 2 .\end{array}$ & $\begin{array}{c}4 \\
\text { Proportion } \\
\text { between } 2 \text { and } 3 .\end{array}$ \\
\hline 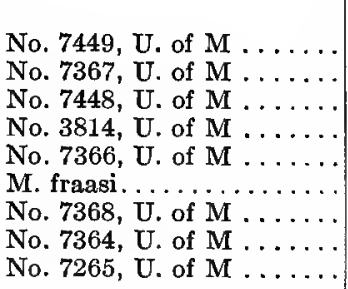 & $\begin{array}{c}m m . \\
355.6 \\
\\
381.0 \\
330.2 \\
\\
428.8 \\
279.4 \\
508.4\end{array}$ & $\begin{array}{c}m m . \\
279.4 \\
381.0 \\
273.2 \\
279.4 \\
254.0 \\
309.0 \\
172.0 \\
189.6 \\
355.6\end{array}$ & \begin{tabular}{r}
\multicolumn{1}{c}{$m m}$. \\
101.6 \\
149.4 \\
120.8 \\
117.6 \\
114.4 \\
150.0 \\
89.6 \\
95.4 \\
225.6
\end{tabular} & $\begin{array}{r}0.36 \\
.39 \\
.44 \\
.45 \\
.45 \\
.48 \\
.50 \\
.50 \\
.63\end{array}$ \\
\hline
\end{tabular}

From the shape of the interclavicles it is believed by the author that only one specimen, No. 3814, can be placed in the genus Metoposaurus; it has been described as $M$. jonesi. ${ }^{1} \quad$ All but one of the others correspond in a general way, and as they were found in the same region as the perfect skull of Buettneria and a second, imperfect skull of the same genus, they may be regarded, provisionally, as belonging to that genus. Specimen No. 7364 is decidedly different in form, proportions, and sculpture and may be distinct; the imperfect state of preservation renders this somewhat doubtful.

The clavicles are not well preserved, except in the specimen No. 3814, but the general form and sculpture do not differ markedly in the portions preserved. In specimen No. 7367 the clavicles are long in correlation with the long anterior process which the interclavicle must have possessed.

Few other bones of Stegocephalia were found. A single humerus of small size and with poorly ossified articular ends was found associated with the small interclavicle, No. 7368, and probably belonged to the same individual. Numerous vertebral centra of typically stereospondylus form were found scattered in the beds. One with a double articular face is undoubtedly the anterior one of the series. No neural spines or other parts of the skeleton were found.

1 Case, E. C., Occasional Papers of the Museum of Zoology, University of Michigan, No. 82, 1920. 


\section{DESCRIPTION OF DESMATOSUCHUS SPURENSIS AND THE NEW SUBORDER DESMATOSUCHIA.}

The remains of this specimen were found near the east bank of the Blanco or Catfish River, about a half mile east of the crossing of the old mail-road from Spur to Crosbyton, in Crosby County, Texas. The site of the discovery is a patch of sand and sandy clay occupying not more than a few hundred square feet, about a half mile north of the road. This patch lies within a half mile of one of the areas of exposure of sands, clays, and conglomerates which mark the occurrence of old river-washes at rare intervals, among the barren clays of the Upper Triassic. The particular patch of sand and clay in which the specimen occurred was evidently accumulated in some isolated hole distinct from the nearest large area of river deposit. No other bones were found within half a mile of the spot, and this important point, bearing upon the association of the bones found in one specimen, was checked during three separate visits to the locality. In working the specimen out of the ground a few scattered bones were found in the sandy clay of the upper part of the deposit, but the greater part of the material was found in single mass near the bottom, where the matrix was a light-colored clay with included grains of sand, abundant traces of badly decayed vegetation, and lumps of charcoal. This part of the clay was filled with gypsum, which had in some places badly rotted the bones and in other places formed a protecting coat which preserved the surface in perfect condition. Next to the bones there was, in may places, a thin layer of pyrite, which rendered the cleaning very difficult, especially the rugose surface of the skull. The pyrite frequently penetrated and filled the small cavities and foramina, making it especially difficult to work out some of the finer details. Some parts of the matrix were very hard and colored a deep black; when this sort of material was in contact with the bone the preparation was even more complicated.

It seems evident that the remains of the animal were washed into a hole with a considerable amount of vegetable material and then the hole was filled with a cleaner sand. There can be no question that the major portion of the bones found together at the bottom of the pit belong to one specimen, but there is also no question that some bones of a second individual found their way into the hole, as there is an excessive number of dorsal vertebræ and there is a second axis. Only a very few of the characteristic dorsal plates of Desmatosuchus were found among the abundant remains of Phytosaurs in the adjacent regions of the county, suggesting the comparative rarity of the form and perhaps its restriction to a certain habitat. The peculiar condition under which the specimen was found and the fact that no other bones were found nearer to it than a half mile must again be emphasized by the author as justification for associating the bones in a mount.

A preliminary description of this form has been published in the Journal of Geology ${ }^{1}$.

The material collected consists of the skull lacking the lower jaw and the anterior end of the nose, the vertebral column, which is apparently complete to the sacrum and a few caudal vertebræ, the dorsal armor of the body and a portion of the tail, an imperfect right scapula, and a portion of the right side of the pelvis. A fragment of one of the long bones is the single bit of evidence of the skeleton of the limbs. One small, irregular plate was found with the mass of vertebræ and may be taken as evidence of the presence of isolated plates upon the sides or abdomen.

The greater part of the material was found in an irregular heap, with no continuity except in the cervical region and a few of the dorsals. A few of the plates seem to

${ }^{1}$ Case, E. C., Preliminary Description of a New Suborder of Phytosaurian Reptiles, with a Description of a New Species of Phytosaurus, Journal of Geology, vol. xxvin, No. 6, p. 524, 1920. 
have retained their normal position. The restoration of the skeleton has been accomplished by placing the bones in their most evident position, with such checks as their original position afforded.

The skull.-In many of its characters the skull resembles that of the Phytosauria, but differs so radically in others that it must be placed at least in a separate suborder. The close occlusion of the sutures and the condition of preservation has made the determination of the most of the sutures impossible. The surface of the skull has been most carefully cleaned with a needle and has been treated with acid to remove the pyrite and the other matrix. It has been repeatedly examined under a binocular microscope, so that the author feels certain that all possible traces of the sutures have been made out.
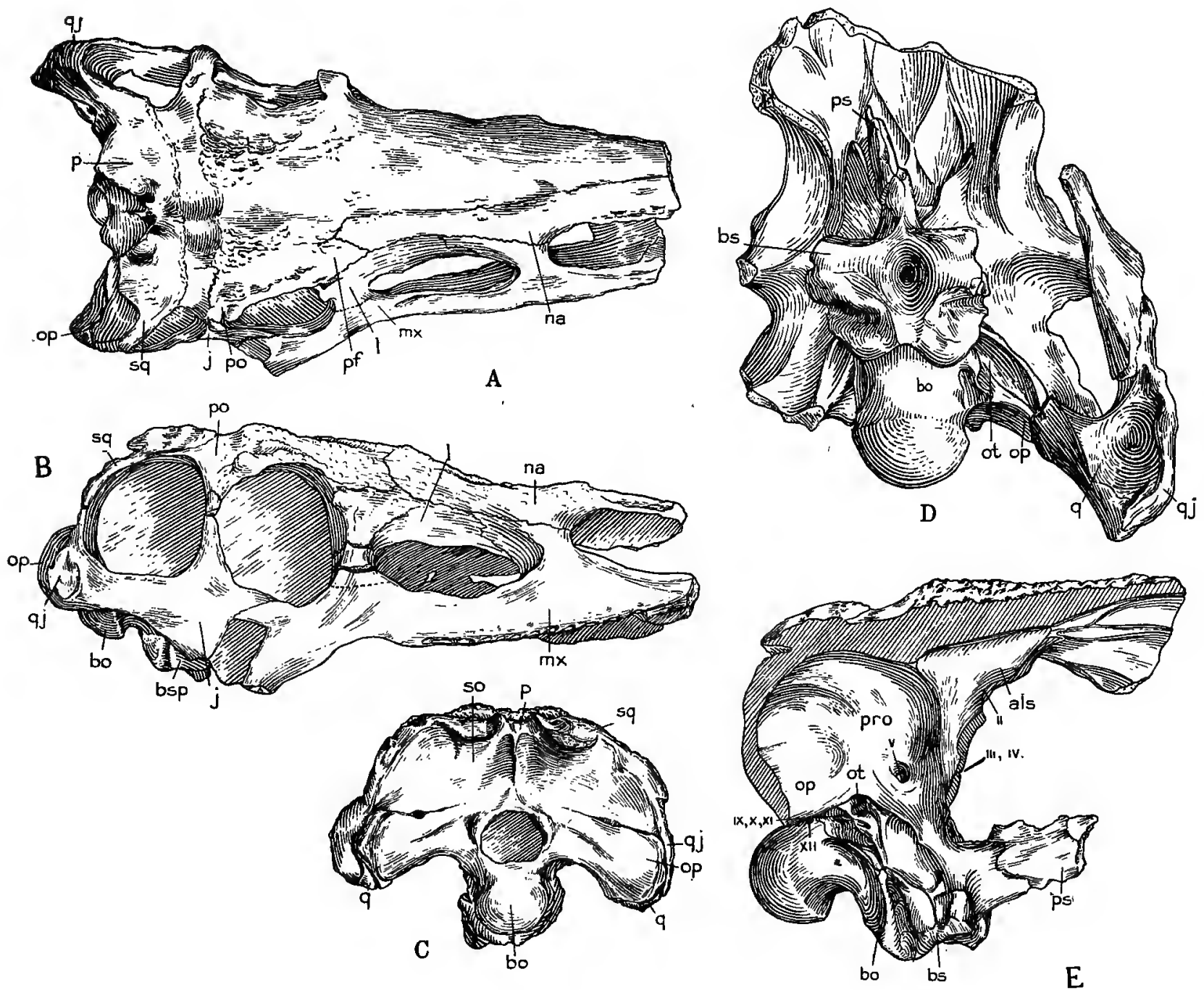

FIG: 7.-Skull of Desmatosuchus spurensis.

A. Upper surface. $\times 0.3 . \quad$ B. Lateral surface. $\times 0.3 . \quad$ C. Posterior surface. $\times 0.3 . \quad$ D. Lower surface of posterior portion. $\times 0.6$. E. Lateral surface of wall of brain-case. $\times 0.6$. bs., basisphenoid; ps., parasphenoid rostrum; ot., otic channel; als., alisphenoid; pro., prootic; ot., otic opening; op., opisthotic; $I I-X I I$, outlets of cranial nerves. 
The general shape, with the exception of the anterior end of the nose, is shown in figure 7 and plate 5 . The small size relative to the body is a striking difference from the condition found in the Phylosauria. It is, of course, uncertain just what length was attained by the nose, but from the position of the nares, the shape of the nose, and the approximation of the maxillaries, it is apparent that not a great deal is missing. The lack of a second temporal fenestra is the most striking character of the skull. This might be considered as a primitive character were it not for the associated characters of the lack of a pineal foramen and the small size of the post-temporal openings, which amount to no more than foramina. The nearly complete closure of the posterior surface of the skull, with the single temporal opening and the prolongation of the jugal forward and downward, led the author to repeated attempts to trace some resemblance between this form and those from South Africa, especially the Deinocephalia-attempts that were just as repeatedly demonstrated to be useless; but superficial suggestions recalled the South African forms many times. The presence of the deep notch below the orbit, with the projecting edges of the jugal and the maxillary, led to the suggestion that the temporal opening was the upper one and that the lower part of the temporal region was broken away and lost. This suggestion was also made to the author independently, by both Doctor von Huene and Doctor Watson, after their consideration of the figures published in the preliminary description of Desmatosuchus. The ideas of these friends are indicated in figure 8. This is, however, impossible, as the lower edges of the bones in this region are paper-thin and complete; moreover, the position, character, and form of the bones on the two sides' are practically identical, a condition that is almost inconceivable if part had been accidentally lost.

The lateral aspect of the skull (fig. $7 \mathrm{~A}$ and plate $5 \mathrm{~B}$ ).-As mentioned above, the anterior end is missing, from about the anterior third of the narial opening forward. The maxillaries are elongate, with only a limited exposure on the sides of the skull; the alveolar edge is slightly convex antero-posteriorly. At the anterior end, below the anterior half of the nares, there is the appearance, on both sides, of a wedge-like insertion of a posterior prong of some bone in front. If this is a distinct element it can only be a part of the premaxillary. Between the narial and the antorbital openings the upper edge of the maxillary rises in a process which is reflected at its upper end and joins the lachrymals and the nasals; the suture is here clear and distinct. The line of juncture between the maxillary and the lachrymal can not be made out on either side, but a break on the left side of the skull, which possibly may be along the line of the suture, indicates that the suture was perhaps convex downward, permitting the maxillary to form the posterio-inferior border of the antorbital opening. The upper edge of the maxillary forms the anterior half of the lower border of the orbit; the suture between it and the jugal is inclined backward and downward. From a point at the posterior edge of the dental series the lower edge of the maxillary is inclined somewhat abruptly backward and downward, terminating in a blunt point of thin bone. The posterior edge of this process is nearly straight and forms the anterior edge of a nearly rectangular notch which lies below the orbit and between the maxillary and the jugal. A posterior narrow prong of the maxillary which articulates with the jugal above forms the upper border of the notch. The complete edges of the bones outlining this notch and the almost exact similarity of the two sides show that this is a notch and not the upper part of a second temporal opening. It is a structure which has not previously been noted, so far as the author knows, in any fossil skull. There are 12 clearly defined sockets on the alveolar edge of the maxillary of the left side and 13 on the right; these indicate teeth of moderate size with nearly cylindrical roots. There is no indication of enlarged teeth at the anterior end and there is no suggestion of antero-posteriorly elongate teeth 


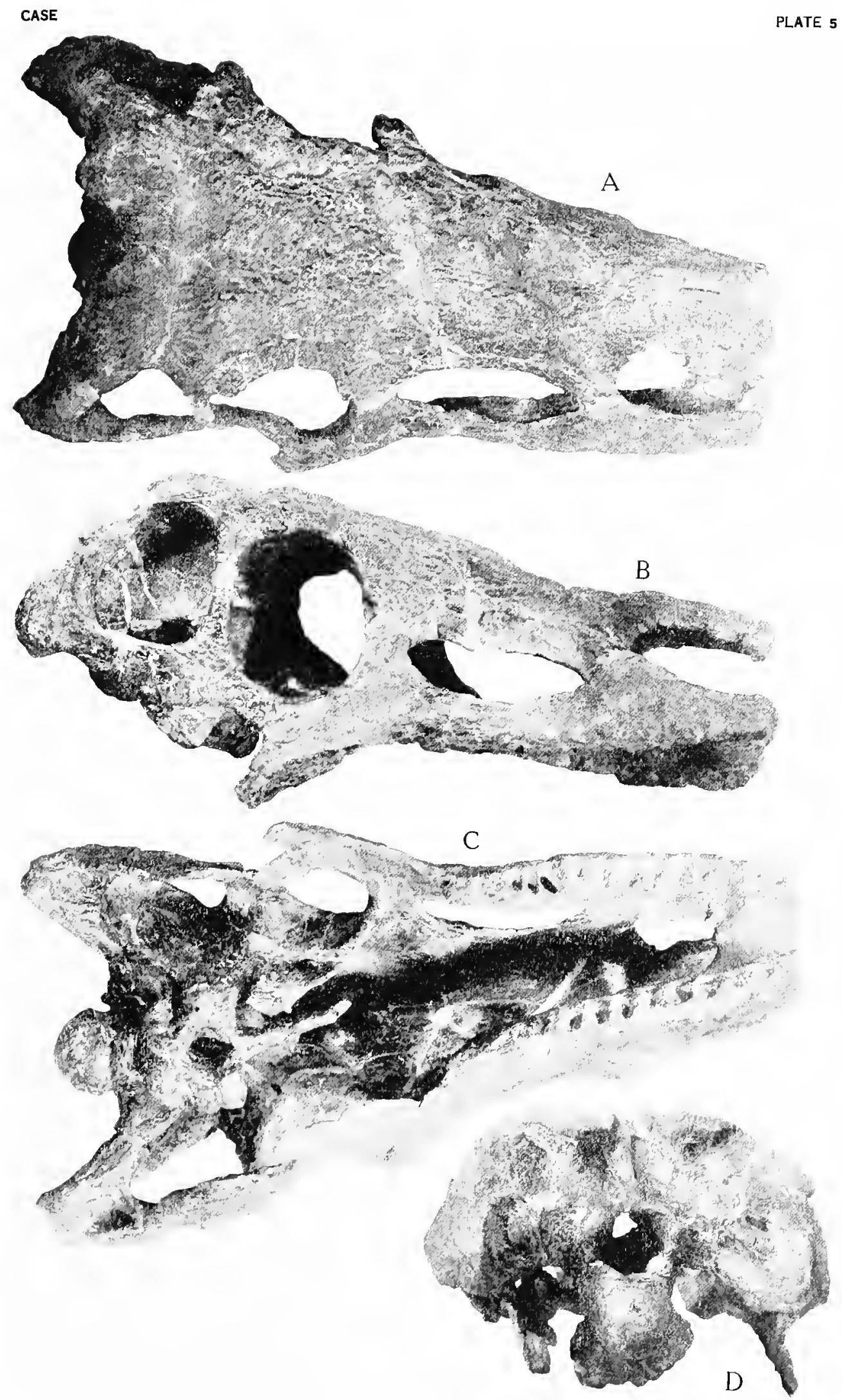

Desmatosuchus spurensis, skull, No. 7476, U. of Mich. All figures $\times 0.36$.

A. Upper surface. B. Lateral surface. C. Lower surface. D. Posterior surface. 

such as occur in the posterior part of the jaws in the Phytosauria. The sockets of the median part of the series seem a little larger than those of the anterior or posterior ends; this may be due to the condition of the specimen. Only a single, badly rotted tooth was found associated with the specimen and from this nothing can be made out.

The nasals are elongate bones lying in the normal position, forming the upper edge of the narial openings and separated from the maxillaries and the lachrymals by distinct sutures. The posterior edge can not be made out exactly, but a suture is traceable for a short distance from a point a little in front of the posterior edge of the antorbital opening toward the median line.

No trace of a septo-maxillary can be made out.

The lachrymal forms the upper border of the antorbital opening and is separated from the nasal and the prefrontal by a distinct suture. It forms the broad bar between the orbit and the antorbital opening and joins the maxillary below, but the suture, as stated above, can not be made out definitely. The portions of the lachrymal and the maxillary adjacent to the upper part of the antorbital opening are smooth and evidently afforded attachment to a strong muscle which helped to close the jaws. The upper portion is marked by a deep but relatively small sculpture. A foramen enters the bone on the inner rim of the orbit.

The jugal occupies the normal position, forming the posterior half of the lower rim and the lower half of the posterior rim of the orbit. The union with the maxillary is sharply defined. The posterior border of the notch beneath the orbit is formed by the jugal. The lower border rises sharply from the posterior lower corner of the notch to the articular region of the skull. The suture between the jugal and the postorbital is rery distinct; the two bones meet at about the middle of the slender postorbital bar. The jugal narrows towards the rear and forms the major part of the bar closing the temporal opening below. Neither the position nor the outline of the jugal-quadratojugal suture can be made out.

The limits of the quadratojugal can not be made out, but it is evident that it is a small element. The posterior lower angle of the skull is narrow and the bar behind the temporal opening is even narrower. The whole region is more slender than appears at first sight, for the distal end of the opisthotic appears on the lateral surface and increases the apparent size of the angle when seen in profile.

The sutures outlining the prefrontal, postfrontal, and frontal can not be followed; the whole region is very rugose and the most careful inspection has failed to reveal more than short traces of the lines of separation.

The postorbital.-Just posterior to the heavy rugose knob which marks the upper posterior angle of the orbit, a suture can be traced for a short distance upon the smooth surface of the skull on both sides; this evidently marks the posterior edge of the postorbital.

The squamosal begins at the suture just mentioned; the anterior part lies in the smooth area above the temporal foramen; the posterior portion is slightly but abruptly elevated and forms a protecting point on the back of the skull. The'edge of the abruptly elevated portion is continued downward and backward and forms the posterior edge of the lateral temporal opening until it meets the quadratojugal at some undetermined point.

The upper surface of the skull (fig. $7 \mathrm{~A}$ and plate $5 \mathrm{~A}$ ).- - The skull is narrow in front and gradually widens to the posterior edge. The nasals form a little more than the anterior half; their surface is sculptured a little more deeply on the median than on the outer parts. The median suture is traceable to the posterior edge of the nasals, but from there back is indistinguishable; it is entirely obliterated in the parietal region, 
where the smooth area permits the most careful examination. This smooth area is the surface of a shallow depression which runs directly across the top of the skull, from a point opposite the anterior half of the upper edge of the temporal opening to the same point on the other side; its posterior border is somewhat sharply elevated by the rugosity of the surface of the squamosal and parietal bones, and it is divided by a low ridge on the median line of the skull. The most of the upper surface is so deeply sculptured that the sutures are not visible, but it appears from the arrangement of the sculpture that the frontals, paired or unpaired, occupy a heart-shaped area from about the posterior line of the orbits as far forward as the nasals. There is, on each side, a deep groove or elongate pit just within the very rugose upper border of the orbit. At the posterior inner edge of this groove there is the center of rugosity which may mark the anterior inner corner of the postorbital.

The posterior face of the skull (fig. $7 \mathrm{C}$ and plate $5 \mathrm{D}$ ).-This face of the skull was readily freed from the matrix and presents a smooth surface of uninjured bones, upon which no marks or sutures could be missed. The whole face is semicircular, with the prominent occipital condyle in the center of the horizontal lower edge. The surface is completely closed, with the exception of the post-temporal openings (which are so small as to be reckoned as little more than foramina) and the large foramen magnum. In the median line above there is a thin but prominent ridge flanked by vertically elongate pits. The whole surface slants backward at a slight angle and is concave from side to side above the line of the opisthotics; below this line the distal ends of the opisthotics slant more acutely backward, increasing the concavity. The line of division between the opisthotics and the plate above is traceable inward for a short distance beyond the post-temporal openings; the sutures between the exoccipitals and the adjacent elements are completely obliterated. Just above the foramen magnum there are small prominences which suggest the presence, in the complete skeleton, of a proatlas. The opisthotics turn sharply outward from their junction with the exoccipital portion; their posterior faces are smooth, with a low ridge which runs outward and slightly downward on the inner half. The distal portion is slightly expanded and the fairly broad, somewhat triangular distal ends are visible from the rear.

Between the distal end of the triangular terminal face of the opisthotic, which points forward, and the quadratojugal there is visible a wedge-like surface of bone which must be a portion of the nearly concealed quadrate. There is no trace of a quadratojugal foramen. The occipital condyle is nearly spherical and is supported upon a well-defined neck; there is no trace of a pit marking the forward extension of the notochord. A distinct line marks the contact of the posterior plate of the skull with the squamosal-quadratojugal; the plate sends a long process to fill the space between the distal end of the opisthotic and squamosal-quadratojugal.

The lower surface of the skull (fig. $7 \mathrm{D}$ and plate $5 \mathrm{c}$ ). - The pterygoids and the bones of the palatal region are, most unfortunately, absent, but the bones of the brain-case are so perfectly preserved that all the foramina can be made out; the sutures are all closed and can not be traced. The phytosauroid characters are seen in the prominent basioccipital-basisphenoid mass lying well below the level of the occipital condyle, in the deep pit which lies in the usual position of the openings of the Eustachian canals, in the strong basipterygoid processes of the basisphenoid, and in the strong alisphenoids rising to the roof of the skull and firmly attached to it. The primitive character is shown in the evident loose attachment of the pterygoids and the prominent, free, parasphenoid rostrum.

The basioccipital.-Anterior to the condyle the lower surface of the bone bends sharply downward and forms, or approaches close to, the posterior edge of the deep 
pit in the basisphenoid. The suture between it and the basisphenoid is not distinct, but on either side of the pit there is a deep groove which marks the position of the suture; it is possible that the sutural region was occupied in life by a considerable mass of cartilage, which in its decay has left the groove. The upper part of the anterior edge is marked by a sharp, thin ridge; just anterior to this is a large foramen through which passed the jugular vein and the IX, X, and XI nerves. Near the posterior edge there are small foramina in the exoccipital portion of the complex, which permitted the escape of the XII nerves.

The basisphenoid.-The lower surface is marked by the presence of a remarkably large and deep conical pit. This is in the position of the openings of the Eustachian canals in the Crocodilia, but the pit was thoroughly cleaned out and no traces of such openings could be detected. On either side of the pit the bone is thickened and passes forward to form the prominent basipterygoid processes. Posterior to the processes the sides of the bone are marked by a groove and then swell backward and outward to the edge of the groove which marks the line between the basisphenoid and the basioccipital. Between the basipterygoid processes there is a thin parasphenoid rostrum of considerable vertical extent. The anterior portion has been injured by decay, but it is apparent that not a great deal has been lost. The upper part of the posterior end of this process is excavated to receive the lower end of the infundibulum and the edges of this excavation are continuous with the alisphenoids above. The anterior face of the basisphenoid is rather broad and slightly inclined backward to the posterior face of the cavity for the infundibulum. Near the middle of this face there is a pair of foramina for the entrance of the internal carotid arteries. The point of juncture of the basisphenoid and the bones above is not determinable. From the bottom of the pit on the upper surface of the posterior portion of the parasphenoid rostrum foramina run through the sides of the basisphenoid to open into the lower part of the groove described as lying posterior to the basipterygoid processes; the function of theseforamina is not known.

The walls of the brain-case (fig. $7 \mathrm{E}$ ) are formed by the alisphenoids, the prootics, the epiotics (?), and the opisthotics, which form a solid lateral mass without distinguishing sutures. The outer surface of the brain-case is marked by two distinct ridges. The first starts below the origin of the bar between the orbit and the temporal opening and descends almost vertically, becoming continuous with the anterior edge of the alisphenoid at a point about one-third of its height above its origin from the parasphenoid rostrum. This ridge probably marks the line of contact between the prootic and the alisphenoid.

The lower ends of the alisphenoids are closely approximated, forming a narrow opening through which the hypophysis extends into the infundibular cavity below; above this the anterior edges of the bones rise nearly vertically, with a slight notch which permitted the escape of the III and IV nerves; at about one-half of their height the edges incline gently forward and contract into a second notch which marks the escape of the II pair of nerves; beyond this they incline more sharply forward and diverge to their contact with the upper wall of the skull.

Posterior to the first ridge, the walls of the brain-case are concave and perforated by the large foramina for the $\mathrm{V}$ nerves; the bulk of this portion of the wall is formed by the prootic. The second, or posterior, ridge on the wall of the brain-case comes sharply forward from the rear. Its posterior portion is formed by the lower edge of the opisthotic; just above the otic opening it bends sharply downward and forward and very nearly reaches the lower end of the first ridge. There are no sutures visible in the space between these ridges, but there is a short, low elevation extending forward from just below the 
upper posterior portion of the temporal opening, which carries slight rugosities and may indicate the location of the suture between the epiotic and prootic. The epiotic, if ever a distinct element, is fused with the opisthotic in the specimen. The edge of the anterior half of the posterior ridge is elevated and behind it is a groove which is continuous with the groove on the side of the basisphenoid. On the inner end of the opisthotic there are two openings - an upper, the otic opening, and a lower, the jugular foramen.

The position and form of the quadrate is one of the puzzling features of the skull. Between the distal end of the opisthotic and the quadratojugal is a deep pit, partly cut off in front by a ridge which runs from the inner side of the posterior end of the jugal-quadratojugal bar to the opisthotic. The quadrate apparently occupies the bottom of this pit, and the articulation with the lower jaw must have been formed by the concave surface, but no distinct articular surface is visible. If this interpretation is correct, the quadrate fills a small triangular area between the distal end of the opisthotic and quadratojugal, forms the bottom of the pit described, and runs forward for a short distance on the inner side of the opisthotic and for an uncertain, but not great, distance on the cranial wall. At best it must have been a relatively small and inconspicuous bone.

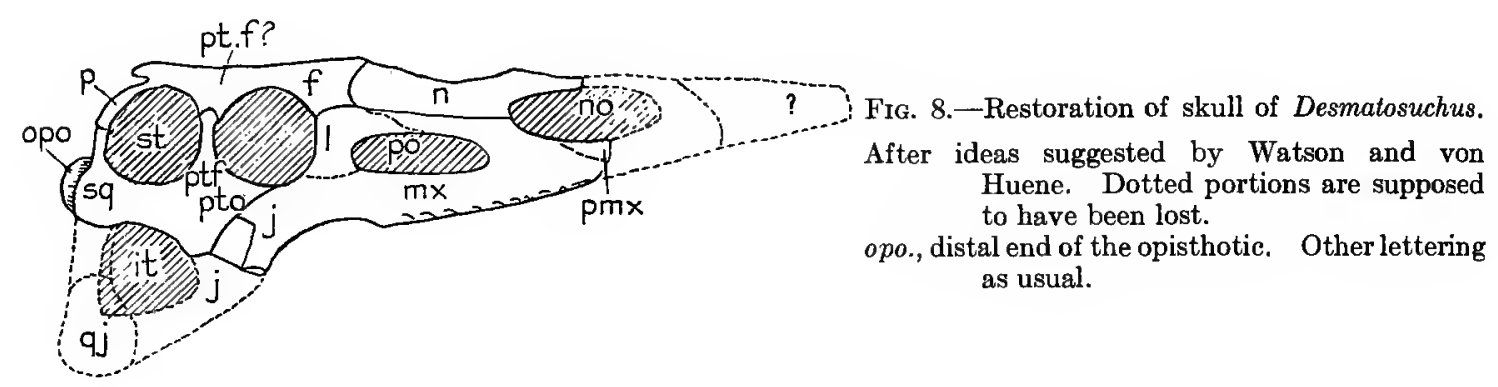

In comparing the skull with that of other forms, it is at once apparent that its closest relations lie with the Parasuchia, but the differences are so fundamental that it can not be placed in that order. The most notable differences are the single temporal foramen, the lateral and anterior position of the nares, and the extremely reduced condition of the quadrate bone. The last is the most fundamental. The lateral position of the nares is found in the Pseudosuchians and in some primitive Parasuchians. The development of the upper temporal opening is so irregular, though constantly present, in the two groups that its complete disappearance would be no great step in specialization; or its absence might be regarded as of primitive character, since it has become apparent that the presence of two temporal openings and arches is not the primitive condition of the Reptilia. The great reduction of the quadrate is a character which does not appear outside of the South African phyla, which can hardly be compared with this form, for in those phyla the reduction of the quadrate is accomplished in an entirely different manner. In most of the Reptilia the quadrate has a greater or less vertical extent upon the side of the skull and is not always closely associated with the bones of the brain-case, its main associations being with the bones of the suspensorial region. Only in the Crocodilia (sens. lat.) does the quadrate extend far inward, having relations with the wall of the brain-case and the bones of the otic region. It is not possible in the specimen to determine whether the quadrate has the relations figured by Huene for the Parasuchia (Geolog. u. Paleont. Abhdlg., vol. x, N. F., Hft. 1, p. 31, fig. 20), permitting the squamosal, epiotic, and prootic to appear in the posterior lateral 
wall of the brain-case, but it seems probable that all of these, except possibly a distinct epiotic, had such an arrangement and that the quadrate runs forward on the brain-case nearly the full length of the opisthotic and joined the prootic in front and perhaps the squamosal above. The quadratojugal did not send any process forward on the anterior or lower edge of the quadrate, as in the Crocodilia.

In figure 8 is given a sketch of the condition of the skull as originally imagined by the author and as suggested to him by both Doctor F. v. Huene and Doctor D. M. S. Watson. Reasons have been given above why this suggestion must be rejected, but there is much weight in the objection offered by Doctor Watson that in the phytosauroid reptiles the basicranial region is never so far below the quadrate. Future discoveries may show that the alternative restoration is correct and that Desmatosuchus must be placed among the Parasuchia. At present the restoration and explanation here given seem to the author the only ones possible.

Description of the endocranial cast (plate 6, figs. A, B, c).-A description and discussion of the endocranial cast of Desmatosuchus has already been published ${ }^{1}$ and only a portion of it is repeated here.

"The cranial cavity of Desmatosuchus was completely cleared out, leaving the surface of the bone in good condition with all the pits and foramina clearly marked. As may be seen in the figures, the cast as finally secured shows the general form and proportions of the brain cavity and the positions of the main outlets. The anterior wall of the cavity was entirely cartilaginous or membranous, and as this portion was not preserved in the fossil the opening was stopped with plastic clay which is easily detected in the figures. For this reason, the form of the olfactory tract and of the pituitary body is not completely shown.

"The olfactory tract was evidently large, as in most of the primitive forms, and extended well forward directly beneath the upper wall of the skull. The cerebral portion was relatively small, scarcely any swelling being revealed in this part of the cast except at the posterior end of the prosencephalic region. The anterior-lower part of this region was enclosed by the ali-, orbitosphenoid bones, and the approximation of the bones of the two sides forms notches in two places which indicate the points of escape of the nerves which supplied the eye. No indication of the origin of the II, III, or IV pair of nerves is shown on the cast, and no outlets except the notches mentioned.

"It is impossible in the cast to distinguish between the diencephalic and the mesencephalic regions of the brain, but the area occupied by these two is marked by a slight but distinct depression, which is outlined by definite elevations, the posterior one amounting to a low, sharp ridge. From this depression rise the processes, above and below, which may be referred to in general terms as the epiphysis and the pituitary body.

"The upper process is complex and is, perhaps, composed of two parts. Just posterior to the edge of the prosencephalic portion there are two protuberances which mark the position of a pair of deep pits in the upper wall of the brain-case. In cleaning the skull it was impossible to be certain that the bottom of these cavities had been reached, but it seemed probable that it had. With the aid of a dentist's mouth-mirror and fine curved awls the pyrite filling was picked out until it seemed that the bottom had been reached, but because of the inaccessibility of the cavities and their small diameter it is possible that the cavities may have been deeper and even that they may be the entrances to foramina. Cope, in describing the endocranial casts of a Phytosaur, Belodon, and of a cotylosaurian reptile, Diadectes, speaks of the 'lateral processes of the epiphysis' and in describing the skull of Belodon speaks of the process as lying in a 'large canal which enters the posterior part of the orbit.' To this canal he gave the name of the orbitopineal process on the casts. The function of this canal he was unable to determine, but suggests that it carried a nerve or blood-vessel. ${ }^{2}$ In his earlier papers he was inclined to the belief that Diadectes was blind because he could find no outlet for the optic nerve and because the structure of the animal suggested that

${ }^{1}$ Case, E. C., On an Endocranial Cast from a Reptile, Desmatosuchus spurensis, from the Upper Triassic of western Texas, Journal of Comparative Neurology, vol. 33, No. 2, p. 133, 1921.

${ }^{2}$ Dr. R. L. Moodie, in conversation with the author, has suggested that these processes may indicate a portion of the course of the ductus endolymphaticus. 
it was burrowing in habit; as the parietal foramen is exceptionally large in this form, he was inclined to believe that the orbitopineal canal might have carried a nerve from the large, probably functional eye which occupied the parietal foramen, which in part supplied the necessary vision. It is impossible to tell whether such a canal existed in Desmatosuchus, but if it was present it was very small, and the author of this paper is inclined to believe that it did not exist. Moreover, there is a decided difference in the endocranial casts in this region. In Belodon and Diadectes the processes are large and rise from the sides of the epiphysis, in Desmatosuchus they are small and are entirely anterior to the epiphysis. It is possible that if a true cast of the brain could be obtained the origin of the processes might be found to be the same in all, but as the casts were all made from empty cavities a similar origin should be apparent.

"The epiphysis is very different in form. In Belodon and Diadectes there is a strong posterior process, and Cope describes the epiphysis of the former as 'subquadrate.' The orbitopineal process extends either directly outward from the side, Diadectes, or outward and forward, Belodon. In Desmatosuchus the epiphysis is erect and narrow antero-posteriorly with no posterior process. In both Belodon and Desmatosuchus the processes referred to as the epiphysis are casts of a deep pit on the under side of the skull in the exact position of the pineal foramen in other reptiles, but in neither of these is the roof perforated. In looking up this matter the author has found that much uncertainty exists as to the exact character of this process in the brain; it is known that both the epiphysis and the paraphysis may reach large size and that either one may terminate in a functional eye; at least, either one may carry organs which possess the histological structures of the retina and the crystalline lens. In some forms there has also been found a third evagination of the brain, posterior to the epiphysis, called the pineal organ, which has a similar histological structure. Wilder, in his History of the Human Body, states that it is the paraphysis which was developed in the extinct Stegocephalia and filled the parietal foramen, and the epiphysis which was developed in the reptiles, birds, and mammals. On the other hand, it is known that the epiphysis is not developed in the modern alligator. The term epiphysis is used in this paper only in a general sense and without knowledge of its true nature.

"On the lower side of the diencephalic region of the cast is the second process; this represents the combined infundibulum and the saccus vasculosus, or the pituitary body. Only the posterior and lower borders are shown, for the anterior part was enclosed by the cartilaginous anterior wall of the skull which was lost in fossilization. The process extended directly downward by a narrow neck which passed through a narrow notch formed by the approximation of the alisphenoid bones at their lower borders. Its posterior face lay against the basisphenoid bone, not penetrating it, and its lower surface in an excavation on the upper surface of the posterior part of the parasphenoid. The lower part of the process was enlarged and the posterior face, at least, extended backward at a sharp angle. The lower end terminates in a bifurcate extension which is formed by the casts of the beginnings of two foramina which open outwardly and downward in an excavation on the upper surface of the parasphenoid. These foramina continue and terminate in deep grooves on the side of the basisphenoid. On the posterior face of the process are two small prominences which mark the position of two foramina on the lower face of the basisphenoid, evidently the openings for the internal carotid arteries.

"The posterior part of the depressed area mentioned above must also include the mesencephalic portion of the brain, but there is nothing to mark the presence of either optic lobes or optic thalami. This does not, however, suggest either their absence or relatively small size, for if a cast were made of the cranial cavity of Sphenodon or of an alligator no evidence of these structures would appear, though they are of large size.

"Posterior to the depressed area the whole cast is curved sharply downward and then straightened out horizontally in the metencephalic region. On the lower edges of the anterior part of this region there are large prominences which mark the position of the large foramina for the passage of the $\mathrm{V}$ pair of nerves. There is no indication in the cast of the division of this nerve into its parts; this must have taken place external to the cranial wall. Within and a little posterior to these prominences is indicated the position of a pair of small foramina in the floor of the skull, evidently the outlets for the VI pair of nerves. Posterior to the V and at about the middle of the posterior part of the cast, there are a pair of processes on each side, one almost directly above the other. The upper pair are the casts of the otic cavities and mark approximately the position of the VIII, and probably, also, the VII nerves, for these two nerves escape from the skull of the Croco- 


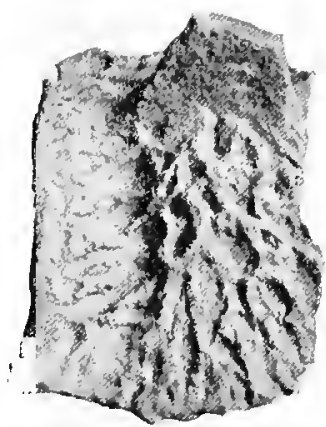

D
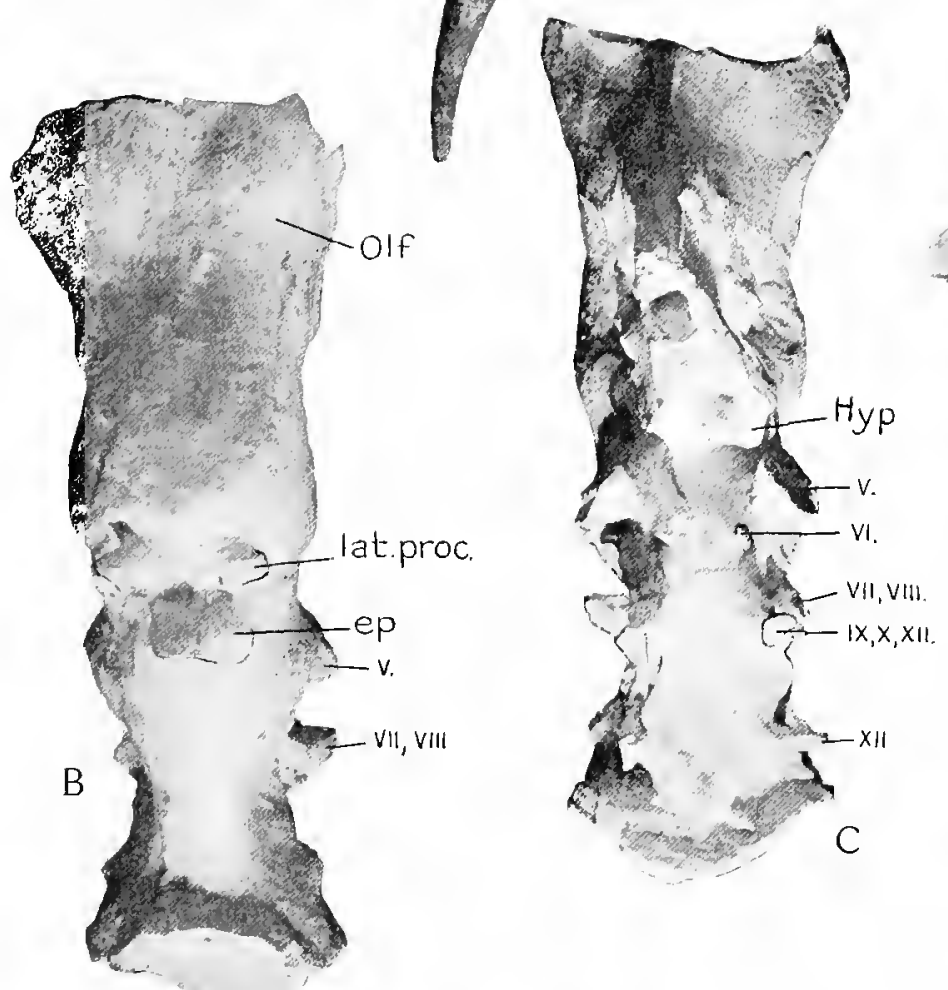

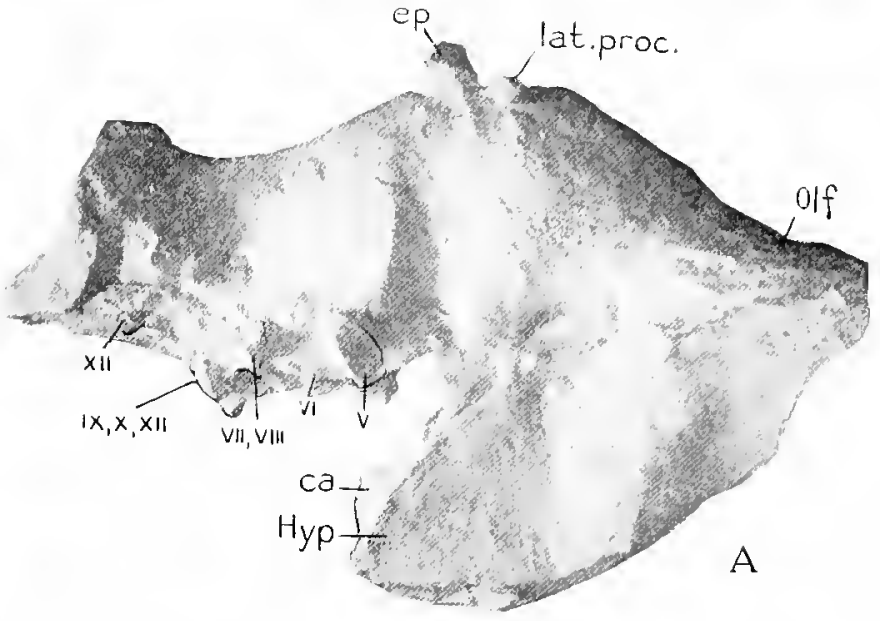

C
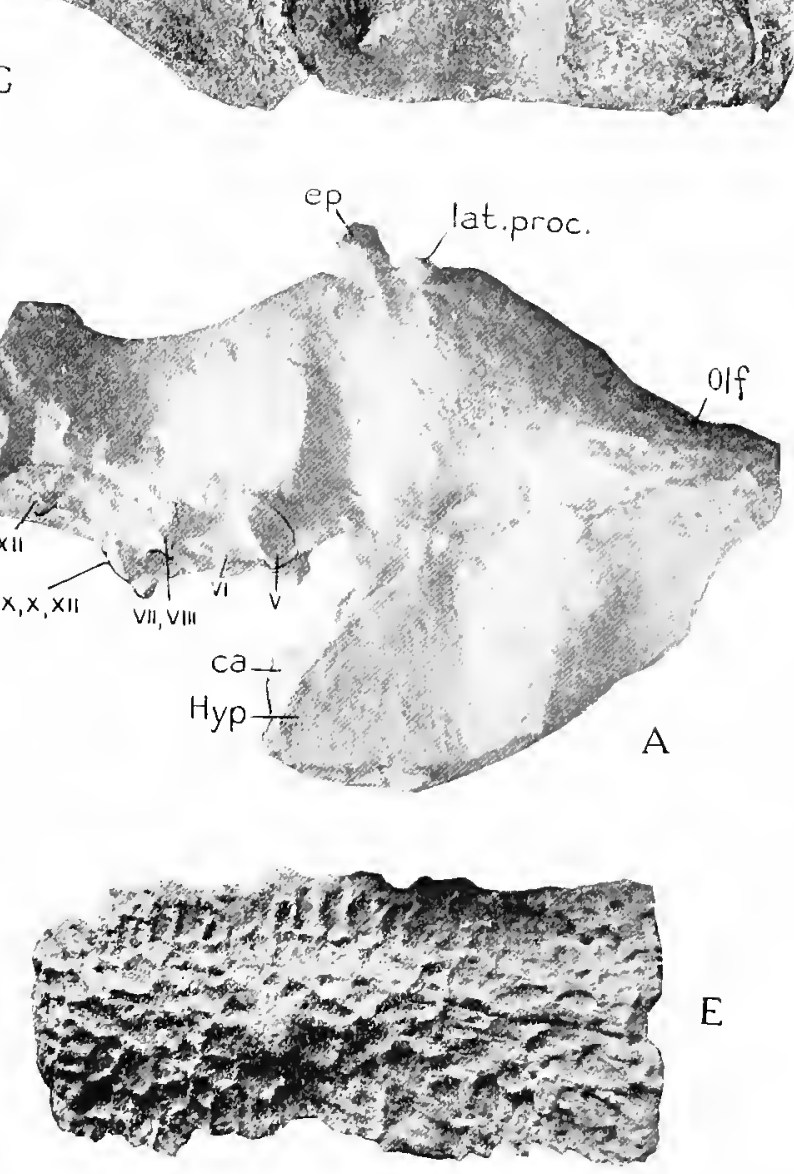

E
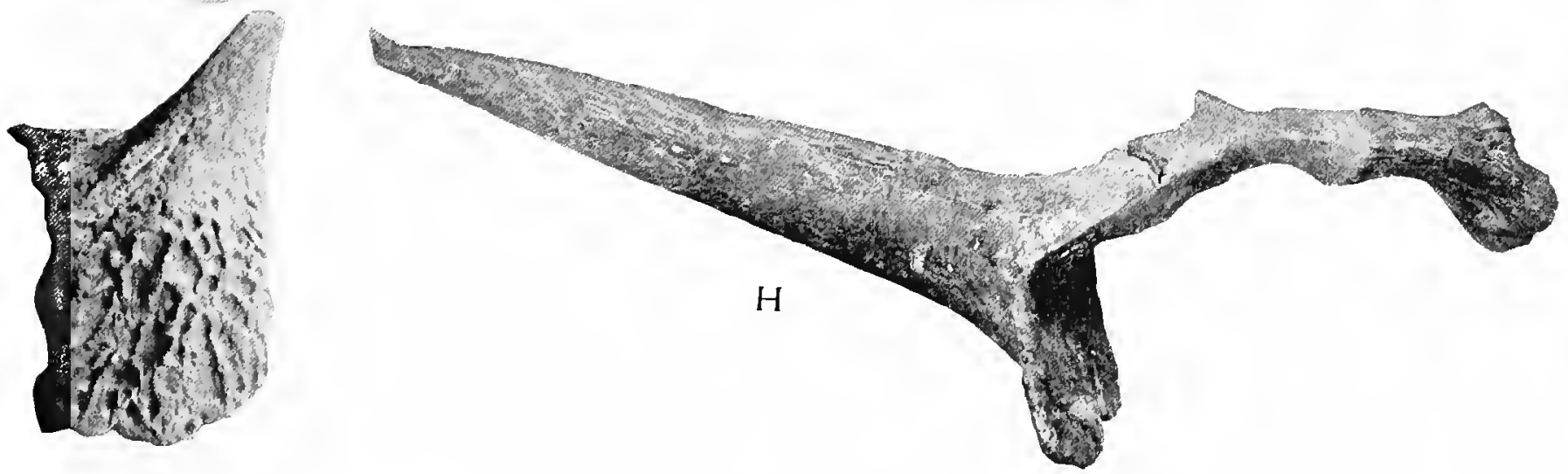

$\mathrm{F}$

Desmatosuchus spurensis, No. 7476, U. of Mich. Endocranial cast. $\quad \times$ about 0.6 .
A. Lateral view. B. Upper view. C. Lower view.
D. Dorsal armor, side view of lateral plate of dorsal region. $\times 0.23$.
E. Dorsal armor, top view of median plate of dorsal region. $\quad \times 0.23$.
F. Dorsal armor, side view of lateral plate of caudal region. $\quad \times 0.23$.
G. Dorsal armor, top of fifth cervical series. $\times 0.32$.
H. Dorsal armor, posterior view of fifth cervical series. $\times 0.32$. 

dilia in almost the same place. The otic cavities were injured in fossilization both by pressure and by the crystallization of the gypsum and pyrite which filled the cavities of the skull. It is apparent that there was a thin wall between the otic cavity and the brain cavity, but this has been so injured that it is impossible to determine the original form of the otic cavity or the form and position of the semicircular canals.

"Below are the large cylindrical projections which filled large foramina carrying the IX, $\mathrm{X}$, and XI nerves and the jugular vein. All of these must have escaped through a common opening, as the walls of the brain-case are very perfect in this place and no other openings are present.

"Near the posterior end of the cast are slender processes which mark the position of the XII nerves. Above these processes there are small prominences which filled pits in the inner walls of the exoccipital bones. These pits were entirely cleared, and it is certain that they were not the beginnings of foramina, their meaning is unknown.

"The whole metencephalic portion of the cast is rather high and narrow. It is possible that this is due in some degree to crushing, but there is no indication of such crushing in the skull, and it is probable that it is the true form. The whole cast is very small relative to the size of the animal, and even assuming that the brain occupied the whole cavity its size would be remarkable, though after all it is not much smaller, relatively, than the brain of Sphenodon or of an alligator.

"It is difficult to make any satisfactory comparison of this endocranial cast with the one made by Cope from the specimen of Belodon buceros because of the unsatisfactory nature of his figures, but some points can be made out. As can be seen by the figures in his paper, the whole shape is different, the cast from Belodon does not show the sharp downward curve posterior to the middle region. The cast of Desmatosuchus is thinner for its height and does not have so long a metencephalic portion.

"The epiphysis lacks the posterior prolongation, certainly it is not 'subquadrate' in form, and the lateral processes rise in front of, not at the sides of, the epiphysis. The olfactory tracts were much broader. The optic nerves did not escape through distinct foramina. Only the origin of the pituitary body is shown in Cope's figures, but he describes it as small and occupying a fossa in the base of the cranial cavity. These characters support the evidence afforded by the bones of the skull that Desmatosuchus must be placed, at least, in a distinct suborder from the Phytosauria."

The vertebral column (see plates 6 to 10).-The exact number of presacral vertebræ has never been determined in the Phytosauria. McGregor says that it is "practically certain that there were not less than 25 or more than 27 " in the presacral series. In the mount and restoration of Desmatosuchus, 28 vertebræ have been included in the presacral series; while this number may not be exactly correct, every consideration of the condition of the specimen and the character of the vertebræ indicates this number; of all the material found, three cervicals, which are obviously duplicates, and one dorsal have been excluded in making the mount. It is possible that the single dorsal should have been included, but it is apparently a duplicate and its inclusion would have made the presacral series seem unduly long. This restoration is subject to correction by future discoveries.

The atlas and axis (fig. $9 \mathrm{~A}$ to $\mathrm{D}$ ). - The first two vertebræ are closely united but not coossified. The shape of the two is very similar to that figured by McGregor ${ }^{1}$ for Mystriosuchus. The atlantal ring is complete, with but slight rugosities indicating the position of the suture between the intercentrum and the neural arch. The arch is completed above by a thin plate which passes obliquely backward beneath the anterior end of the neural spine of the axis. On either side the centrum bears projections from the anterior edge near the lower level of the neural canal; these are marked off by a deep notch below and project sharply from the anterior edge of the neural arch above. The one on the right side is smooth, as if there were an articulation for a proatlas. This may be deceptive, however, as the corresponding projection of the other side does not have this appearance. There are strong projections from the rear of the neural arch

${ }^{1}$ MeGregor, J. H., American Museum Natural History, Memoir Ix, pt. II, p. 62. 
which extend back to the middle of the axis and carry distinct facets for articulation with the anterior zygapophyses of the axis. The lower face of the centrum is broad and flat or even slightly concave. On the posterior external corners there are small but prominent processes for the capitula of the atlantal ribs; smaller processes, almost destroyed by decay, lie on the sides of the arch near the level of the base of the neural canal. The anterior face is deeply concave below, forming a socket for the nearly spherical occipital condyle. The upper edges of the face are drawn in sharply below the anterior processes and form the sides of the deep notch which receives the anterior end of the odontoid process. The diameter of the neural canal is considerable.
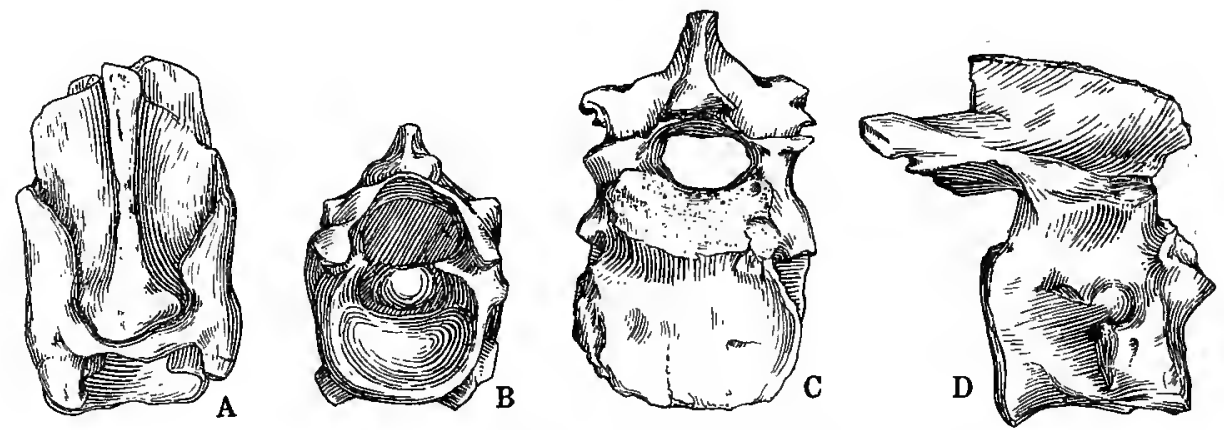

Fig. 9.-Desmatosuchus spurensis.

A. Upper surface of atlas and axis. B. Anterior surface of same. C. Anterior surface of a second axis, No. 7504, U. of Mich. D. Lateral surface of same. All figures $\times 0.5$.

The axis is much larger than the atlas, and though the sutures are closed it is evident that the vertebra is composed of the elements suggested by McGregor, an intercentrum and the axis proper. The neural spine is elongate and thin, except at the anterior end, where it is expanded and heavy; this portion lies upon the downwardly and backwardly sloping arches of the atlas. The anterior zygapophyses are covered, but are of good size, with the faces looking almost directly upward. The posterior zygapophyses are nearly normal in form; they overhang the posterior edge of the centrum for some distance. The lower face of the centrum is flat from side to side and concave antero-posteriorly on the posterior or true axial portion. The process for the capitulum is larger than for the tuberculum and a little in advance of it. The neural canal is still large, but smaller than in the atlas; the transverse diameter is the larger. The posterior face of the centrum is deeply concave.

A second axis found with the remains of Desmatosuchus, and evidently belonging to an individual of the same genus and species, is even more perfect. In this (fig. 9, $\mathbf{C}$ and $\mathbf{D}$ ) it is seen that the odontoid process is quite broad; the posterior zygapophyses show a peculiarity which is continued backward for some distance in the cervical series; the posterior end of the zygapophyses extends beyond the articular face and on its upper surface there is a decided prominence.

The next two vertebræ (fig. 10) were found isolated in the matrix of the specimen and are regarded as the third and fourth because of their size and shape. They, are in poor condition, but show the main characters. The neural spine of the third is partly rotted away, but the base of the spine indicates that it was thin laterally and somewhat elongate. It was evidently low. The anterior and posterior zygapophyses are on nearly the same level and are normal in form and position. The transverse process is elongate and extends nearly straight downward, but a little to the rear. The sides of the centrum are concave and the lower end of the transverse process is free for some 


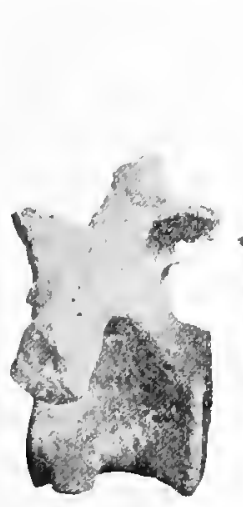

A

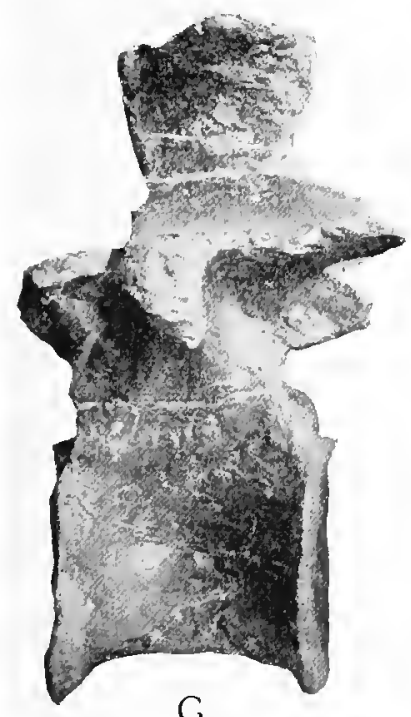

G

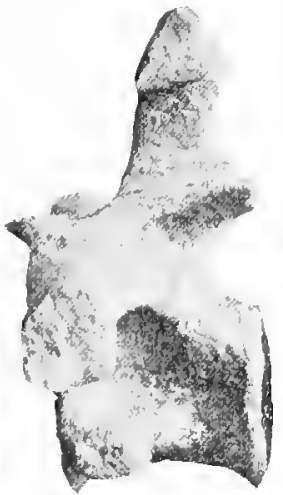

B

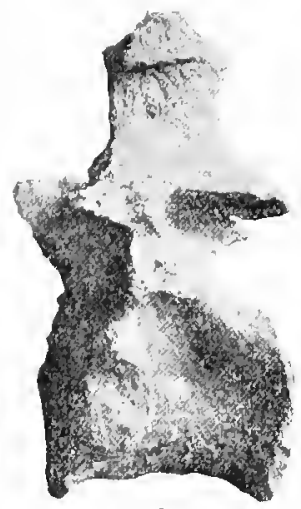

C

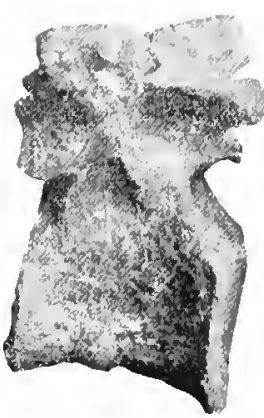

D

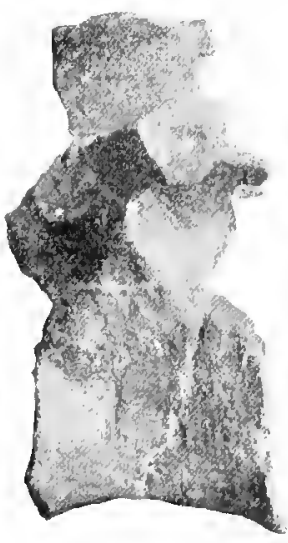

E

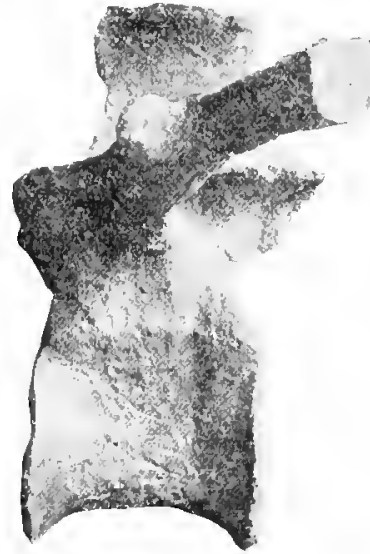

F
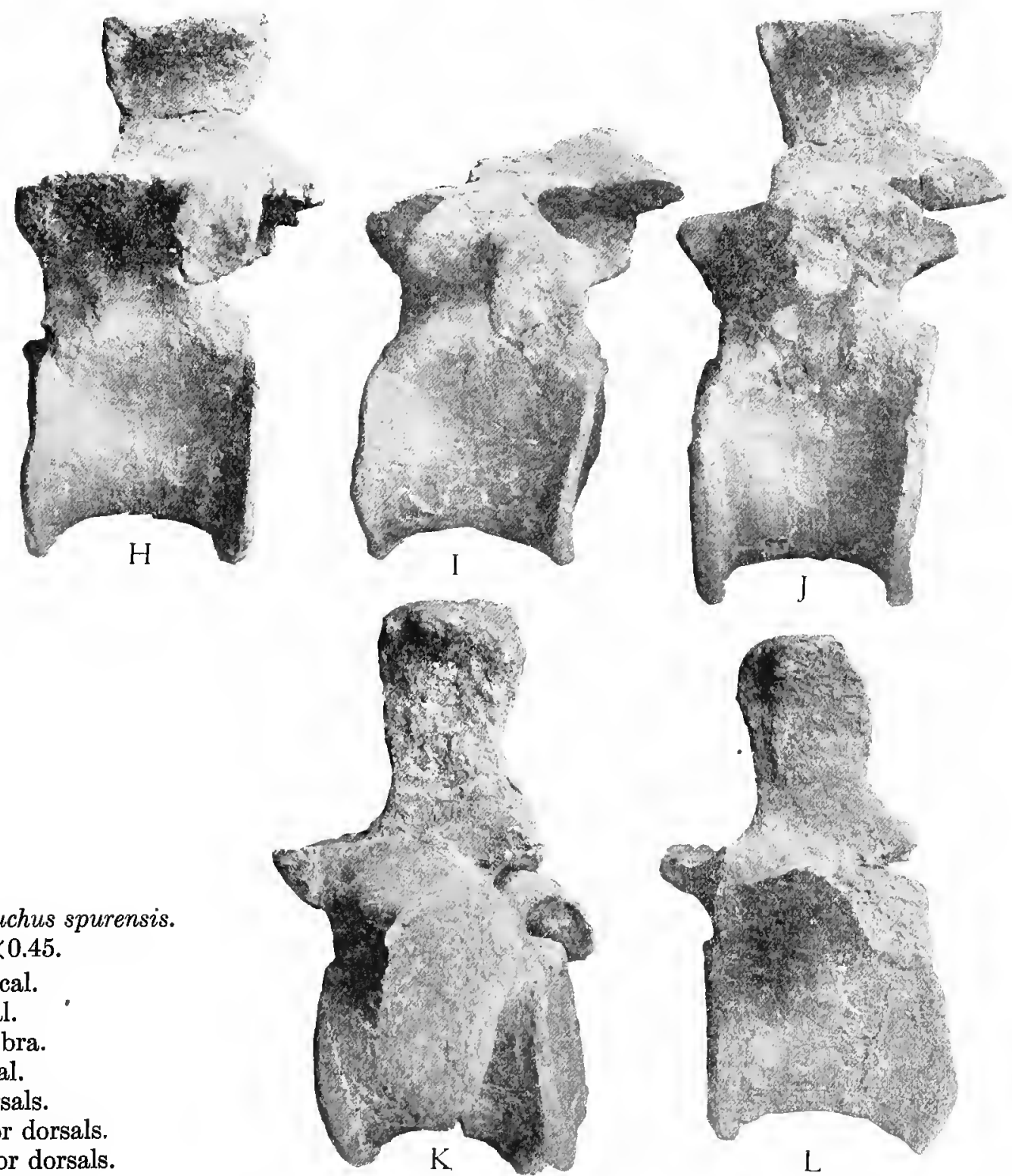

Vertebræ of Desmatosuchus spurensis. All figures $\times 0.45$.

A. Fifth(?) cervical.

B. Tenth cervical.

C. Twelfth vertebra.

D. Anterior dorsal.

E to H. Mid-dorsals.

I and J. Posterior dorsals.

$\mathrm{K}$ and L. Anterior dorsals. 

distance. The capitular facet stands on a short process (fig. 10) rising from the anterior outer angle of the lower face of the centrum; this process is inclined slightly backward. The anterior face of the centrum is nearly circular; the posterior face is oval, with the long axis horizontal. The neural canal is still large.

The fourth vertebra has lost the upper part of the neural arch and the zygapophyses. The transverse process (fig. $11 \mathrm{~B}$ ) is curved outward and downward; the capitular process is similar to that of the third. The lower face of the centrum is concave anteroposteriorly, but nearly flat transversely. The anterior and posterior faces are transversely oval.
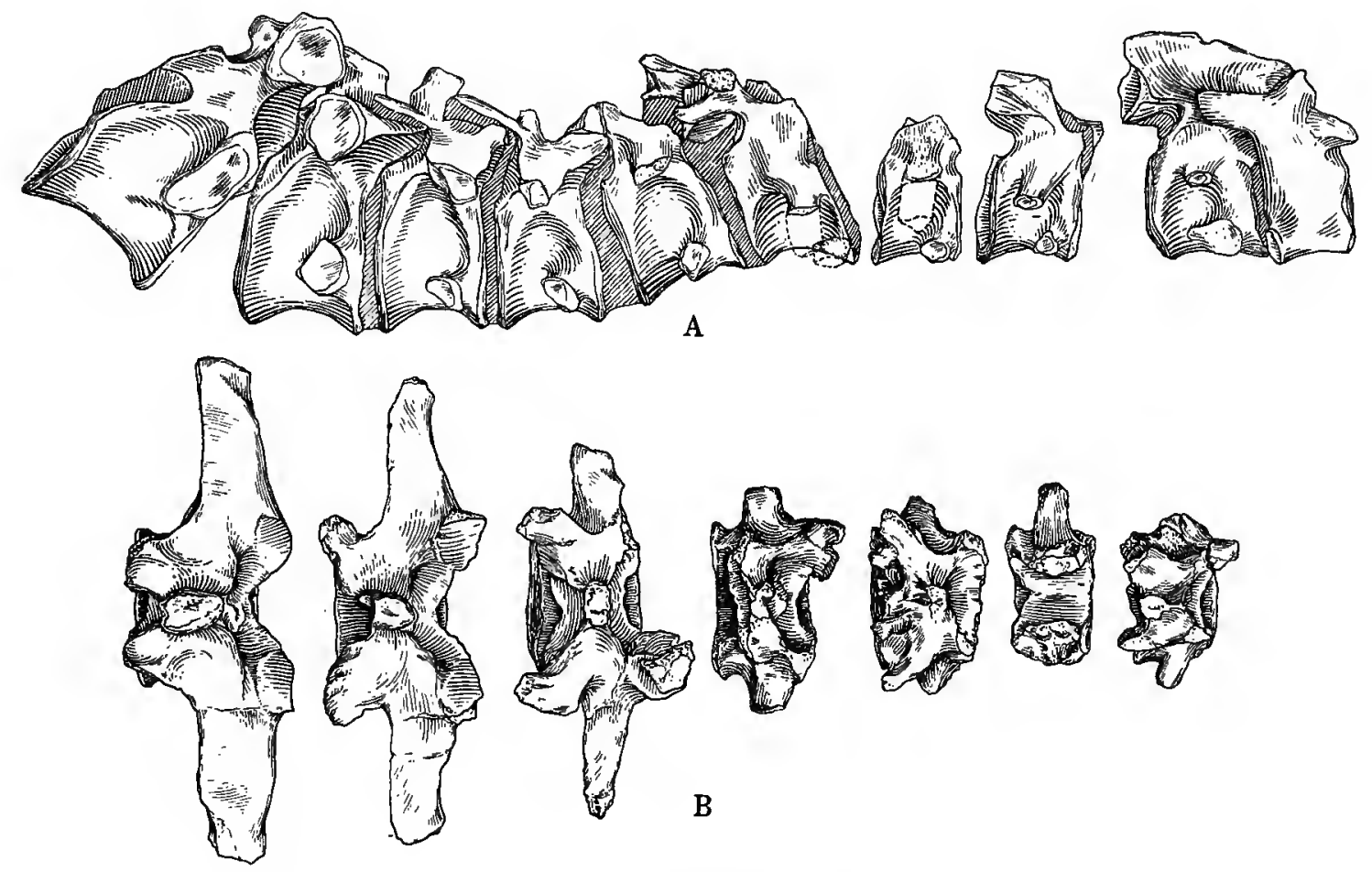

FIG. 10.-Desmatosuchus spurensis.

A. Lateral view of first ten vertebræ; the last six as they were found connected. $\quad \times 0.3$.

B. Upper view of third to ninth cervical vertebræ. $\times 0.3$.

The next six vertebræ (figs. 10 and 11) were found in close association, the first five in position and the sixth slightly distant and turned to one side. The last is thought, from its shape, to be the twelfth of the whole series and will be described in that position. In the first five the faces of the centra are transversely oval and the lower surface is flat. These characters change slowly toward the rear until in the tenth vertebra (fig. 11) the posterior face is nearly circular and the lower surface of the centrum is much narrower and longer than in those anterior to it. The zygapophyses of all are low and flat and closely overlapping. The posterior zygapophyses of the fifth vertebra show clearly a structure which is only indicated in the less perfectly preserved ones adjoining it, but is very prominent on the second axis. From a point just above the articular facet there is a strong spinous process which extends backward and outward for at least a centimeter. This character is confined to the anterior cervicals, as it is not noticeable on the eighth vertebra, where the zygapophyses are thin and broad. 
The neural spine of the fifth is low, thin, and broad, but posterior to this one the spines of the vertebræ increase in height, become thinner at the base, transversely, and elongate antero-posteriorly, and develop a knob or expansion at the apex. The transverse processes rise progressively toward a horizontal position and increase in length and thickness. On the sixth vertebra is seen the beginning of a ridge running from the upper outer angle of the posterior face of the centrum to the base of the transverse process; this continues to increase in importance until on the eighth it is continued on to the lower face of the process as a thin supporting ridge inclined backward, and the cross-section of the process is that of a T-beam. In the same manner the capitular process increases in thickness and weight, but not in length. On the ninth vertebra this process is over a centimeter in its two diameters, and a low, sharp ridge runs from its upper face upward near the anterior face of the centrum, until it joins the ridge on the lower face of the transverse process at the level of the base of the neural canal.
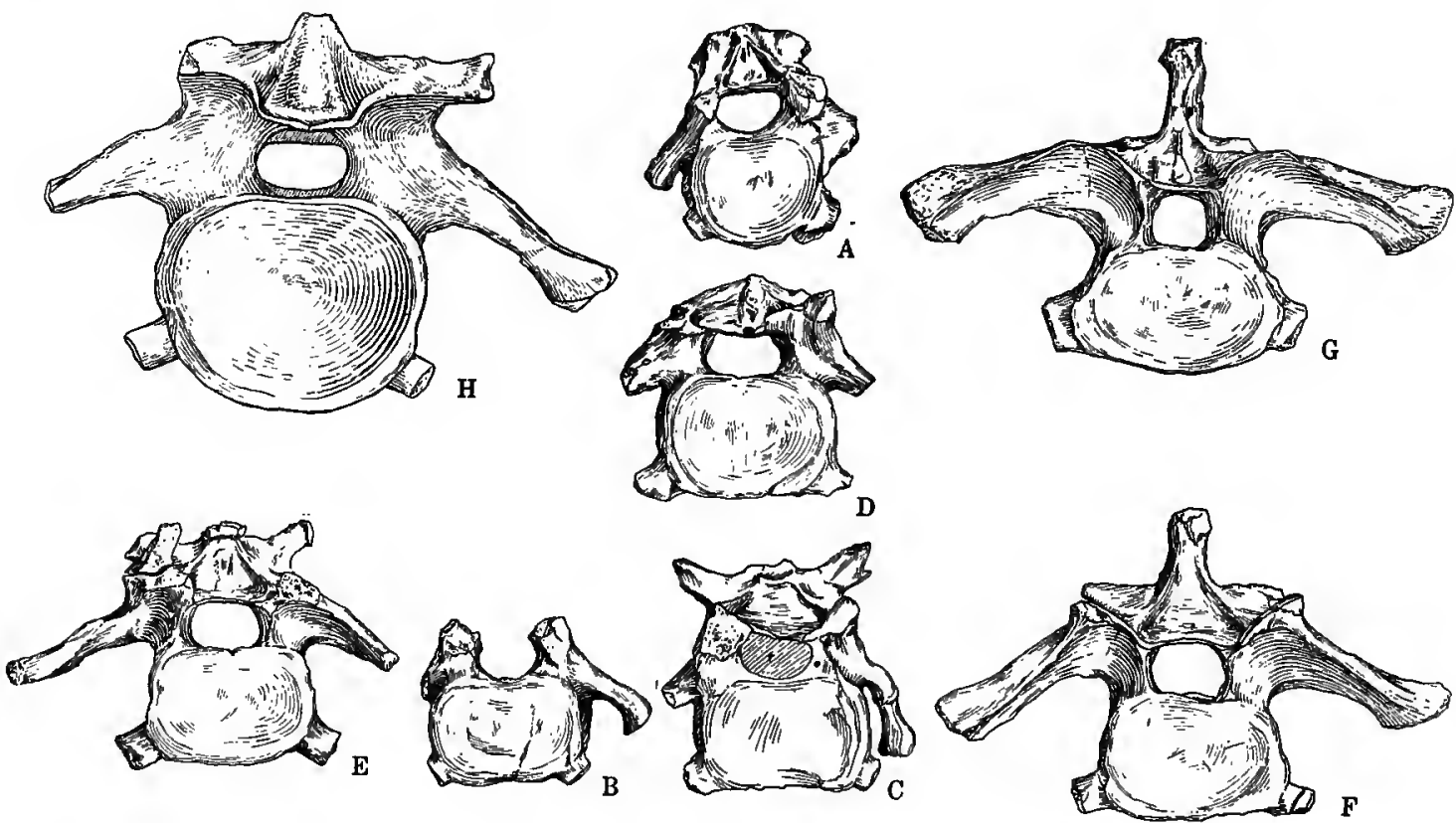

FIG. 11.-Desmatosuchus spurensis. A to $\mathrm{G}$. Anterior views of the third to ninth cervical vertebræ. The figure of the fifth vertebra is slightly
restored. $\times 0.3$.

H. Posterior view of a duplicate tenth (?) vertebra, No. 7504, U. of Mich. $\times 0.6$.

In all these vertebræ the neural arch is deeply excavated between the zygapophyses both anteriorly and posteriorly, so that a considerable portion of the neural canal is left uncovered between the vertebræ.

The vertebræ posterior to the ninth were all found isolated, with the exception of the one reckoned as the twelfth and a few in the mid-dorsal region. They have been placed according to their size and form. There may be some error, but it can hardly

In the vertebra reckoned as the tenth the zygapophysial processes are broad and thin and the faces are nearly horizontal. The transverse process is broad above; its anterior edge is nearly on a line with the center of the face of the anterior zygapophyses. The T-section of the process is well developed. On this vertebra a ridge extends back- 
ward from the anterior upper angle of the centrum and ends on the anterior face of the posterior ridge as it turns outward on the lower surface of the transverse process. The neural spine is elongate antero-posteriorly. The expanded upper end is wedge-shaped, with the faces of the wedge directed laterally; the spaces between the faces of the wedge are roughened. The lower part of the anterior face of the spine is rendered deeply concave by the development of ridges on each side, which continue downward and outward to end upon the surface of the anterior zygapophyses. The space between these ridges and the zygapophyses is floored by a thin plate of bone which covers the neural canal. On the posterior face of the spine there is a similar development, but the excavation of the face of the spine is much deeper. The faces of the centrum are still transversely oval and the lower surface flat, but the faces are approaching a circular form and the lower surface is becoming rounder.

The eleventh vertebra has the transverse processes broken away, but the bases are still preserved. The capitular face is now elongate vertically, and a strong ridge runs from its upper origin, above the level of the base of the neural canal, backward and upward to join the posterior ridge which forms the lower arm of the T-shaped transverse process.

The neural spine is elongate antero-posteriorly and thin transversely. The upper end has a triangular expansion on each side, but the ridges on the edges of the anterior and posterior faces run to the apex. The depression between these ridges is similar to that in the preceding vertebræ; the zygapophyses are closer together. In the tenth and eleventh vertebræ is seen for the first time the deep depression in the floor of the neural canal. The anterior face of the centrum is transversely oval and much larger than the posterior face. This is in part due to the development of the capitular process with its vertical extension.

In the twelfth vertebra the capitular process rises from a point above the lower edge of the centrum, which is now rounded, and is elongated vertically, the face being nearly twice as high as broad. The ridge upon its upper face, noted as beginning in the eleventh vertebra, is now developed as a strong process which rises as a wall and is united with the lower part of the transverse process at about the middle of the length of the latter. The ridge from the posterior corner of the centrum is still strong at its origin, but has become obsolete on the transverse process itself; the transverse process is still $T$-shaped, but the lower flange is now formed by the anterior ridge instead of the posterior one. In this vertebra the transverse plate between the zygapophyses has a different form. From the inner edge of each of the posterior zygapophyses a thin plate runs inward to form the transverse plate and there is a vertical extension downward in the form of a very thin septum which reaches to the upper edge of the neural canal, which is not more than half as large as in the cervical vertebræ. There is also a tendency for a similar plate with a vertical septum to form between the anterior zygapophyses.

In the thirteenth vertebra the transverse process stands out directly from the side of the vertebra and rises slightly in its course, so that the distal end is higher than the origin of the process. The capitular face has now left the centrum entirely and is attached to the transverse process at about its middle portion. This face is supported by three ridges-one very slender, running from the lower edge of the face to the anterior upper angle of the centrum, the second running from the lower edge of the face upward and inward to the lower surface of the base of the anterior zygapophyses; the third ridge is the anterior half of the posterior ridge. Its posterior half, so strong in the preceding vertebræ, is now obsolescent. Its position marks the dividing-line between the capitular and the tubercular portions of the transverse process. This sudden change of position in the capitular face is characteristic of the Crocodilia and the Phytosauria; 
with it, in the present specimen, begins the elevation of the sides of the neural arch which is so notable in Desmatosuchus. The neural spine is lost, but the space between the zygapophyses is much narrower. The centrum is narrower and more elongate, with the base rounder and the faces more nearly round.

From the fourteenth back to the twenty-fourth (?) the vertebræ are of the true dorsal series (fig. 12). The transverse processes increase to their maximum length and are inclined slightly backward, the capitular faces gradually come to lie on the anterior

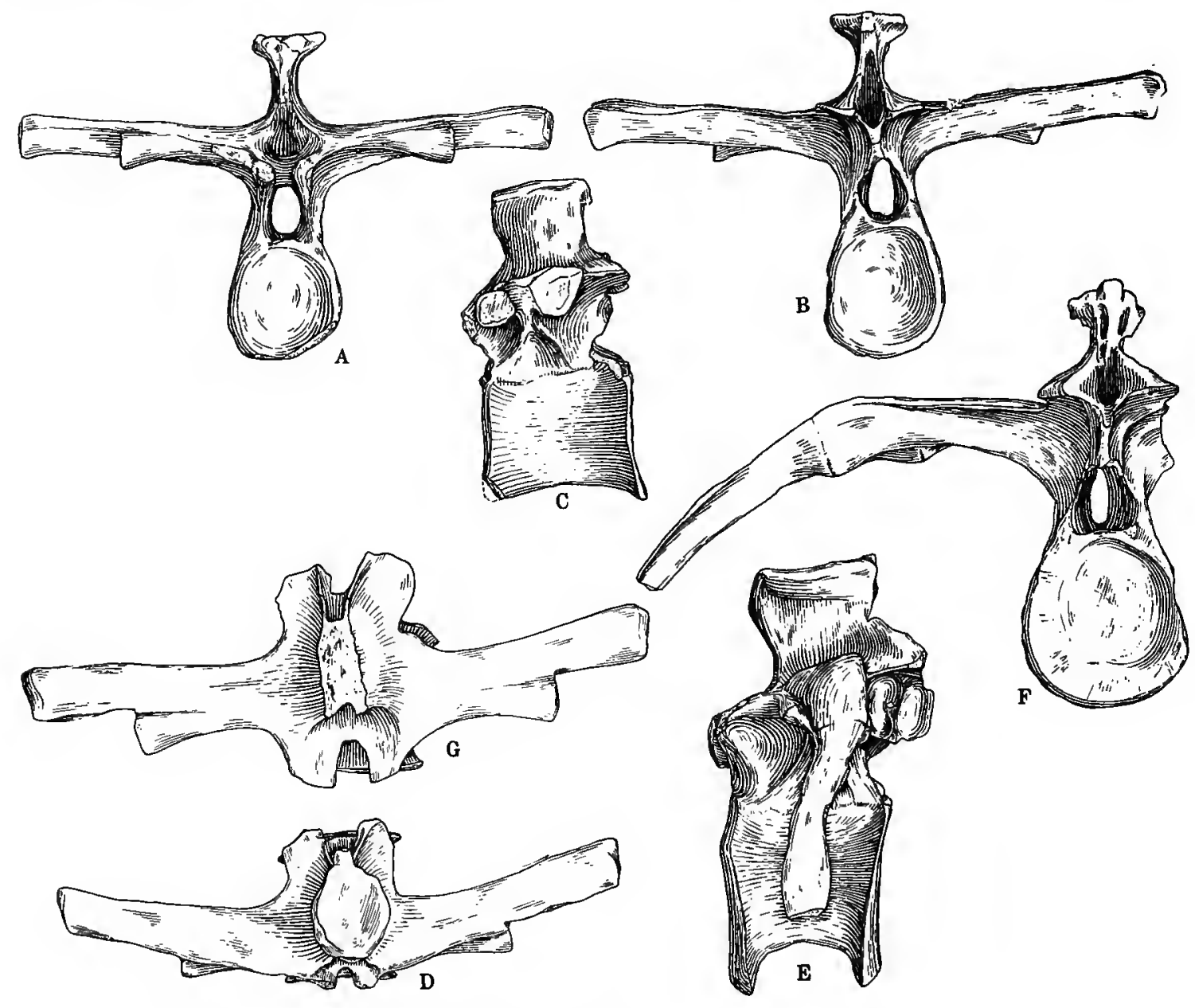

FIG. 12.-Desmatosuchus spurensis. All figures $\times 0.3$.
A. Anterior view of a mid-dorsal vertebra.
B. Posterior view of $\mathrm{A}$.
C. Lateral view, left side of $\mathrm{A}$.
D. Upper view of $\mathrm{A}$.

E. Lateral view of a posterior dorsal vertebra with the rib of left side attaehed.

F. Posterior view of $\mathrm{E}$.

G. Upper view of a posterior dorsal. The broad apex is broken off.

side of the transverse processes, and the supporting ridges become obsolete on the face of the elevated neural arch. The neural spines become more elongate antero-posteriorly and the apex is expanded abruptly into a rounded rugose table. The centra become elongate antero-posteriorly, and the edges of the faces flare out so that the lower face is concave antero-posteriorly and convex from side to side. 
The posterior dorsal vertebræ (fig. $12 \mathrm{E}$ and $\mathrm{F}$ ) become heavier in all of their proportions; the spines remain thin transversely, but the apex becomes heavier; the transverse processes become shorter by the abbreviation of the distal end, so that the capitular face approaches the tubercular. Even in the posterior dorsals the sides of the neural arch remain elevated and the transverse processes take their origin entirely from them. The edges of the faces of the centra are expanded so much that a section of the middle of the centrum is not more than half as large as that of the faces.
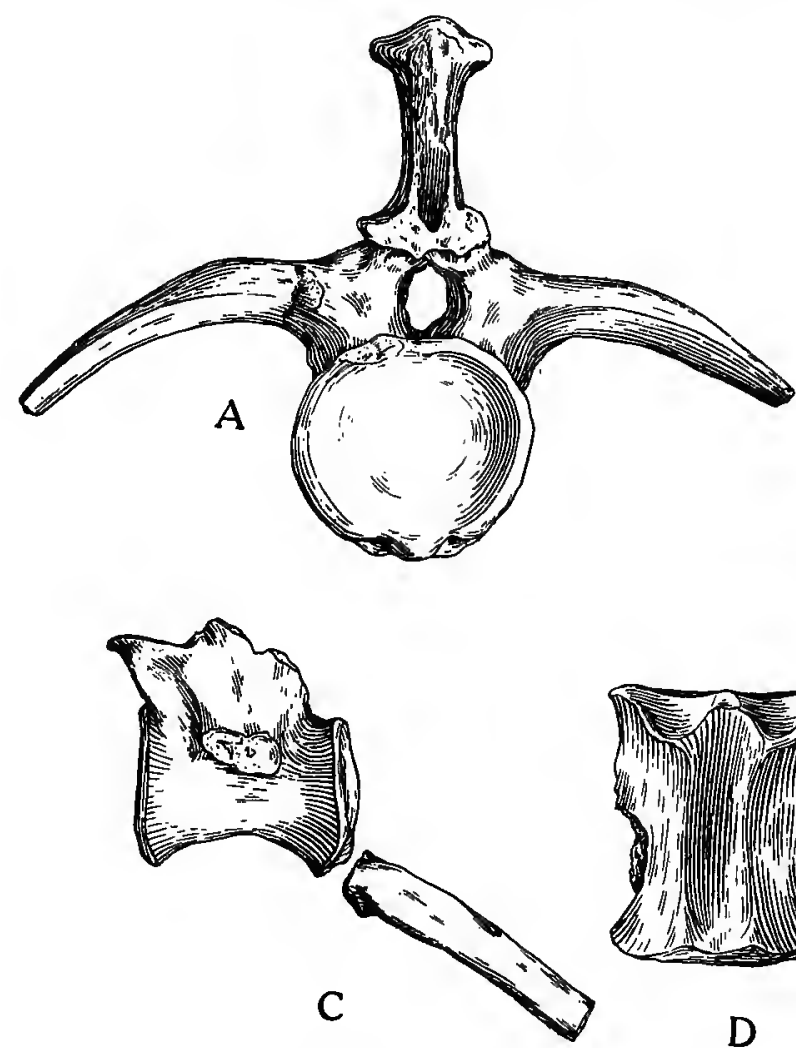

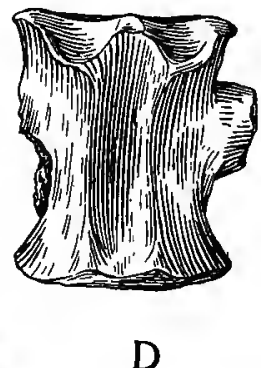

D

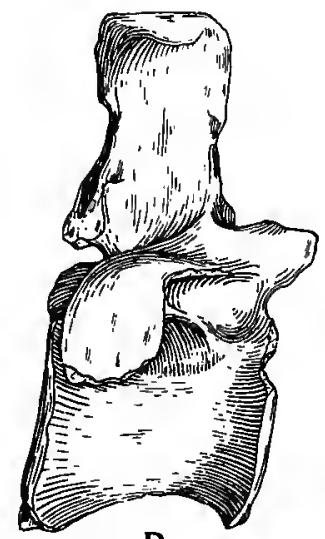

B

FIG. 13.-Desmatosuchus spurensis. All figures $\times 0.3$.
A. Posterior view of the first true caudal vertebra.
B. Lateral view, left side of $A$.
C. Lateral view of a median caudal vertebra with the incomplete chevron, left side.
D. Lower view of $\mathrm{C}$.
E. Posterior (upper) view of the chevron shown in C.

The posterior presacral vertebræ resemble those of the dorsal series in all major particulars; the last three or four become decidedly heavier, with larger centra, and the transverse processes become broader antero-posteriorly, with the tubercular and capitular faces at nearly the same distance from the origin of the transverse process. The ribs are lost, but there is evidence that even to the last the ribs were articulated with the transverse process and not reduced and coossified with them; in this sense there are no true lumbars.

A single very poorly preserved vertebra which seems to have a very heavy neural spine and a short, heavy transverse process, or origin of a sacral rib, may be regarded as one of the sacrals. This region is in poor condition; only a portion of a very poorly preserved half of the pelvis, as noted below, is preserved. 
There are six caudals preserved, all chevron-bearing (fig. 13). It is probable that there were two or three pygal vertebræ present. In the caudals preserved the transverse process springs from the side of the neural arch and curves outward and downward, becoming thin and more horizontal toward the distal end. The zygapophyses are well developed, with the faces nearly flat; the characteristic recess continues at the base of the neural spine, but with the decrease in height of the neural arches the median descending vertical plate between the zygapophyses disappears. The first three, which are evidently anterior caudals, have heavy spines with thickened apices. The lower face of the centrum is marked by a median depression which separates two strong ridges on the sides; these terminate posteriorly in the faces for the chevrons, which look more downward than backward.
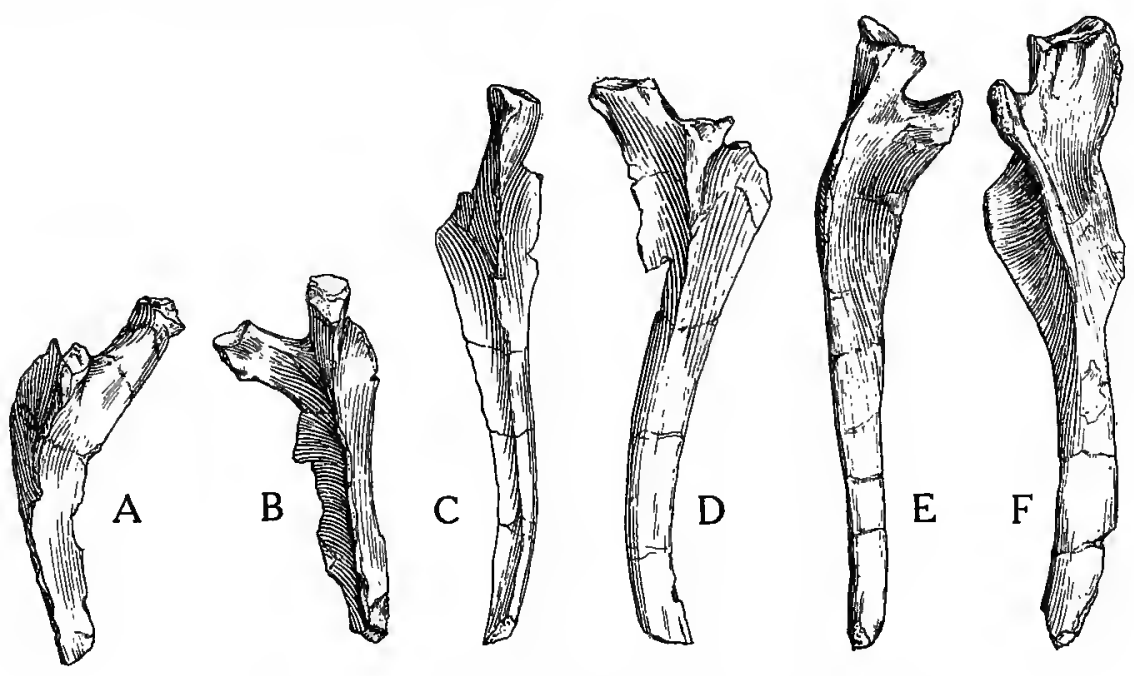

Fig. 14.-Desmatosuchus spurensis. All figures $\times 0.3$.

A. Upper surface of the seventh (?) rib of the left side.

B. Lower view of A.

C. Lower view of tenth rib, left side.

D. Upper view of $\mathbf{B}$.

E. Upper view of eleventh rib, right side.

F. Lower view of $\mathbf{E}$.

The last two caudals (fig. $13 \mathrm{c}$ and $\mathrm{D}$ ) are in poor condition, due to decay, but are more elongated than the anterior ones, and there is a decided tendency for the posterior faces to descend lower than the anterior ones.

The chevron bones (fig. $13 \mathrm{~A}$ and $\mathbf{E}$ ) are widely separated at the proximal end, but meet in a strong terminal portion. The exact length is not shown in any one.

The ribs.-There were free ribs on all of the vertebræ of the presacral series, but the posterior ones show a strong tendency to a close anchylosis with the transverse process. Those of the cervical series were small and turned back close to the side of the vertebræ, as is evidenced by the small amount of space between the vertebræ and the sides of the dorsal armor. The first rib preserved was, in all probability, attached to the seventh vertebra, as it was found close to it and fits the articulations quite closely: This rib (fig. $14 \mathrm{~A}$ and $\mathrm{B}$ ) is still short, and the capitular and articular processes are nearly equal in length. The dorsal surface of the rib is expanded into a broad, thin surface, which is supported by a thin, high ridge running the length of the rib on the under side; this ridge has its origin on the tubercular process. 
CASE
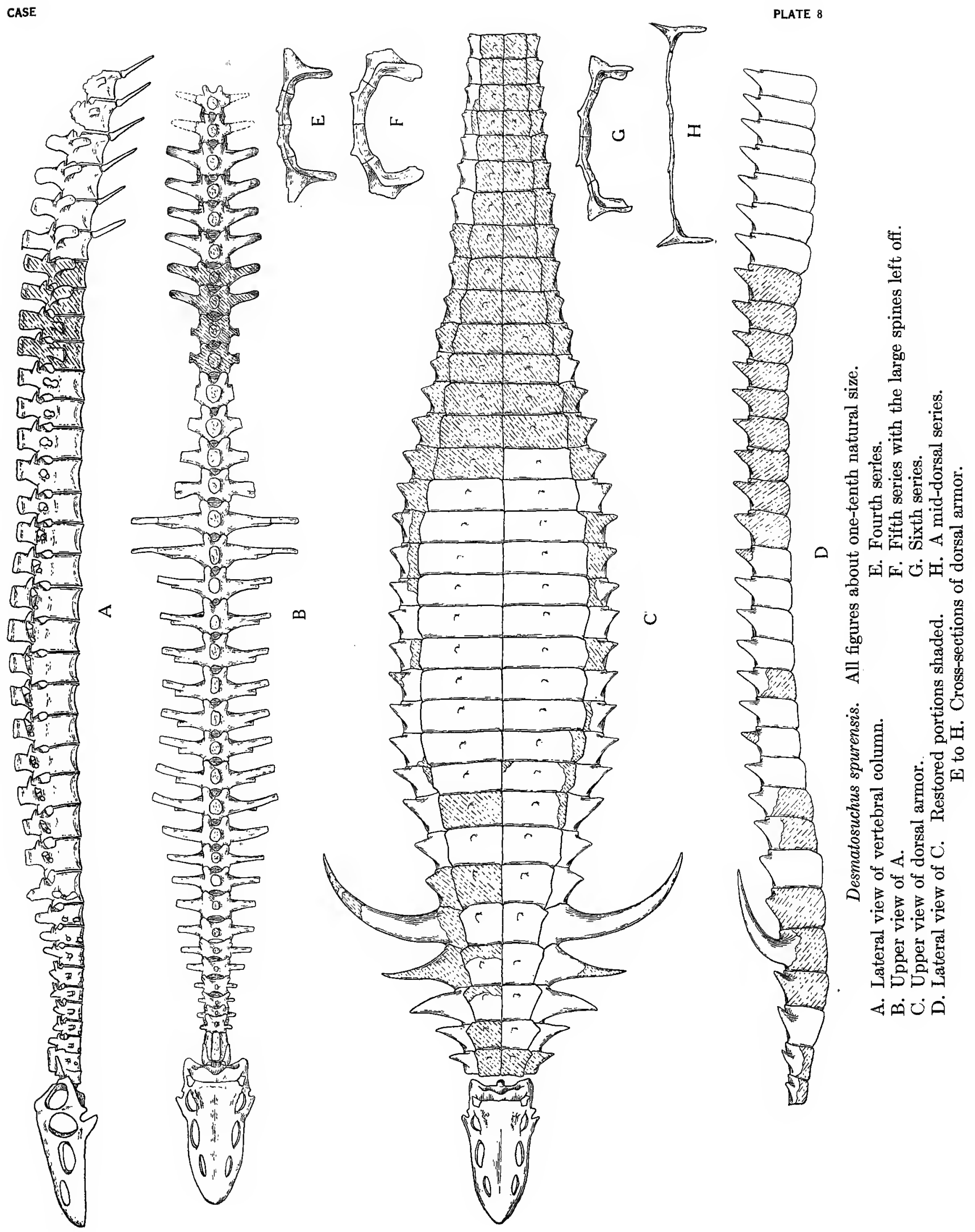

The second well-preserved rib is assigned to the tenth vertebra (fig. $14 \mathrm{C}$ and $\mathrm{D}$ ). It is much longer than the seventh and the tubercular process is much shorter than the capitular. There is still some expansion of the upper surface, though much less than in the ribs anterior to it. Traces of the supporting ridge on the lower side are still present.

The third well-preserved rib is assigned to the eleventh vertebra (fig. $14 \mathrm{~F}$ and F). This closely resembles the rib assigned to the tenth, but is even longer, and the expansion of the upper surface is more closely confined to the proximal end. The capitular and tubercular faces are close together, corresponding to the approximation of the facets upon the vertebræ.

A fourth well-preserved rib is assigned to the twelfth vertebra (fig. 15). This rib is much stronger than the preceding ones and longer. The whole rib is flat and rather thin. The capitular process and face are stronger than on the anterior ribs and the tubercular face is located as a notch on the body of the rib. This is the first rib that shows any decided downward curvature of the shaft.

In the following ribs, which are only incompletely preserved, the tubercular and capitular faces are on the same plane; the ribs are relatively broad in the dorsal series, with a considerable outward extent, indicating a well-rounded barrel in the animal. In the posterior dorsal and lumbar (?) regions the ribs become shorter and more slender; the capitular and tubercular faces gradually approximate until they are nearly on a line.

The dermal armor (plates 8 and 9).-The back of Desmatosuchus was covered by a complete armor consisting of four rows of plates. The presence of any

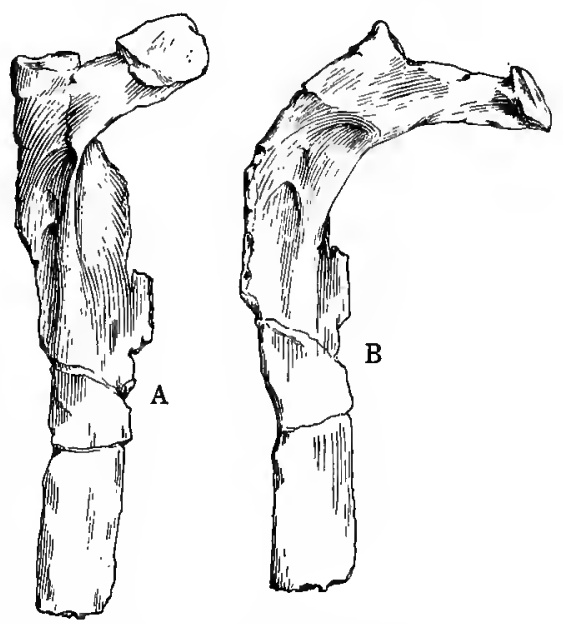

Fig. 15.-Desmatosuchus spurensis.

A. Lower view of the twelfth rib, left side. $\times 0.3$.

B. Upper view of $\mathrm{A}$. lateral or abdominal armor is uncertain. Aside from the presumption that such plates occurred, there is a single small, irregular plate which was found intimately associated with the rest of the armor and skeleton.

The dorsal armor consists of four rows of plates arranged symmetrically in successive transverse series. The two inner rows are composed of flat plates with a small subcentral knob; these plates increase in breadth toward the dorsal region, at the same time decreasing in their antero-posterior extent. The outer rows are composed of plates which have the two sides of the bases bent almost at right angles to each other, so that a portion lies over the back and a portion over the sides; they bear spines which are of varying height in the different parts of the body. It is probable that the median rows disappeared in the posterior-caudal region, but of this there is no direct evidence. It will be best to describe the plates according to the transverse series. The general arrangement is shown in the plates and figures. The transverse series of dorsal plates begins immediately behind the skull, but the anterior ones are not arranged in relation to the vertebræ below; the first five series of plates cover the entire cervical series of vertebræ.

The plates of the first series are represented by the lateral one from the right side; it is incomplete, but shows a decided spine.

The second series is represented by the median plate of the left side and the two lateral plates. In common with all the plates of the cervical region, the median plates were quite thick on the inner and outer edges and thin on the anterior and posterior 
edges. The low knob is nearer to the posterior corner of the plate (fig. $16 \mathrm{~A}$ ). The anterior edge is the broader and the outer edge slopes backward and inward to the posterior edge. The left plate of the outer row of this series is nearly complete. The inner edge is thickened to form a firm union with the inner plate; the outer edge is thinner and slopes backward and outward to the broader posterior edge. The spine is located on the outer half of the plate and is inclined outward and slightly backward. The anterior surface of the spine is drawn out into a narrow, sharp edge which slopes forward to the middle of the plate.

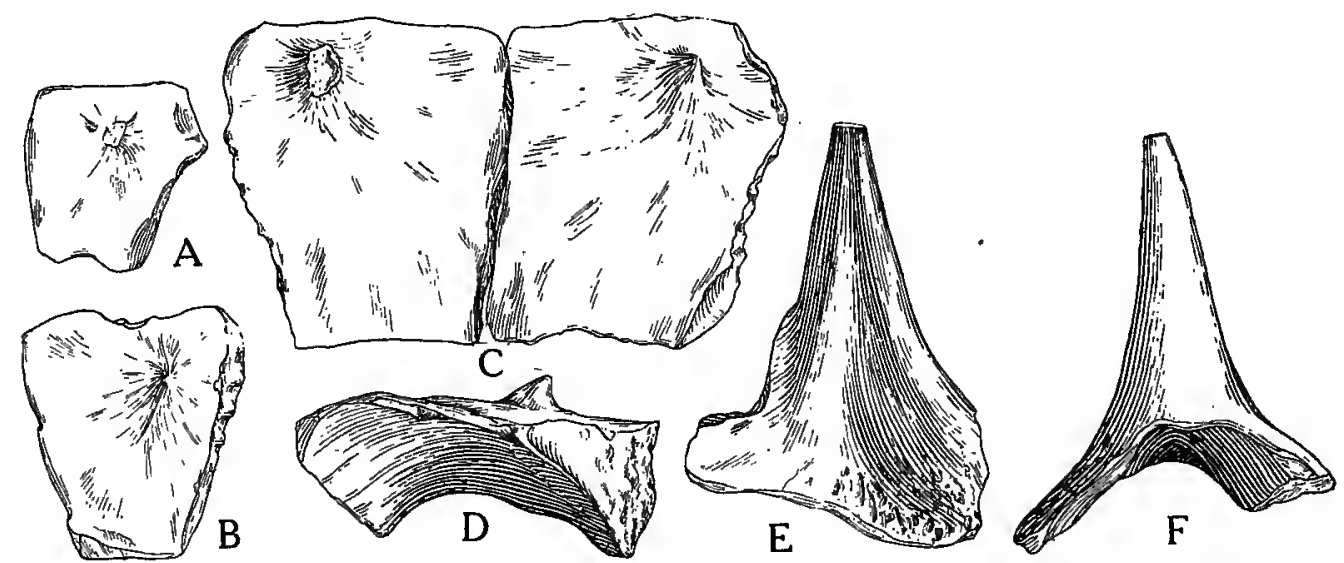

F1G. 16.-Desmatosuchus spurensis, dorsal armor of. All figures $\times 0.3$.

A. Upper view of median plate of second series, right side.

B. Upper view of median plate of the third series, left side.

C. Upper view of the two median plates of the fifth series.

D. Anterior view of the right side of $\mathrm{C}$.

E. Inner (upper) view of the lateral plate of the third series, left side.

F. Posterior view of E.

The third series has the plates (fig. $16 \mathrm{~B}$ ) nearly complete. The median plates are similar to the second, except that they are proportionately larger. It is clear in this series that the plates overlap to the rear, and this is continuous throughout the series. There is little, or a very fine, sculpture. The outer plates have high spines located near the posterior edge, with a thin flange extending down the anterior side. This is shown in figure $16 \mathrm{~A}$ and $\mathbf{B}$. The two parts of each plate lie nearly at right angles to each other. The inner edge is thickened for articulation with the median plate, while the outer part is thin and larger. The anterior edge is narrower, but the outer edge slopes backward and outward to meet the broader posterior edge. The outer side shows the beginning of a rough sculpture of relatively small pits and ridges. When in position the spines point outward and a little upward.

The fourth series is represented by the conjoined plates of the left side and an imperfect median plate of the right side. The left plates are complete, except for the extremity of the spine. The median plates are similar to those preceding, but are larger. The outer plate carries a heavy spine, of which the lower half only is preserved. The inner side of the spine is nearly flat, but there is a thin, strong ridge on the anterior side. As in the preceding plates, the anterior edge is shorter than the posterior, and the outer edge slopes backward and outward. Both the inner and the outer plates show an increase in the size of the sculpture, which becomes so heavy and rough in the dorsal region. 

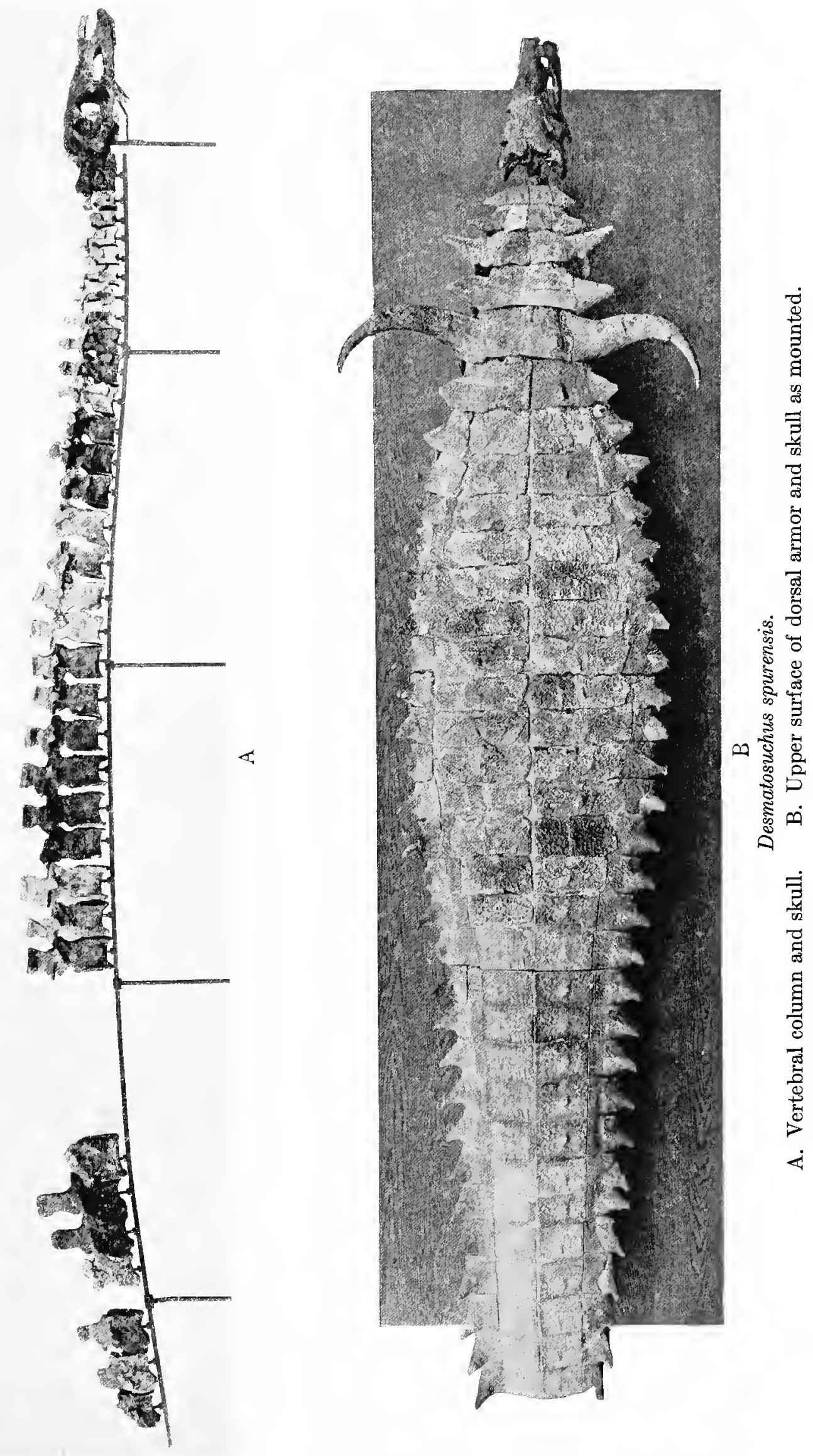

The fifth series is represented by two complete median plates (fig. $16 \mathrm{C}$ and $\mathrm{D}$ ), the complete plate of the outer row of the left side and an incomplete spine of the right side. The median plates are similar to the preceding plates. The outer plates present the most remarkable feature of the armor. Each one bears an enormous spine, over 45 centimeters in length; this extends almost directly outward, but a little upward, and from its middle

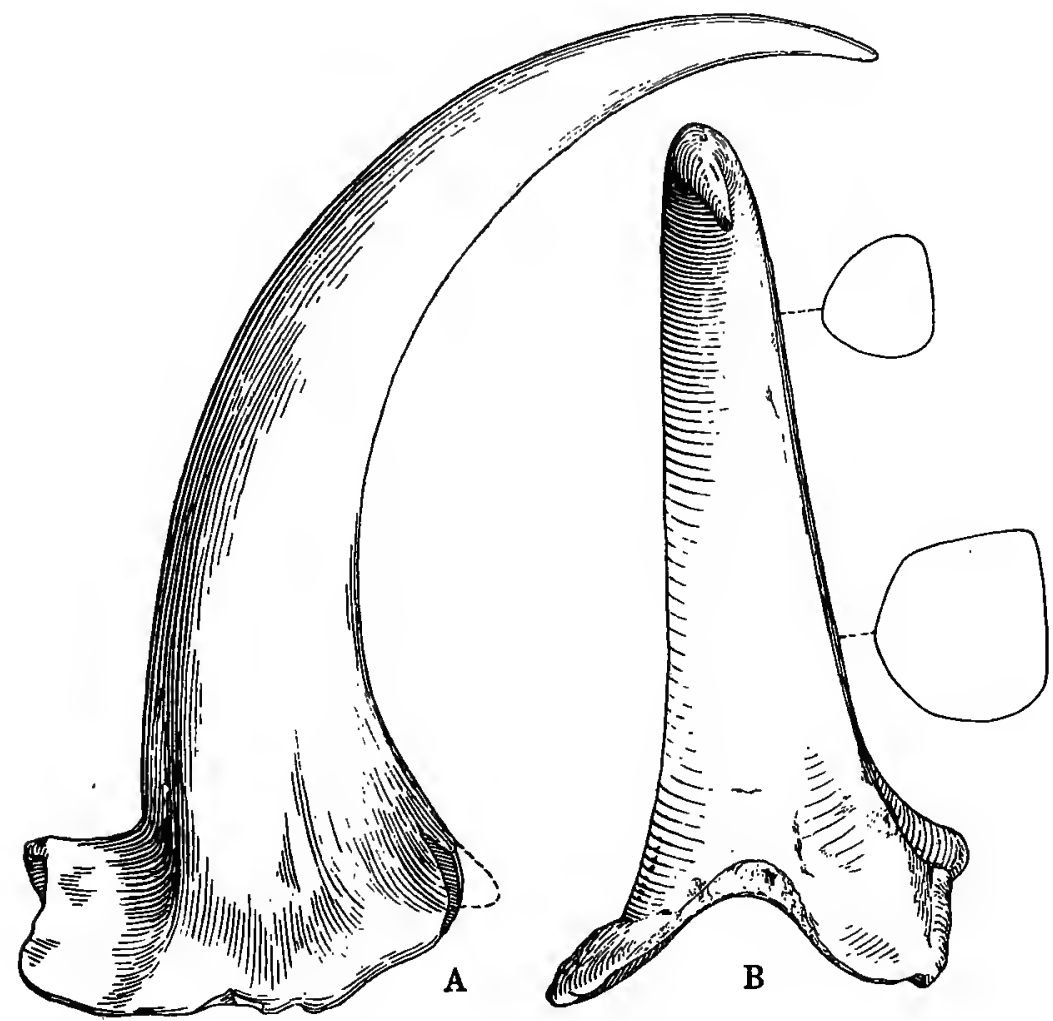

FIG. 17.-Desmatosuchus spurensis.

A. Lower (outer) view of the lateral plate of the fifth series in the dorsal armor, left side. $\times 0.3$.

B. Posterior view of $A$.

point curves backward as far as the middle of the seventh series of plates (fig. 17). The base of the spine is flattened on its inner and anterior side, but is rounded on the outer side. The angle between the inner and anterior faces is continued to about the middle of the spine and then disappears, the section then becoming circular, which continues to the acute distal extremity. The base of the plate is actually larger than the preceding ones, but relative to the spine much smaller; the inner edge is thickened for attachment to the median plates; the outer edge is thin and the anterior and posterior edges are of about equal width.

The accurate fit of the plates of this row permits a determination of the outline of the armor at this point, and this is checked by the conjoined plates of the fourth ring (see plate $8 \mathbf{E ~ t o ~} \mathbf{H}$ ). This is most fortunate, as the position and attitude of the spine would hardly be credible otherwise. The position of the great spine curving outward and backward could hardly have been imagined, and its meaning is still a puzzle.

Posterior to the fifth series the armor becomes flat and broad and descends but a short distance on the sides. The plates of the median row rapidly contract antero- 
posteriorly and broaden transversely through the sixth, seventh, and eighth rows, and by the ninth they have reached the normal form of the dorsal series, which continues back nearly to the sacral region. The low spine or knob is located a little outside of the center and is directed backward and inward. The plates are covered by a rough sculpture, shown in figure $18 \mathrm{c}$, which extends to the thin edges except for about 1. or 1.5 centimeters on the anterior edge. This smooth area on the edge of the plate indicates an overlapping, but it must have been very slight in the dorsal region. Examination of the plates in the armor of several species of alligators, crocodiles, and caimans shows that there is no, or very slight, overlapping of the plates in any of these forms, and that it occurs only in an overflexion of the back. The same smooth area appears on some of the plates in these living forms and seems to be a region of attachment of tough skin or tendinous material. The outer plates have low, sharp spines, which are broader antero-posteriorly in the sixth and seventh rows, but of nearly equal diameters in the ninth and following ones. The spines were inclined outward and a little backward. The inner half of the base is shorter than the outer. The inner half is nearly horizontal and the outer half is nearly vertical, but inclined a little outward. There is evidence from one side or the other of 17 plates of this kind, making at least 9 rows in the mid-dorsal series.
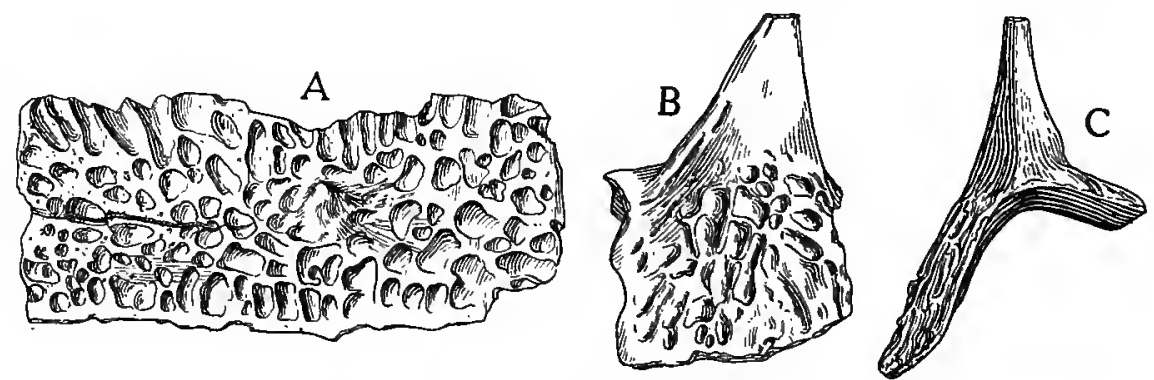

F1G. 18.-Desmatosuchus spurensis.

A. Median plate of a mid-dorsal series. $\times 0.3$.

B. Outer view of a lateral plate of a caudal series, left side. $\quad \times 0.3$.

C. Posterior view of $\mathbf{B}$.

Posterior to the plates of the dorsal series there are no representatives of the median plates, but there is a considerable number of plates from the outer series. They differ notably from those of the prepelvic region (fig. 18 B and c). The outer half of the base is much longer than the inner, and is in the same plane with the outer sides of the spines. This character becomes more noticeable as the plates become smaller, that is, in the posterior part of the caudal series. The spines are relatively higher than in the dorsal series. The sculpture becomes less rough in the posterior plates. It is believed that in the distal portion of the tail the median row disappeared, as it does in the Crocodilia.

The scapula-coracoid.-With the skeleton was found the distal end of a scapulacoracoid so radically different from the usual form found in the Phytosauria that it is difficult to reconcile it with the vertebral column, but it is no more peculiar than the skull. It does, however, resemble very closely the scapula-coracoid of Stagonolepis. The cotylus is large and cleanly formed and is somewhat obliquely placed in the bone. The upper edge overhangs strongly; the lower edge is broken away. A ridge interrupting the smooth face of the articular surface is perhaps due to pressure, but seems normal. Just anterior to the edge of the cotylus is a pit which seems to belong to the bone and not due to the action of decay and gypsum. The coracoid foramen is at about the level of the lower edge of the cotylus and perforates the bone upward and inward; on the posterior side the opening of the foramen is directly upward. On the anterior edge 

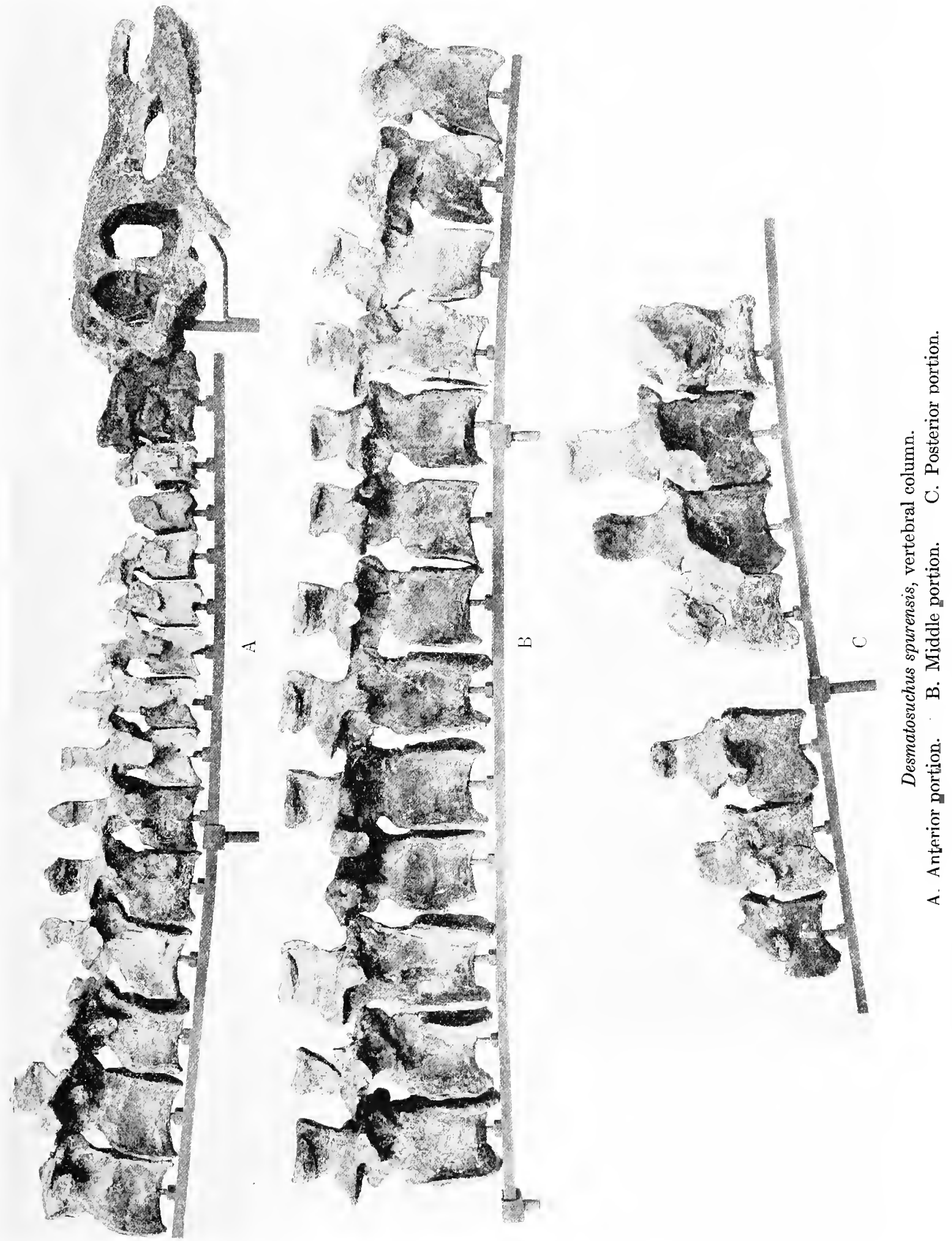

opposite the upper edge of the cotylus there is a decided prominence; below this the edge of the bone is quite thin. The lower and anterior edges of the coracoid have been injured by decay, but could not have had a very much greater extent.

Measurements of Desmatosuchus.

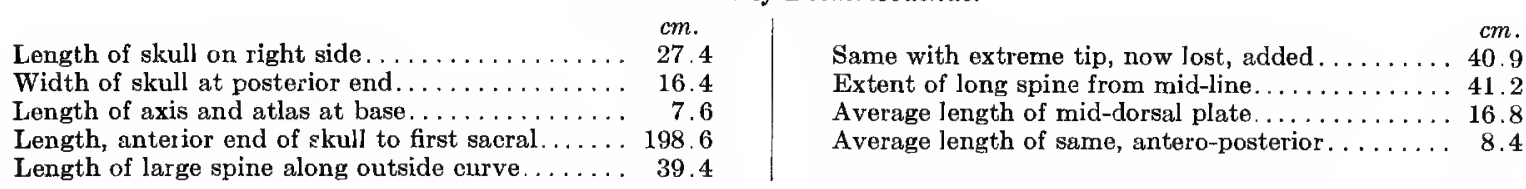

The restoration (fig. 20).-In the attempted restoration consideration has been given to several factors. It is obvious that such an animal as Desmatosuchus, with its spiny armor, would have considerable difficulty in making progress through tangled vegetation, either aquatic or terrestrial, and it is in accord with this character and the suggestion of the sediments that sparse vegetation and open water are indicated in the environment. It must be remembered in considering the nature of the animal that its remains are very limited in quantity in a region where the remains of Phytosaurs are relatively abundant. It would appear that Desmatosuchus inhabited a region somewhat different from that occupied by Belodon and Mystriosuchus, either more remote from the pools which formed the favorable environment of more common forms or a region geographically remote from the locality where the collection was made. It is exceedingly unfortunate that no teeth were found with the specimen, and so no more than a guess can be made of the nature of its food; but as the sockets are simp'e and rounded, it is safe to assume the teeth were single cones and that the animal was carnivorous. Inhabiting an area of

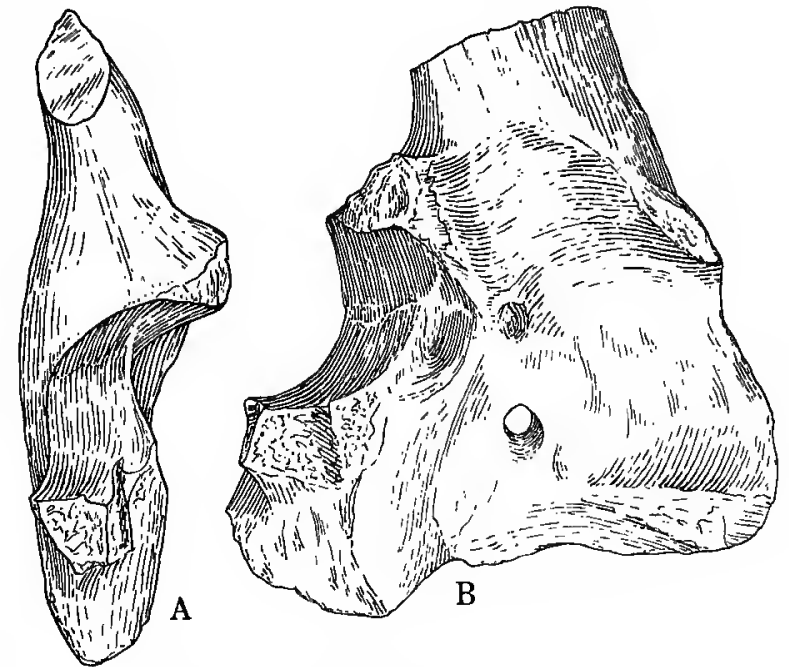

FIG. 19.-Desmatosuchus spurensis.

A. Anterior viow of the distal portion of the scapula-coracoid' right side. $\times 0.3$.

B. Outer view of $\mathrm{A}$. $\times 0.3$. open land, it is probable that the animal must have had relatively long limbs, a probability borne out by the size of the pelvis and the shape of the acetabulum, and further by the facts that no short limb-bones were found in the locality and that the fragment of the shaft of a limb-bone found with Desmatosuchus is evidently part of a long femur or humerus. No trace of the feet or claws was found, and the suggestion of partially webbed feet, implying a dominantly aquatic habitat, may be erroneous. The weight of the great carapace would, perhaps, also be an objection to the assumption of an aquatic life. For the same reason-the possibility that the habitat was not dominantly aquatic-it is possible that the tail has been made too long and too much of a swimming organ.

Critical study of the specimen in the course of mounting the skeleton has led to the conclusion that the plates of the dorsal armor did not overlap when the animal was in a normal position, but overextension, as by a strong upward curvature of the body, would have been possible only by the overlapping of the plates. This is the condition found in the modern Crocodilia. 
The relationships of Desmatosuchus.- To the author it seems apparent that Desmatosuchus can be considered only as a member of a branch of the Parasuchian stem which has developed a high degree of specialization. The character of the vertebral column and the carapace indicates close relationships to the Parasuchia; all the remarkable features of the carapace are simple developments of possibilities clearly indicated in the more conservative line.

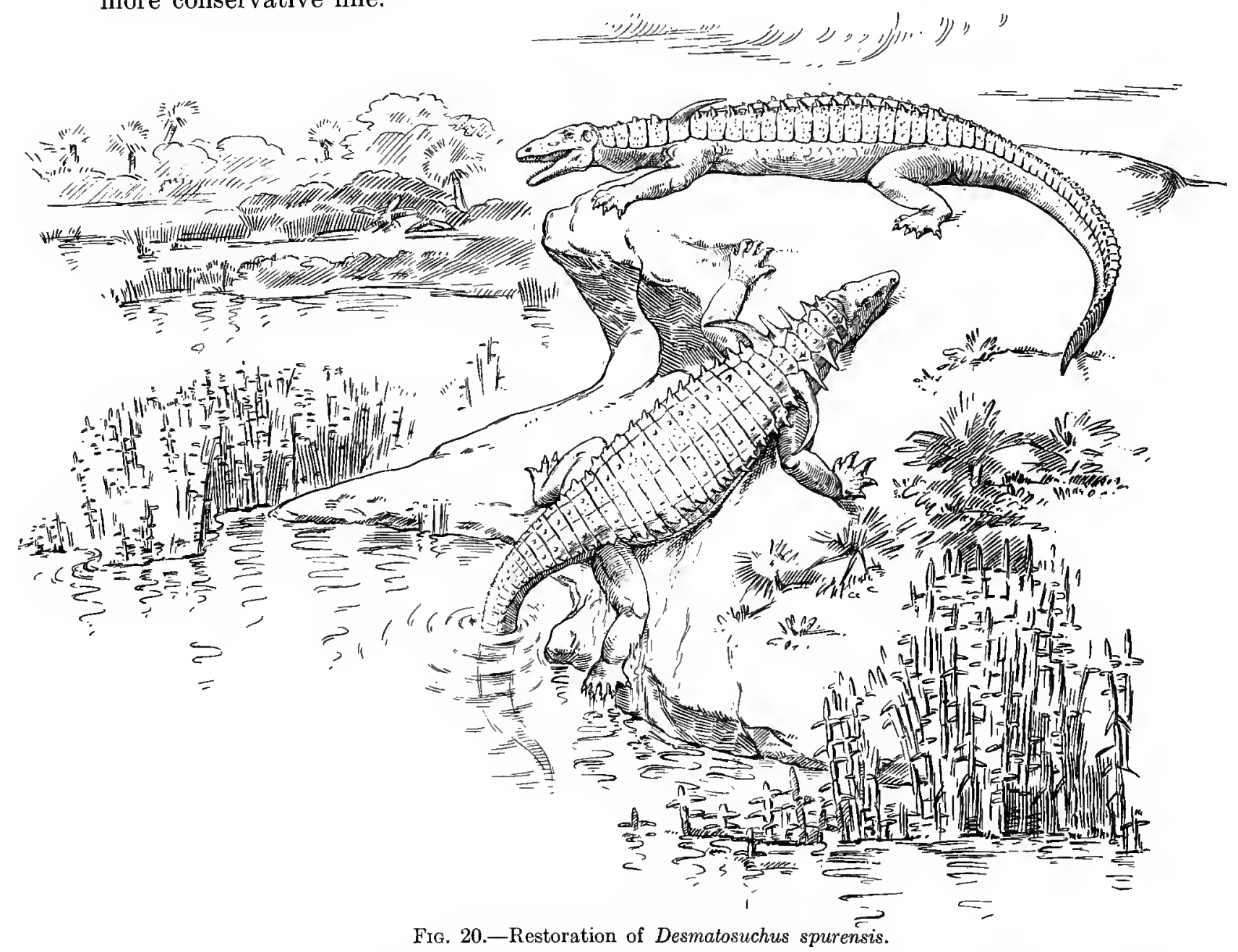

It is in the skull that the morphological divergence from the line of the Parasuchia is clearly evident. The author, as indicated in the body of the description, is unable to accept the suggestion made by Doctors Huene and Watson that the single large temporal opening is the upper and that the bones outlining the lower opening have been lost. Reasons for this opinion have been given in detail in a preceding portion of this article. The single temporal opening and the amazing condition of the quadrate region clearly place the animal in a separate suborder or even order. The basicranial region, the antorbital opening, and the lack of a pineal foramen, together with the character of the vertebral column and the carapace, just as clearly indicate affinities with the Parasuchia. Until future discoveries shall prove the author's interpretation of the skull to be erroneous, or shall reveal further structures which will make more evident the affinities of the animal, Desmatosuchus must be considered as a member of a distinct order or suborder of phytosauroid reptiles, highly specialized in its morphology and confined to the Upper Triassic of North America. 


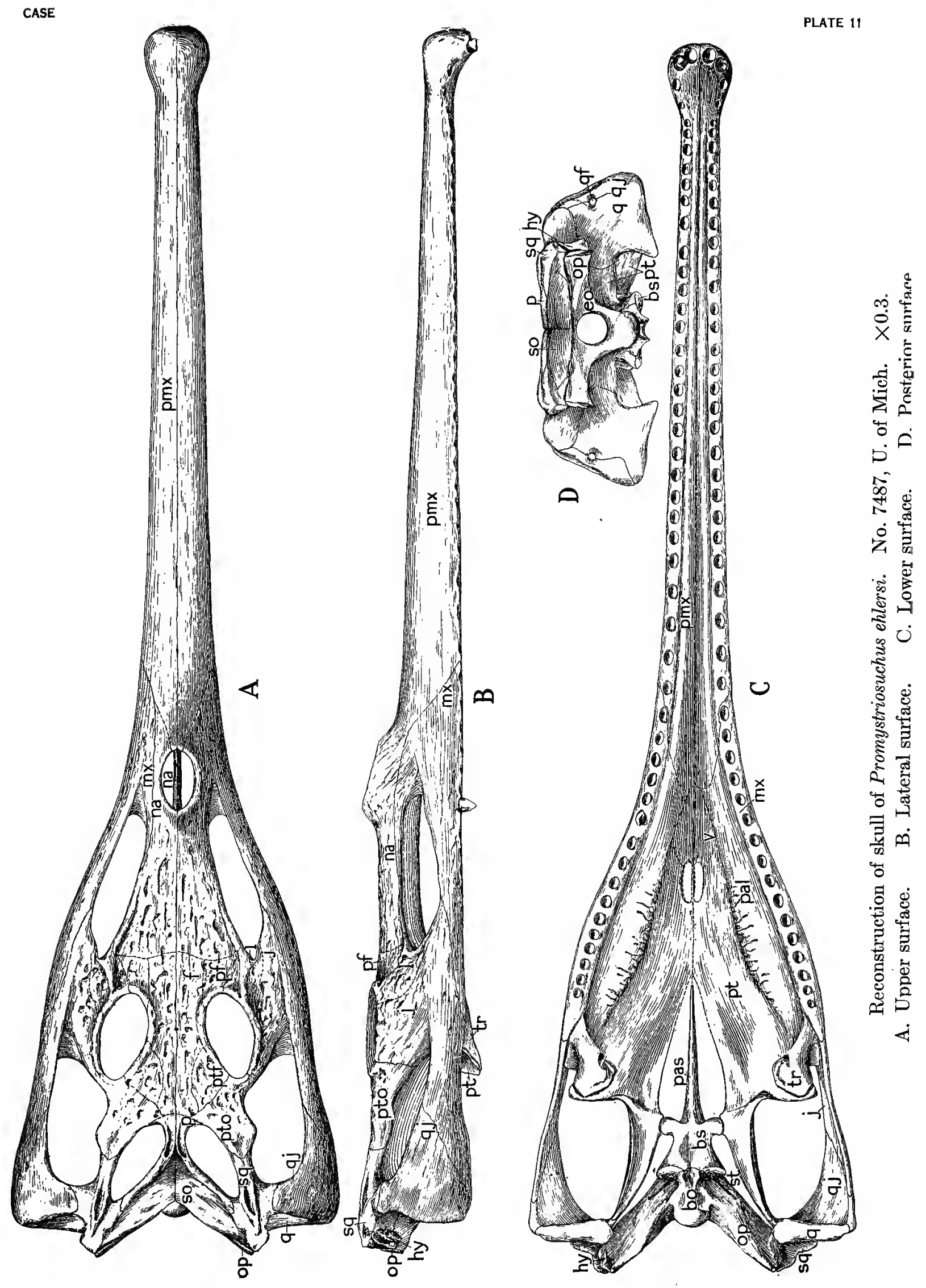





\section{A NEW PARASUCHIAN, PROMYSTRIOSUCHUS EHLERSI.}

The specimen (No. 7487, University of Michigan) described below was discovered by the author in a bed of yellowish sandy clay near the head of Holmes Creek, Crosby County, Texas, in the summer of 1921. The patch of sandy clay is but a minor phase of the larger deposit in which so many remains of reptiles and amphibians occur in this locality. Near the specimen, and in the same kind of matrix, occur large numbers of fragmentary bones, teeth, and coprolites. This small patch is evidently a bit of an old sand-bar, or an accumulation of sandy clay in some small depression which has been well leached by percolating waters. The relatively small percentage of clay rendered the matrix easily permeable by the waters which converted the iron into limonite and in spots removed it so completely that the matrix is pure white; in other spots the matrix is still purple from the unchanged iron of the original deposit. The limonite was concentrated upon the bones, covering them with a thin scale, and was deposited in the cracks between the pieces of the broken bones. Movements in the ground crushed the skull and broke it into many small pieces which are slightly displaced. The cleaning and restoration were rendered difficult by the distortion and breaking of the bones, but as the fragments were only slightly displaced it was possible to harden the matrix or replace it by plaster cement and work out the original form of the skull. The anterior half of the long rostrum was weathered out, but it has been possible to fit the pieces into place and determine very accurately the length and form of the nose. From the narial opening forward, the two halves of the skull were separated slightly; the palate was crushed and pushed somewhat toward the left side. The posterior part of the lower jaw of the left side was recovered, but the anterior end was destroyed by decay before fossilization.

Because of the fractured and compressed condition of the skull, it is intelligible only after considerable study; the figures presented are restorations which have been made with as great accuracy as possible, being the result of six different attempts, made as checks, and are, in the opinion of the author, very satisfactory representations of the original condition. The location of the sutures was rendered difficult by the innumerable cracks and the condition of the specimen; only those that have been determined with certainty are represented in solid line.

The peculiar characteristics of the specimen are the slight extension of the squamosal region behind the occipital condyle, the elevated position of the parieto-squamosal arch, the absence or small size of the post-temporal opening, the very long parasphenoid process, and the large interpterygoid space. The lack of any great posterior extension of the squamosal region, the great length of the parasphenoid, and the large interpterygoid space are primitive characters recalling the condition in Mesorhinus, but the development of the external process of the pterygoids, the character of the transverse, the shape and condition of the palatines, and the elongate rostrum are features belonging to the more highly specialized of the Phytosaurs of the Upper Triassic. The suggestion of immaturity conveyed by the small size of the skull is not borne out by the condition of the bones and the sutures. It is evident that we have to do with a fully mature Phytosaur of the Mystriosuchid group, of small size and distinct in its characters from any previously described.

The upper surface of the skull (plate 11, fig. A).-The openings in the skull: The supratemporal openings are elongate oval and lie entirely upon the upper surface of the skull; their boundaries are shown in the figures. The orbits are somewhat oval in outline and lie almost entirely upon the surface; the lateral presentation is very slight. The narial opening is entirely upon the upper surface and is surrounded by an elevated rim; it is divided somewhat deeply below the rim by a pair of small bones which are 
described below. The lateral temporal openings are elongate and inclined downward and forward, reaching as far forward as the center of the orbit. The antorbital openings are elongate and rather narrow vertically; they reach from just anterior to the orbit to a point below the center of the narial opening. Both the lateral temporal openings and the antorbital openings are but partially visible from above.

The parietal bones are small, each with a slender process extending outward and backward and forming the upper edges of the deep notch at the posterior end of the skull. These processes form the inner borders of the upper temporal openings and terminate near its posterior end. The anterior portion of each parietal meets its fellow of the opposite side in the median line; the extent forward is not accurately made out, but it is, in all probability, not great. This portion of the parietal forms the anterior edge of the upper temporal opening. There is no trace of a parietal foramen.

The squamosals are cruciform in outline. The anterior arm unites with the postorbital to form the bar between the two temporal openings. The inner arm is very narrow and unites with the parietal; the outer arm is much wider and is overlapped by the upper end of the quadratojugal. On the lower surface of this arm there is a concave surface, elongate laterally for the reception of the upper end of the quadrate; this is clearly shown on the left side, where the quadrate is missing, having been lost by maceration before the fossilization of the skull. The posterior arm is short; its upper surface is marked by prominent rugose ridges extending in the direction of the greatest length of the bone. The posterior end overhangs the distal end of the opisthotic.

The postorbital forms a small part of the posterior edge of the orbit and articulates with the jugal below. It sends backward and slightly outward a broad arm which unites with the squamosal. Just anterior to the suture there is a broadening of the outer side which forms a constriction in the lateral temporal foramen.

The outlines of the frontals, postfrontals, prefrontals, and nasals can not be made out clearly. This portion of the skull is rugose and is badly broken and cracked, the cracks being filled with limonite, so that the sutures can not be followed. The probable course of the various sutures is indicated in dotted lines in the figures. It seems altogether probable that the nasals had considerable extent posterior to the narial opening. Dividing the narial opening some distance below the upper edge of the rim, there is a slender rod formed by two narrow, elongate bars which meet in a close, relatively broad symphysis, as shown in figure 21 . This septum is, in all probability, formed by the anterior ends of the nasals.

The septomaxillaries.-No trace of these elements could be found, but it may well be that the limiting sutures are obscured in the specimen.

The premaxillaries form the greater part of the long, slender rostrum anterior to the narial opening. The origin of the maxillary-premaxillary suture lies about 3 centimeters in advance of the opening; the suture is traceable backward between the two bones and then is apparently continued backward between the premaxillaries and the nasals, allowing the premaxillaries to take a small part in the anterior portion of the rim of the nares; this last point is, however, uncertain. The anterior ends of the premaxillaries are only very slightly thickened and expanded to accommodate the alveoli of the anterior teeth. The rugosity of the upper surface terminates with the narial opening and the surface of the maxillaries and premaxillaries is relatively smooth. The quadratojugal,jugal, maxillary, and lachrymal are only obliquely and imperfectly exposed in the upper view.

The side of the skull (plate 11, fig. в).-The small extent of the projection of the squamosal beyond the quadrate and occipital condyle is very noticeable in this view. The posterior process of the squamosal is excavated below, so that the whole projection is thin and without a terminal descending portion. In the notch below can be seen the distal extremity of the opisthotic. 
The quadratojugal is high behind, forms the posterior edge of the lateral face of the skull, and conceals the quadrate. Its upper anterior edge forms the posterior half of the lower edge of the lateral temporal opening. Its lower edge forms the extreme posterior part of the lower edge of the skull, but is soon covered by the jugal; the suture between these two bones passes obliquely upward and forward.

The jugal forms the lower edge of the skull as far forward as the anterior end of the lateral temporal opening; it is then covered by the maxillary and the suture between them runs forward and upward, terminating, apparently, on the lower edge of the antorbital opening, about one-third of the length of the edge from the posterior end. The jugal is deeply notched posteriorly by the anterior end of the lateral temporal opening and forms both the upper and lower edges of this part of the opening. The suture between the jugal and the postorbital lies at the posterior end of the orbit and the jugal forms much of the outer orbital rim. The suture between the jugal and the lachrymal can not be made out.

The lachrymal can not be delimited with certainty; it probably occupies the same position as in most of the Phytosauria and forms the posterior border of the antorbital opening.

The maxillary starts from a point below the anterior edge of the lateral temporal opening and forms the lower edge of the skull as far forward as about 3 centimeters in front of the narial opening. Its upper edge forms the anterior two-thirds of the lower border of the antorbital opening. A thin groove, which apparently marks the position of a suture, rises from the middle of the upper border of the antorbital opening and runs forward close to the edge; it is traceable out upon the face of the skull for some distance; it apparently joins the suture between the maxillary and the premaxillary. It is believed that this groove marks the position of the suture between the maxillary and the nasal, as the form of the maxillary thus outlined is found in several genera of the Phytosaurs.

The nasals can not be exactly outlined. If the suture described above is correctly determined, the nasals form most of the sides of the skull above the antorbital opening, form a part of its upper border, and join the lachrymals and prefrontals posteriorly. Anteriorly the nasals probably form the borders of the narial opening, except, possibly, the median portion of the anterior edge, and send slender processes forward between the maxillaries and the premaxillaries. The septum in the narial opening is in all probability formed by the nasals.

The premaxillaries. - The outline of the posterior end of the premaxillaries is uncertain, but they apparently send long processes backward and upward which terminate in the anterior median portion of the edge of the narial opening and join the nasals and maxillaries. Anteriorly they form the major portion of the long, slender rostrum. The anterior end is but slightly decurved, and there is a very shallow constriction just posterior to it.

The lower surface of the skull (plate 11, fig. c).--The bones of the palatal surface have been largely preserved, but have been badly broken, slightly displaced to the left side, and crushed against the lower surface of the bones of the roof of the skull.

The basioccipital.- The condyle is nearly hemispherical and has a rather long neck, with the sides flattened. Low ridges appear near the posterior end of the lower face and rise rapidly forward until just anterior to the suture between the basioccipital and the basisphenoid they form high processes on the sides of a deep notch.

The basisphenoid is separated from the basioccipital by a distinct suture. On either side of the notch described above there are prominent processes, the tubera basioccipitalia, rounded externally and with flat, oval faces looking posteriorly. These processes contract anteriorly, disappearing just posterior to the origin of the basipterygoid processes. The lower face of the bone is flat and there is no deep pit; the bone is broken 
in this place and is filled with matrix, but an examination of the depression shows that the edges of the pieces are sharply fractured and that there is no surface leading down into a pit. The basipterygoid processes are prominent, extend slightly forward as well as outward, and terminate in slightly convex faces. The parasphenoid process is of remarkahle length, extending forward for 75 millimeters. It gradually contracts anteriorly to a very thin lower edge. The sides of the process are flat, about 20 millimeters high at the posterior end, and contract to not over 5 millimeters at the anterior end. There is no indication of a division into upper (presphenoid) and lower (parasphenoid) portions.

The opisthotics are indistinguishable from the exoccipitals; they extend outward and backward. The proximal portion of the complex is thick, but the distal portion contracts to a thin oval, with the major axis placed vertically. To the outer, i. e., toward the quadrate, side of the extremity of the right opisthotic there is attached a small fragment of bone of irregular form. This was at first regarded as a displaced fragment of no significance, but the extremity of the opisthotic of the opposite side shows a sutural surface in the same position. The fragment is in exactly the position where McGregor found a small element in Mystriosuchus ${ }^{1}$ which he considered to be calcified cartilage and identified as a hyoid element.

The stapes.- On the lower side of the right opisthotic there is preserved a portion of a very slender stapes apparently in position. The portion preserved is about 1.5 centimeters in length, with a diameter of less than 1 millimeter. The outer extremity is lost, but the inner end is evidently in place in the fenestra ovalis; the crushed condition of the specimen in this region renders it impossible to determine the exact relations of the inner end.

The quadratojugal and the jugal are represented on the lower surface by their thin lower edges only.

The pterygoids.- These bones are badly broken, but the parts are sufficiently well preserved on the right side to permit a restoration of a major portion of the bones. The articulation with the basipterygoid process of the basisphenoid is accomplished by a well-formed, slightly concave facet on the inner edge of the bone, which is slightly thickened at this point. The quadrate process extends backward, with a narrow, concave face presented downward, which rapidly contracts toward its distal end. As this face contracts, the body of the process assumes a vertical position. Union with the quadrate is accomplished by a definite suture with the slender pterygoid process, which is of considerable vertical extent. The external process of the pterygoid extends outward almost at a right angle from a point a little in advance of the basisphenoid process. The external process is not greatly thickened, but the posterior end descends somewhat abruptly from the palatal surface, and from this point the bone slants gently forward and upward. The posterior edge is thin and the outer corner is nearly a right angle; the outer border descends rather sharply beneath the transverse. The anterior process is broad posteriorly and contracts anteriorly as its inner edge is cut out by the development of the interpterygoid vacuity. This portion of the bone is very thin and much has been crushed and lost; the outline of the interpterygoid vacuity as represented is uncertain, but enough can be made out to show that it was elongate, broader posteriorly, and gradually contracting in front until the bones of the two sides met near the anterior end of the parasphenoid process. The suture with the palatine is obscured, as the latter bones are somewhat overthrust on both sides.

The transverse is thin throughout; its posterior end is expanded and fits closely over the lower face of the outer part of the external process of the pterygoid; the inner edge is

${ }^{1}$ McGregor, J. H., Memoirs American Museum Natural History, vol. IX, pt. II, 1906, pl. vir. 
marked by a slight ridge, and below this is a groove which is continuous with a foramen which excavates the pterygoid and connects with the small palatine vacuity which is not visible from below. The bone is narrowed in the median portion and then expands to articulate with the maxillary, the palatine, and the jugal. The outer face is bent sharply down and forms a nearly vertical face; its distal end is reflected upon the inner sides of the maxillary and jugal.

The palatines are elongate bones lying between the maxillaries and the pterygoid. On the right side the palatine is separated by a fracture from the maxillary, but on the left side the bones are in contact. The surface of the palatine is convex downwardly in the middle of its length, but the anterior and posterior ends are flatter. The greatest height of the convexity is near the inner edge of the bone and the whole surface of the middle portion is slightly rugose.

The anterior termination of the pterygoids and the palatines is uncertain. They apparently join the vomers near the median line, but as the premaxillaries of the two sides meet in the median line as far back as a point just below the posterior edge of the external narial opening, the palatines, pterygoids, and vomers must have risen somewhat in the skull at this point. Just posterior to the point where the premaxillaries terminate, the inner edges of the median bones of the palate are slightly excavated and rounded, indicating the position of the very narrow internal nares, but whether the boundaries of these openings are formed by the vomers alone or by the vomers and pterygoids can not be made out. There is no suggestion of a median septum, but the opening was probably paired. In the light cast by the study of the skull of Leptosuchus, this interpretation may be erroneous.

The maxillaries appear on the lower side of the skull only as the alveolar edges; anterior to the external narial opening they join the premaxillaries by oblique sutures running backward and inward, so that the posterior ends of the premaxillaries extend backward as long processes between the maxillaries.

The premaxillaries extend forward with nearly straight outer sides; the lower surface is divided between the alveolar edges and smooth convex surfaces; the two bones meet in a broad median symphysis. This symphysis is divided into an upper and a lower part; between the two articulating surfaces there is a smooth, somewhat concave area, indicating the presence of a narrow median cavity running nearly the full length of the rostrum. On either side of this groove the palatal surface of the premaxillaries is raised into convex (longitudinally) ridges, forming, with similar process on the dentaries, a buttress which prevented injury to the teeth when the jaws were snapped together.

The teeth are typically phytosaurian in shape and arrangement. The posterior teeth are broader and lower, with sharp anterior and posterior serrate cutting edges. The inner side of each tooth is nearly flat, except at the tip, where the convexity becomes greater; the outer side is decidedly convex. The cutting edges are sharply crenulate from the apex nearly to the base. The greater part of the teeth are lost, but certainly at the middle of the premaxillaries the teeth were elongate and slender. The inner side of the few anterior ones preserved is less convex than the outer and the cutting edges are lower; the crenulations do not appear on the single tooth, which is well preserved, but they were probably present to some extent. The extremity of the snout was occupied by four large teeth, which on the right side are represented only by the base of the inner one and the apex of the just erupting outer one. The apex of the outer tooth shows the same disparity between the convexity of the inner and outer sides that appears in the other teeth of the series. There are 47 teeth and alveoli on each side in the upper jaws. The separation of the two sides of the skull at and anterior to the external narial is a pair of bones, at the level of the surface of the skull posterior to the narial opening, 
which divides the nares some distance below the level of the rim. These bones are thin, but nearly a centimeter in height on the broad inner surface, which was closely applied to the bone of the opposite side. These are probably extensions of the nasals. On the left side, in what is apparently a direct continuum with the median palatal element, probably the palatine (vomer ?), there is a slender bar of bone distinct from both the nasal and the premaxillary. As this bar is above the premaxillaries in the region where they meet in the median line, it can not be a bar separating the internal nares; rather it seems to be a bar vertically placed beneath the nasals and defining an opening which permits the nasal to open laterally into passages which lead back to the somewhat posteriorly placed internal nares. The separate character and distinct identity of this bar is proven by the fact that it was surrounded by matrix, which has penetrated between it and the adjacent bones, and by its rounded edges revealed under the binocular microscope.

The posterior face of the skull (plate 11, fig. D).- The crushing of the skull has almost completely closed the foramen magnum, and in the restoration allowance has been made for this depression as accurately as possible. The sutures between the elements forming the edges of the foramen magnum can not be made out.

The basioccipital carries a good-sized, nearly hemispherical condyle; the sides of the neck run forward and upward to join the exoccipital-opisthotics. It has been impossible to determine the position of any of the nerve outlets.

The exoccipital and the opisthotic are closely fused; the opis-

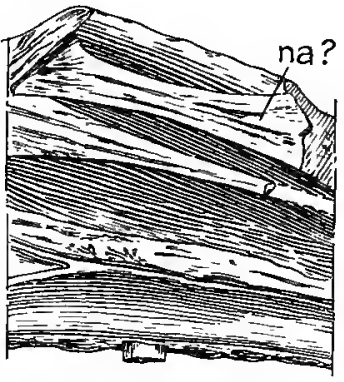

Fig. 21.-Promystriosuchus ehlersi.

Median surface of the narial region, left side. na., nasal. $\times 0.6$.

thotic portion extends outward and backward at a fairly sharp angle; the outer portion becomes thinned laterally, but retains its vertical extent; the outer end terminates freely below the distal end of the squamosal.

The supraoccipital is a rather broad plate inclined sharply forward in the median line, but becoming more nearly vertical toward the sides; it is closely attached to the slender parietals above, which are visible only as thin edges from the rear. The posttemporal openings are entirely closed, if they were present, which is quite probable. An enlargement visible on the upper edge of the opisthotic in the usual position of the openings may be due to crushing. Small post-temporal openings have been shown in the restoration.

The squamosal has a relatively small presentation on the posterior face of the skull; it sends a short prong inward between the distal end of the opisthotic and the supraoccipital and a second one above the supraoccipital to unite with the parietal. Just above the distal end of the opisthotic is the prominent posterior termination of the squamosal, and below this is the small fragment of bone on the outer side of the opisthotic which MeGregor identified as a hyoid element in Mystriosuchus. Externally the squamosal sends a strong process forward and outward to join the quadratojugal; the lower surface is excavated for the reception of the upper end of the quadrate.

The quadrate has a nearly quadrangular posterior surface. This surface inclines inward and forward beneath the opisthotic; the upper half of the inner edge forms the articulation for the pterygoid. The outer edge is covered by the quadratojugal, which sends a short process around the outer edge on to the posterior face near the outer lower corner. About midway up the outer edge there is a good-sized quadrate foramen surrounded by the quadrate and quadratojugal. There is no indication that the quadrate process of the pterygoid appeared on the outer face of the skull, as described by Huene ${ }^{1}$ in Mystriosuchus pleiningeri.

${ }^{1}$ Huene, F. v., Geolog. u. Paleontolog. Abhdlg., N. F., Bd. x, Hft. 1, s. 81, 1911. 
A review of the known skulls of the Parasuchia reveals the fact that they may be divided into two more or less clearly marked groups-those with long, slender, depressed rostra and those with elevated rostra. To the first group, the Mystriosuchid group, belong Mystriosuchus, Rhytidiodon, Paleorhinus, and Promystriosuchus; to the second group belongs Phytosaurus (Belodon). Intermediate between the two are the forms which have been described by Cope as Belodon buceros and by Mehl as Machceroprosopus validus. In the opinion of some workers, Belodon buceros Cope and Machoroprosopus validus Mehl should be placed in the genus Phytosaurus. The two specimens described in this volume as Leptosuchus help to further bridge over the gap between the two groups.

The form described as Promystriosuchus belongs in the Mystriosuchid group and is nearest to Angistorhinus. Because of its retention of certain primitive characters, it will be best to compare it first with Mesorhinus, the earliest and most primitive of the Parasuchia. Mesorhinus was described by Jaekel ${ }^{1}$ from the middle Bunter sandstone of Bernburg.

\section{Comparison with Mesorhinus.}

The anterior portion of the rostrum of the specimen was not recovered, and Huene considers that it has been made too long in the restoration by Jaekel. Granting the correctness of Jaekel's restoration, which would be the maximum possible length of the rostrum, there is still a great disparity between the relative lengths of the prenarial and postnarial portions of the skull and the same measurements in Mystriosuchids from the Upper Triassic. Measuring from the anterior end of the narial opening, Jaekel's figure (as copied by Huene) gives a relative proportion of lengths between the prenarial and postnarial portions of the skull as $5: 6$; the same measurements on the figure given by Abel (Stamme der Wirbelthiere, p. 516) give proportions of $4: 5$. In Promystriosuchus the rostrum has become relatively much elongated, a distinctive character of the specialized Parasuchians of the Upper Triassic, the proportional lengths being as $3: 2$. In Mesorhinus the narial opening is elongate and clearly divided by a septum at the level of the surface of the skull, formed by an anterior extension of the nasals; the antorbital vacuity reaches either to the middle of the narial opening or only a little way anterior to the posterior edge, according to figures of the lateral and the upper view of the skull as given by Jaekel (copied by Huene); the lateral temporal opening is nearly circular; the parieto-squamosal bar defining the inner border of the supratemporal foramen is complete and at the level of the roof of the skull; the supratemporal foramen itself is entirely on the top of the skull; the squamosals do not extend far posterior to the occipital condyle. In Promystriosuchus the narial opening is round, is surrounded by a high rim, and the septum is far down within the cavity of the nares; the antorbital opening is elongate and reaches as far forward as the middle of the narial opening; the lateral temporal opening has assumed, more or less perfectly, the characteristic parallelogrammic form of the Parasuchia; the parieto-squamosal bar is at the level of the roof of the skull, and the supratemporal opening is entirely upon the upper surface; the squamosals do not extend far posterior to the occipital condyle.

On the posterior surface of the skull the shortness of the opisthotic process in Mesorhinus is a striking difference from the condition found in the younger Parasuchia.

On the lower surface the palate of Mesorhinus, as figured by Jaekel, is radically different from that of the majority of the Parasuchia. The pterygoids lack the strong external process; the transverse articulates with the outer edge of the pterygoid instead of underlying an external process; the palatine vacuity is large, lying between the palatines, pterygoids, maxillaries, and transverse. The peculiar articulation between the

I Jaekel, O., Sitz. Ber. d. Gesell. Naturf. Freunde, Berlin, No. 5, p. 197, 1910; see also Huene, F. v., Geol. u. Paleont. Abhdlg., N. F., Bd. x, Hft. 1, s. 50, 1911. 
pterygoid and the palatines is not found in any other form of the Parasuchia. In Promystriosuchus there is a strong external process of the pterygoids which is underlain by the posterior end of the transverse; the palatine vacuity is represented by a small foramen between the palatine and the transverse, which appears on the lower surface near the posterior end of the transverse.

The primitive characters of Promystriosuchus appear in the elevated parieto-squamosal arch, the relatively anterior position of the narial opening, ${ }^{1}$ and the elongation of the parasphenoid process. The other characters cited are those of the more specialized Parasuchia, and it is evident that the form here described must be placed in the Mystriosuchid group of the Phytosauridæ. The primitive characters are conservative features which are found in at least one other member of the same group and family.

Comparison with Angistorhinus.

Angistorhinus ${ }^{2}$ is in many ways the nearest known form to Promystriosuchus. A consideration of the comparative characters will make more evident the similarities
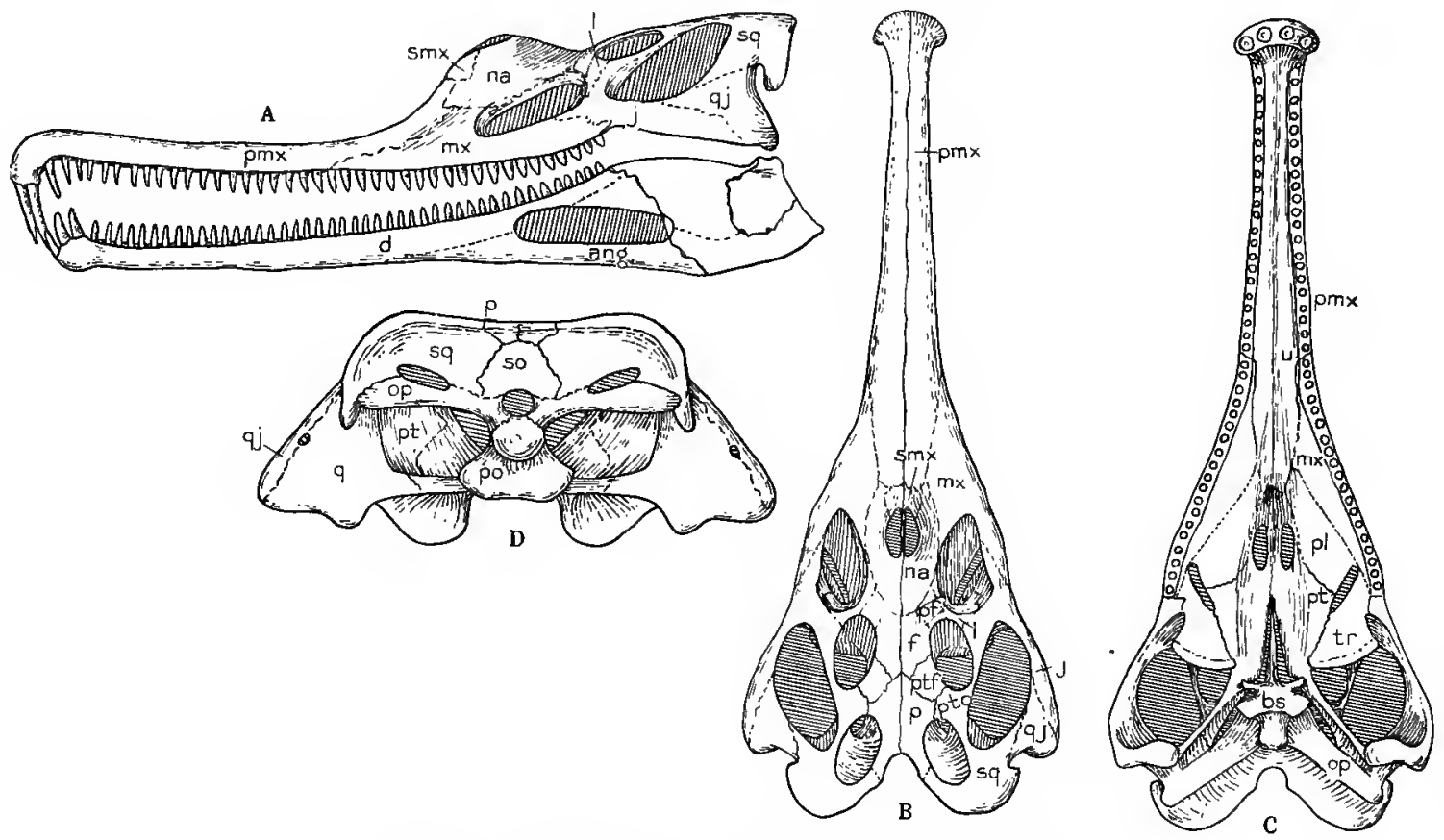

F IG. 22.-Angistorhinus, lateral view of skull, after Mehl.
A. Lateral view of skull.
B. Upper view of skull.
C. Lower view of skull.
D. Posterior view of skull, somewhat larger.
smix., septomaxillary. Other lettering as usual.

and differences between Promystriosuchus and the other Mystriosuchids. The relative proportions in length of the prenarial and postnarial portions of the skull of Angistorhinus are as $10: 6.4$, or approximately $5: 3$; the antorbital vacuity is elongate and extends as far forward as the anterior edge of the narial opening; the opening is surrounded by a

${ }^{1}$ Huene, in the Geol. u. Paleont. Abhdlg., N. F., Bd. x, Hft. 1, s. 53, has suggested that the position of the narial opening and the elongation of the rostrum are two distinct things and that the retreat of the nares is conneeted with the shortening of the posterior part of the skull. The relation between the antorbital vaeuity and the nares is regarded by him as a phylogenetie character; as the nures retreated the antorbital opening would appear more and
more anteriorly in the skull.

${ }^{2}$ Mehl, M. G., Journal of Geology, vol. 21, No. 2, p. 186, 1913; Ibid., vol. 23, No. 2, p. 129, 1915. 
high rim, but the septum is placed deeply within the cavity; the parieto-squamosal arch is complete and on a level with the roof of the skull; the interpterygoid vacuity is relatively large, and the parasphenoid process is long, reaching to the anterior end of the vacuity. The two forms differ in that in Angistorhinus the squamosals are much larger and extend well beyond the occipital condyle, so that it is not visible from above; there is a much sharper depression of the rostrum anterior to the external nares; the anterior end of the rostrum is much more down-turned and is wider; the pterygoid is represented by Mehl as having no external process and the transverse joins it laterally, not by underlying an external process; the posterior arm of the parietal is short, the greater part of the upper edge of the posterior part of the skull being formed by the squamosal; the opisthotic process extends out to the squamosal, but is surrounded by it both above and externally; the post-temporal foramen is relatively large.

\section{Comparison with Paleorhinus. ${ }^{1}$}

If Huene's suggestion of the phylogentic value of the relative position of the externa nares and the antorbital vacuity is correct, Paleorhinus retains the primitive character in a marked degree, for the antorbital vacuity is entirely posterior to the nares and has a rounded anterior outline, indicating a very different form of the jaw-muscle; the squamosal has a very large extension behind the occipital condyle. The proportion between the relative lengths of the prenarial and postnarial portions of the skull is as $8: 8.8$, or nearly as $1: 1$, approaching in this the probable condition in Mesorhinus. On the other hand, the specialized character of the skull appears in the depression of the parieto-squamosal arch, the shortness of the posterior bar of the parietal, the elevated rim of the external nares, the position of the internal nares posterior to the external, the small interpterygoid vacuity and the short parasphenoid, the strong external process of the pterygoid with the transverse articulating with its lower surface, and the position of the palatine vacuity anterior to the middle of the transverse. The characters described by Lees ${ }^{2}$ of the elongate vomers reaching back to take part in the anterior edge of the interpterygoid vacuity, the otic foramen between the squamosal and the quadratojugal, and the position of the quadrate foramen on the lateral surface of the skull have all been questioned by Mehl and Huene ${ }^{3}$ and are so unlike the normal characters of the other Parasuchia that they can not be accepted or discussed until the skull is reexamined. The improbability of the existence of an otic foramen in the position described by Lees is further emphasized by the discovery of the stapes in the normal position of the lower side of the opisthotic in Promystriosuchus.

\section{Comparison With Mystriosuchus.}

This comparison is based on the published descriptions of Mystriosuchus planirostris and $M$. pleiningeri by McGregor and Huene. ${ }^{4}$

The lengths of the prenarial and postnarial portions of the skull of Mystriosuchus are very closely as $5: 2$; the antorbital openings are elongate and extend forward either to the anterior end of the nares (planirostris) or slightly anterior to them (pleiningeri); the nasal septum reaches the level of the skull; the parietals have no posterior bar defining the inner side of the supratemporal opening; the parietals descend to the top

${ }^{1}$ Williston, S. W., Journal of Geology, vol. xi1, p. 696, 1904; Lees, J. H., Journal of Geology, vol. xv, No. 2, p. $121,1907$.

${ }^{2}$ Lees, J. H., The Skull of Paleorhinus, Journal of Geology, vol. xv, No. 2, p. 133, 1907.

${ }^{3}$ Mehl, M. G., Journal of Geology, vol. xxı1, No. 2, p. 157, 1915; Huene, F. v., Neues Jahrb. f. Min. Geol. u. Pal., No. 19, p. 587, 1909.

${ }^{4}$ McGregor, J. H., Memoirs American Museum Natural History, vol. Ix, pt. II, 1906; Huene, F. v., Geologische u. Paleontologische Abhandlungen, N. F., Bd. x, Hft. 1, p. 68, 1911. 
of the opisthotic and the openings look as much backward as upward; the posterior face of the skull is very similar, except for the depressed parieto-squamosal bar; the posttemporal opening is small, and the opisthotics extend out to the squamosal and are

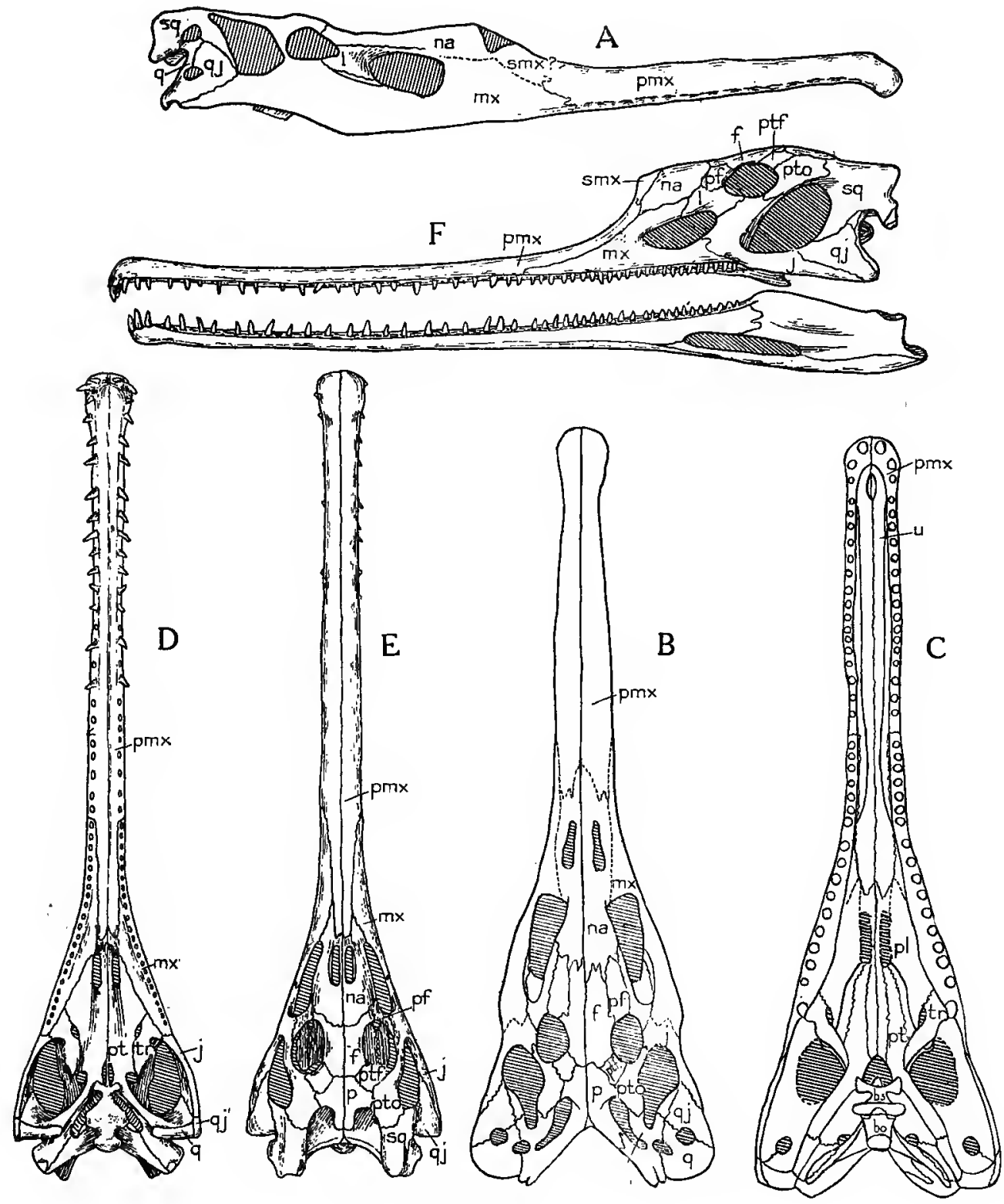

FIG. 23.

Paleorhinus, after Lees. Lettering as usual.
A. Lateral view of skull.
B. Upper view of skull.
C. Lower view of skull. Mystriosuchus, after McGregor.

D. Upper view of skull.

E. Lower view of skull.

F. Lateral view of skull.

overlapped by it. In the specimen of $M$. planirostris, described by McGregor, the small element on the outer side of the distal end of the opisthotic is apparently calcified cartilage; in Promystriosuchus the fragment in this position is true bone; the opisthotic process stands a little higher above the condyle in Promystriosuchus. On the lower 
face of the skull the relation of the transverse to the pterygoid is very different in the two forms. In $M$. planirostris and pleiningeri the transverse lies external to the process of the pterygoid and articulates with it laterally instead of underlying it; the outer corner of the dependent process is formed entirely by the transverse; the palatine foramen is small, but lies anterior to the middle of the transverse; the quadrate process of the pterygoid is shorter and articulates with an elongate process of the quadrate; the suture, as figured by McGregor, lies, at least on the lower face, near to the basisphenoid process of the pterygoid; there is but a small interpterygoid space and the parasphenoid process is short or in large part covered by the pterygoids; the internal nares are directly beneath the external nares; the inner edges of the palatines are elevated, but do not show the rugosity which appears on these bones in Promystriosuchus. It is apparently this elevated edge of the palatines which Huene ${ }^{1}$ refers to as the median edge of the pterygoids.
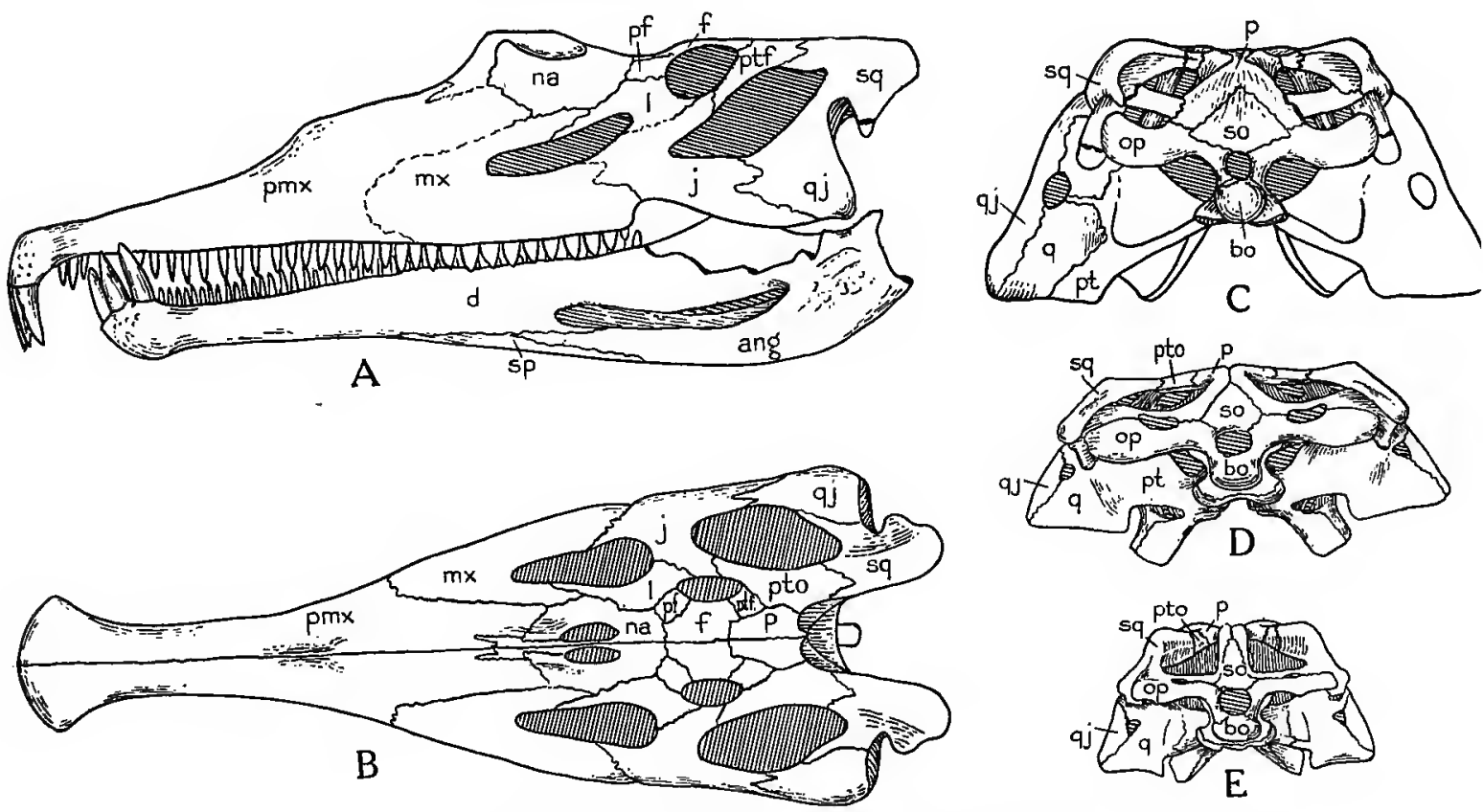

FIG. 24.-Phytosaurus (Machœroprosopus), after Mehl.
A. Lateral view of skull.
B. Upper view of skull.
C. Posterior view of skull.
D. Posterior view of skull of Mystriosuchus, after McGregor.
E. Posterior view of skull of Phytosaurus kappfi.
Lettering as usual.

\section{Comparison With Rhytidiodon. ${ }^{2}$}

Most of the material representing this genus was recovered from the Triassic coal-beds of Egypt, Chatham County, North Carolina. Most of the skulls, as reported by McGregor, are in a very fragmentary condition; a single skull, lacking the anterior end, permits of some comparison. The antorbital opening extends beyond the anterior edge of the external nares; the orbits have a considerable lateral presentation; the parieto-squamosal bar is depressed; the squamosal region extends well posterior to the occipital condyle; the palatine vacuities are at the extreme anterior end of the transverse. 
The figures show this specimen as having no interpterygoid vacuity and no parasphenoid; this is, in all probability, the result of the condition of the specimen. There is an elevated rim to the external nares, and the septum is at the level of the top of the skull. By utilizing a specimen in the New York State Museum, which he assumes to have been of the same size as the one in the American Museum, McGregor determined the prenarial and postnarial proportion to be as $3: 2$.

\section{Comparison with Phytosaurus (Macharoprosopus).}

The specimen described as Machoroprosopus by $\mathrm{Mehl}^{1}$ and regarded by him as congeneric with Belodon buceros Cope is in many ways intermediate between the Mystriosuchid and the Phytosaurid groups of the Parasuchia. The elevation of the posterior half of the rostrum, the posterior position of the nares, and the extreme depression of the parieto-squamosal arch are all characters of the Phytosaurid group, while the long, slender anterior half of the rostrum is distinctly Mystriosuchid-like. The prenarial portion of the rostrum is relatively short, its proportional length to the postnarial portion being as $7.8: 8.3$, or a little less than $1: 1$; the antorbital opening is elongate and reaches almost to the anterior end of the exterr al nares; the parietals have no posterior bar, and the squamosal region is much extended, reaching far behind the condyle; the supratemporal openings look almost entirely to the rear; $\mathbf{M e h}^{2}$ has drawn in outline a rather broad bar separating the supratemporal from the post-temporal openings on the posterior surface of the skull. This is probably correct, as its width is indicated by the broken edges, but, if so, it leaves a much larger post-temporal opening than occurs in any other of the Phytosaurid group.

${ }^{1}$ Mehl, M. G., Quarterly Bulletin University of Oklahoma, n. s., No. 103, 1916.

${ }^{2}$ Mehl, M. G., loc. cit., fig. 3. 


\section{NEW PARASUCHIANS, LEPTOSUCHUS CROSBIENSIS AND LEPTO- SUCHUS IMPERFECTA, FROM CROSBY COUNTY, TEXAS.}

The first skull (Leptosuchus crosbiensis, No. 7522, University of Michigan) is singularly perfect. All of the bones except those of the posterior portion of the upper surface are preserved in place and the loose ones were found close to the specimen. One half of the lower jaw was found overlying the skull, and the posterior portion of the other half was found not far distant. Total length of the skull, $87.5 \mathrm{~cm}$.

The second skull (No. 7523, University of Michigan) is much larger than the first and was found entirely washed out and lying on the surface as a mass of fragments. Some parts had disappeared and the skull as mounted is in part restored. Total length as restored $112 \mathrm{~cm}$.

Skull No. 7522 is so singularly perfect that it warrants a rather full description. It was completely covered when found, the removal of the half of the lower jaw overlying it leading to its discovery. The matrix is a fine yellowish clay broken into innumerable small pieces, between which are sheets of calcite not over $0.1 \mathrm{~mm}$. thick. The skull is slightly compressed, the right side is a little displaced upward, and the bones of the posterior portion are a little distorted. The extremely complex fracturing of the matrix compelled a fracturing of the bone which is only slightly less in degree, but the fragments are all in position. The skull was collected in a block of matrix and has been prepared and mounted by the painstaking and skilful work of Mr. William H. Buettner.

Particularly important is the preservation, in the natural position, of the extremely thin bones of the palatal region. This permits a determination of the complete osteology of the skull.

The upper surface of the skull.-The best idea of the position and relation of the bones may be gained from figure $25 \mathrm{~A}$. The narrow upper surface of the squamosals is in striking contrast with most other forms of the Phytosaurs.

The lateral surface of the skull.- Seen from the side, the premaxillaries are similar in form and relations to the same bones in the majority of the forms of the Mystriosuchid group. The anterior end is sharply down-curved, with a decided notch behind the prominent anterior tusks for the reception of the tusks of the lower jaw. Near the middle of the bone there is a low but very evident prominence on the upper surface. This seems to be a common and normal structure in most, if not all, of the Mystriosuchids. It occurs in all the specimens preserved in the University of Michigan collection and is figured and described by v. Huene in $M$. pleiningeri. Huene attributed the prominence to an accident, but it is clear that it may be a normal feature. The peculiar condition found in this region in specimen No. 7523, University of Michigan, is described below, but is not yet understood.

The articulation with the maxillary starts on the alveolar edge, just posterior to the twenty-third tooth. The surface of the premaxillary is devoid of rough sculpture, unless it be at the extreme posterior end, where it approaches the nasal prominence just anterior to the external nares.

The maxillary has the usual position and relationships. It forms the lower border and the anterior border of the antorbital vacuity and the anterior part of the upper border of the same opening. The portion below the vacuity is smooth and the alveolar edge is convex downward. There are 21 tooth-sockets in the maxillary, which are rounded in the anterior portion, but by the eighth or tenth from the anterior end become decidedly oval in outline. The upper portion of the maxillary is more rugose. The position of the suture between it and the nasals is indicated by the sudden increase in the coarseness of the rugosities, as well as the change in the course of the bone-fibers. 
The exact outline of the nasals is not determinable. The anterior end appears to be opposite a point halfway between the anterior end of the maxillaries and the anterior end of the antorbital vacuity. The bone is marked by a deep radiating sculpture which apparently starts from the region around the external nares, but is more pronounced on the sides of the bone. The eminence of the nose is 2 or 3 centimeters anterior to the

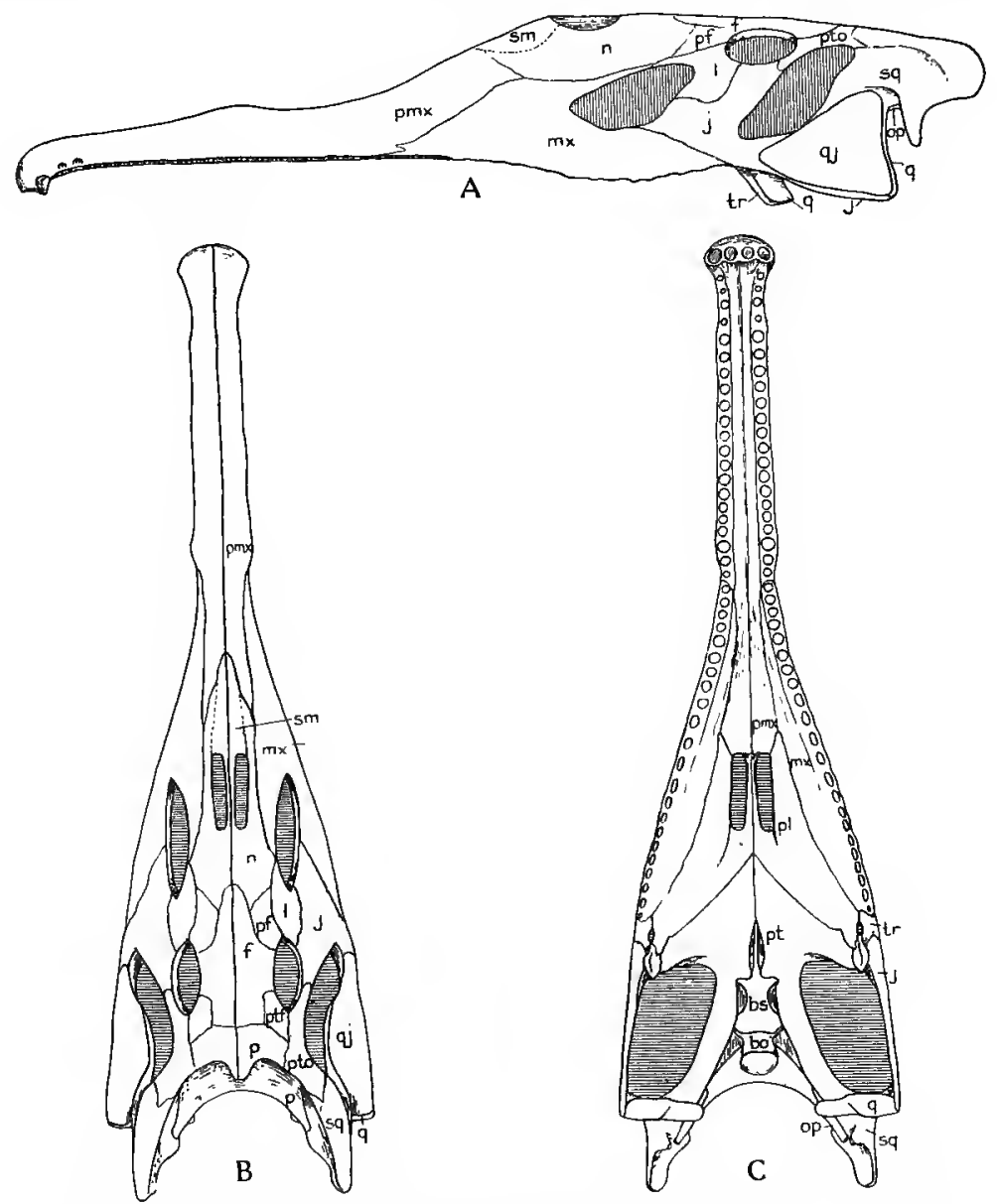

Fig. 25.-Leptosuchus crosbiensis, No. 7522, U. of Mich. $\quad \times 0.16$.
A. Lateral view of skull.
B. Upper view of skull.
C. Lower view of skull. Lettering as usual.

external nares, and from this point the front slopes gently down to join the premaxillaries. The lower edge of the nasals is excluded from the upper edge of the antorbital vacuity by the juncture of the maxillary and the lachrymal.

It is impossible to determine the exact outline of the septomaxillaries. It is evident from the direction of the bone-fibers that a distinct element is present in front of the nares, perhaps taking part in their anterior edge, but the sutures have not been made out with certainty.

The jugals articulate with the maxillaries by a broad sutural surface which underlies the posterior end of the maxillary. A broad vertical process rises to articulate with the postorbital and a relatively slender bar extends backward to articulate with the quadratojugal and the quadrate. The articulation with the quadratojugal is as described previously by the author. ${ }^{\mathrm{I}}$ The quadratojugal is deeply cleft on the lower edge and

${ }^{1}$ Case, E. C., Journal of Geology, vol. xxviri, p. 530-531, 1920. 
the jugal is deeply dovetailed into it. This method of articulation is confirmed by its presence in two specimens in the University of Michigan collection. The jugal is visible along the lower edge of the skull to the posterior end of the quadrate.

The quadratojugal is a nearly triangular plate which covers the outer side of the quadrate almost entirely and takes slight part in the formation of the posterior edge of the lateral temporal fenestra.

The quadrate appears on the side of the skull only at the posterior lower corner and as a thin edge at the posterior line of the skull.

The squamosal has a very large lateral presentation and a correspondingly small presentation on the upper surface, apparently less than in any previously described form. The lateral surface is nearly vertical; its posterior portion extends $52 \mathrm{~mm}$. beyond the end of the opisthotic, forming a very decided projection at the posterior end of the skull. From the lower edge of this projecting portion there is a strong descending process, the anterior edge of which forms the posterior border of the otic notch. Within the notch the upper part of the quadrate and a portion of the distal end of the opisthotic can be seen from the side.

The posterior face of the skull.-This face of the skull is more distorted than any other, due to the upward movement of the right side in the compression accompanying fossilization. The occipital condyle is forced somewhat to the left and the bones above the condyle are somewhat broken and displaced. It is, however, easy to restore the original condition.

The parietals descend very abruptly and lie upon the upper edge of the opisthotic. The post-temporal opening was either entirely occluded or was represented by a small opening not greater than a large foramen. The outer edge of the parietal articulates with the anterior edge of the process described on the inner side of the squamosal.

The supraoccipital is a small triangular bone which in the specimen is separate from the exoccipital-opisthotic on the left side, so that the outline is plain.

The exoccipitals are separated from the basioccipital by distinct sutures, but are still in position. The lower portions meet in the median line, excluding the basioccipital from any part in the floor of the foramen mangum, at least its posterior part. There is no suture visible between the exoccipitals and the opisthotics.

The opisthotics are expanded at the inner end, where they contain a portion of the cavity of the inner ear. Beyond the exoccipital portion they contract rapidly, and the outer half is spatulate in form, with the outer end reaching to the extreme outer edge of the squamosal, but, in the specimen, not visible in a lateral view of the skull. The lower edge of the inner third is marked by a distinct groove, which evidently protected the stapes in part. This groove becomes deeper toward the inner end and is continued on the lower edge of the prootic.

The squamosals. - The inner side of the squamosal is best seen from the posterior surface. This face is nearly vertical, but is divided by a horizontal ridge which originates near the posterior end and, growing more prominent as it advances, terminates near the middle of the length of the squamosal. To the anterior end of this ridge is articulated the distal end of the parietal. Immediately below the ridge lies the distal end of the opisthotic, which is here a narrow, oval plate with its greatest diameter nearly vertical. The extremity of the opisthotic reaches nearly to the posterior end of the descending process from the squamosal, but is not visible from the outer side. The upper outer corner of the quadrate articulates with the squamosal by a rounded head just anterior to the end of the ridge described on the inner surface of the squamosal.

The quadrates. - These are much as described in other specimens. Each quadrate stands upright in the skull, with a broad posterior face, which contracts toward its 
upper extremity. The articular face for the lower jaw is convex antero-posteriorly and divided into two parts by a sharp median elevation which runs obliquely from within outward and backward. The suture with the quadratojugal is vertical and nearly straight, running from the lower extremity of the bone nearly to the top. There is a large quadrate foramen at about the middle point of the suture, which runs slightly downward and forward. On the inner face there is a slight concavity just above the articular surface and then a strong spout-like process, concave downward, which extends forward for a short distance, but not nearly so far as is indicated by v. Huene in $M$. pleiningeri. The inner edge of this process rises gradually, shortening as it rises, and disappears on the anterior face of the quadrate at about the middle of its height. At the origin of this process and above and outside it there is a fairly deep pit. The posterior edge of the quadrate process of the pterygoid fits over this process on the lower and inner side. The upper portion of the outer edge of the quadrate is inclined inward slightly, and the upper extremity terminates in a smooth, nearly hemispherical face which fits into a pit on the lower surface of the squamosal. There can be no doubt that there was a certain amount of motion possible at this point, which would be permitted by the sliding of the quadrate process of the pterygoid on the spout-like process of the quadrate. This reveals a greater flexibility of the posterior portion of the skull of the Parasuchia than has previously been suspected. Versluys ${ }^{1}$ regarded the skull of the Parasuchia as akinetic, but there is a possibility of movement between the parietal and supraoccipital and a possibility of movement of the pterygoids on the basipterygoid processes of the basisphenoid; these possibilities, taken with the evidence of the movable quadrate and the smooth face between the pterygoid and the transverse, indicate that the skull of the Parasuchia was certainly kinetic.

The lower surface of the skull.-In this portion of the discussion is included the description of the walls of the brain-case and the narial region.

The basioccipital-basisphenoid.-On the lower surface the basioccipital differs decidedly from specimens Nos. 7261 and 7505, described on a later page. In these specimens the lower surface of the neck of the condyle is smooth and rounded, without any ridges running forward to the tubera basioccipitalia. In No. 7522 the lower surface of the neck is flat, with two prominent rounded ridges on the sides of the neck running from the condyle to the tubera. This forms a decided concave area with a nearly flat bottom, but a little more depressed on the sides. A similar condition is indicated in the imperfect specimen, No. 7474.

The tubera are prominent and formed by the basioccipital and basisphenoid. The basipterygoid processes are well formed and project outward, downward, and forward; at the posterior end of each there is a sharp, low prominence; such prominences are described in No. 7257, and their position is indicated in the other specimens by more or less evident areas of slight rugosity. The space between the basipterygoid processes is occupied by a low, sharp ridge which is continuous with the very sharp lower edge of the parasphenoid rostrum. This condition is quite different from the other specimens. In No. 7257 the space is occupied by three ridges; the middle one, somewhat asymmetrically placed on the right side, was probably continuous with the lower edge of the parasphenoid rostrum; in No. 7261 there are faint ridges on each side and no median ridge; in No. 7505 there is the faint beginning of a median ridge; in No. 7474 the region is not preserved.

The parasphenoid rostrum starts to rise almost directly upward in the skull; the proximal portion of the lower edge is nearly at right angles to the line of the basicranial axis, but quickly assumes a horizontal position. The lower edge is very sharp. There 

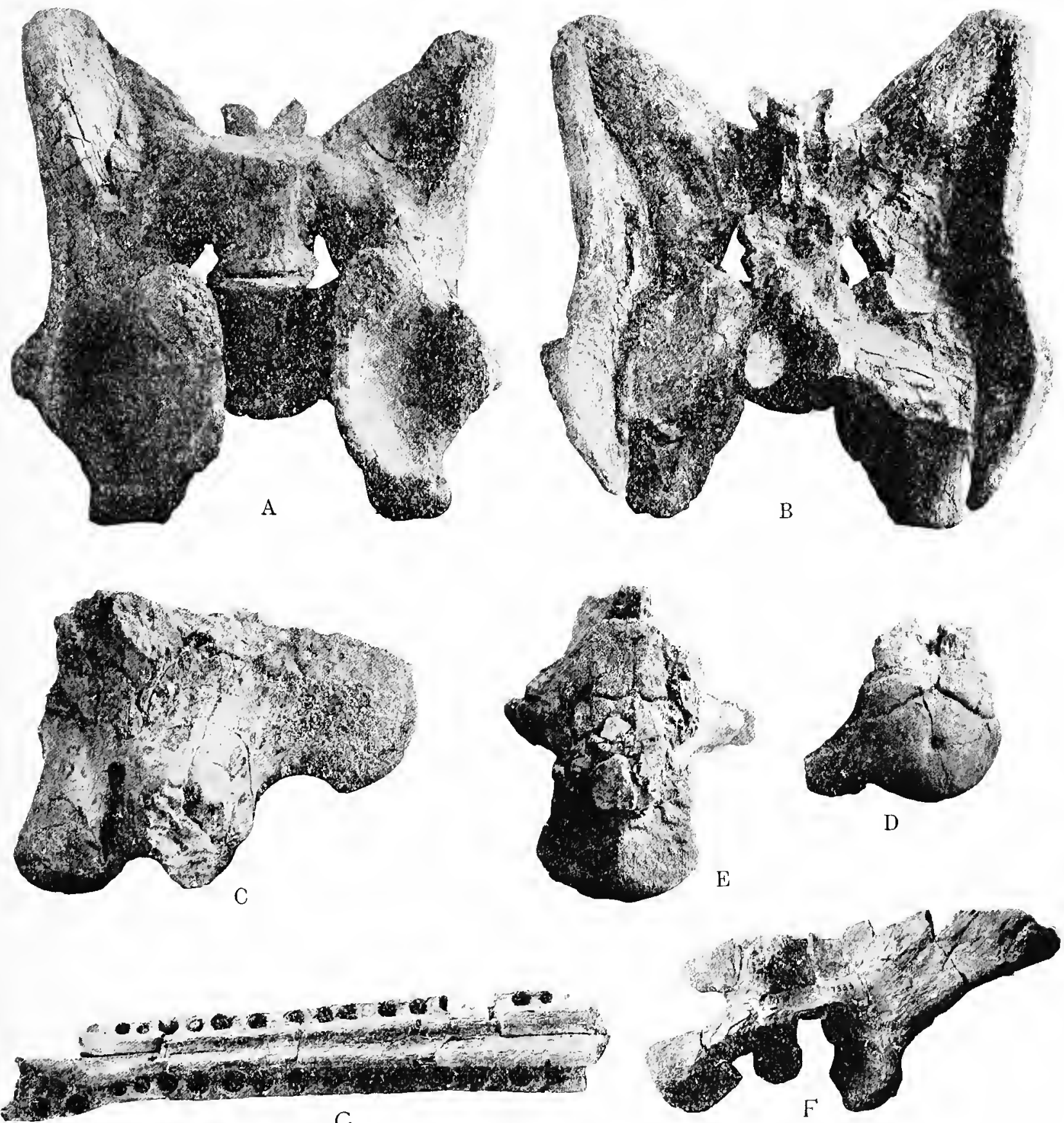

C.

A. Lower surface of sacrum of a phytosaur, No. 7266, U. of Mich. $\times 0.3$.

B. Upper surface of the sacrum shown in A.

C. Lateral view of the basicranium of a phytosaur, No. 7261, U. of Mich. $\times 0.72$.

D. Posterior view of the basicranıum of a phytosaur, No. 7474. $\times 0.75$.

E. Upper surface of a basicranium of a phytosaur, No. 7505, U. of Mich. $\times 0.67$.

F. Outer surface of the ilium of a phytosaur, No. 7333, U. of Mich. $\times 0.38$.

G. Lower surface of snout of a phytosaur, No. 7505, U. of Mich. $\times 0.36$. 

is no indication of a composite structure of the rostrum, i. e., a presphenoid and a parasphenoid portion, as described by Huene in $M$. plieningeri.

The side of the basioccipital-basisphenoid.-The structure of the sides of these bones coincides very closely with those described in other specimens. Between the ridge connecting the side of the condyle with the tubera and the suture between the basioccipital and basisphenoid there is a deep groove passing upward and terminating, apparently, in the otic opening. Just posterior to the upper end of this groove and in the exoccipital bones, which are in place, there are two foramina-a posterior, larger for the exit of the XII nerve, and an anterior, smaller, which probably transmitted the IX, X, and XI. Between the tubera and the basipterygoid process, on each side, are the openings of the foramina for the internal carotid arteries, which open into the base of the small hypophysial cavity.

The upper surface of the basioccipital-basisphenoid.-The exoccipitals come together below, forming the floor of the foramen magnum; anterior to these can be seen the very distinct suture between the basisoccipital and basisphenoid. On the right side this suture terminates in a deep pit entirely upon the upper surface of the bones. The left side is partly obscured by the prootic, but the pit is apparently present, showing that its occurrence on the right side is normal. The presence of the pit can not be confirmed from other specimens, but its presence is suggested in No. 7505. The sella turcia is prominent just posterior to the hypophysial pit. On either side of the pit the edges of the basisphenoid are thickened, forming a strong articulation with the prootic.

The prootics.-The prootic of the left side is in place; that of the right side was found detached, but it fits well into its position. The posterior portion extends backward in a point for some distance, and articulates with the opisthotic both above and below; an epiotic is not distinguishable as a separate element. The upper edge is thickened for attachment to the parietal, and the lower and anterior edges are thickened for attachment to the basisphenoid. Near the anterior end is the foramen for the $\mathrm{V}$ nerve; this is a vertical oval with the greatest diameter nearly twice as long as the horizontal diameter. The portion of the bone anterior to the large foramen is bent inward nearly at right angles, to form the anterior wall of the brain-case. The two bones do not meet in the median line. On the anterior face of this portion of the bone, at about the level of the lower edge of the large foramen (in the undistorted bone of the right side), there is a small foramen which probably transmitted a branch of the V. On the inner side of the prootic, posterior to the large foramen, is a large and deep pit which sheltered a portion of the inner ear. When the bone is in position this pit comes into close association with two pits on the anterior inner end of the opisthotic and the large pit on the suture between the basioccipital and basisphenoid. On the lower edge there is a groove continuous with the groove on the lower edge of the opisthotic.

The pterygoids show the usual tripartite form, but are rather different in shape from that common to most of the reptiles. The middle portion of the bone is thickened and has a decided notch which fits, loosely, the basipterygoid process of the basisphenoid. The quadrate process is a thin plate standing nearly vertical in the skull, which extends backward and slightly outward and articulates with the pterygoid process on the inner side of the quadrate. The outer process is fairly heavy. Its anterior edge is deeply concave, giving the whole process a distinctly crescentic form. The process extends outward, downward, and backward. The distal end is broad and very thin and lies upon the upper surface of the distal portion of the transverse, meeting it by a very smooth, flat surface which undoubtedly permitted free movement. The anterior process extends forward and quickly becomes a thin vertical plate. In the 
specimen this plate lies directly in contact with the parasphenoid process and rises considerably above it, but not so high as figured by v. Huene. ${ }^{1}$

The upper edge of the pterygoid rises slowly, forward, from the median portion and passes above the upper edge of the parasphenoid process at about its middle point. The anterior portions of the pterygoids are joined at their lower edges, forming a $V$, which lies between the anterior portions of the palatines.

The epipterygoid.-There is no evidence of an epipterygoid, either of a separate bone or of an articular space upon the pterygoid. If such a bone were present, as figured by Huene ${ }^{2}$ it is remarkable that no evidence remains in a specimen otherwise so complete.

The transverse.-This bone is radically different, both in position and form, from the conception which has been derived from the study of crushed specimens. It stands nearly vertical in the skull, slanting slightly backward as it descends. The upper end is attached to the maxillary and the jugal. The upper portion of the shaft is a rather thin oval in section. Below, the bone becomes broader and thicker, with a prominent, heavy supporting ridge on the lower surface. The upper surface of the distal end is smooth and flat, meeting a similar face on the pterygoid. The anterior outer edge of the smooth face of the transverse is terminated by an elevated shoulder which limited the direction of motion between the bones. The palatine was attached to the posterior end of the inner side of the transverse by a close suture, forming a rigid joint; this fixed the transverse in its position and allowed motion in the pterygoid only. The transverse forms the greater portion of the descending process of the palatine region; the pterygoid is visible from the side only as the thin edge of the distal portion of the descending process.

On the inner side of the jugal, or the jugal and the postorbital, there is a thin, prominent extension of the bone which forms the anterior border of the lateral temporal opening; this gives the bone an L-shaped section and contributes largely to its strength. The lower portion of this extension becomes quite heavy just posterior to the last of the maxillary teeth and is penetrated by a large foramen running antero-posteriorly for a short distance. The transverse is attached just below this heavy extension. Just anterior to its attachment to the distal end of the palatine the transverse is free for a short distance, but the bones are united again, leaving a small palatine fenestra opposite the middle of the shaft of the transverse.

The palatines are rather heavy posteriorly, where they unite with the transverse, but soon become more thin and plate-like. The median portion of the palatine is thicker, and this portion forms the characteristic ridge on the lower surface of the palate and the outer edges of the choanæ. On the inner side of the heavier portion is the shoulder described and figured by $\mathrm{v}$. Huene as supporting the lower edge of the pterygoid. The palatine sends out two very thin extensions: an upper, which overlies the pterygoids for a short distance, not nearly so much as is indicated by v. Huene, and an outer, which unites with the palatine plate of the maxillary. The upper plate forms the posterior and outer borders of the choanæ. Near the middle of the plate there is a strong vertical ridge which ends upon a prominence upon the upper edge. Just anterior to this ridge the palatine divides into two vertical plates. The upper edge of the inner plate descends rapidly and soon joins its fellow of the opposite side, leaving a shallow V-shaped channel on the upper surface; the two together form the septum which divides the choanæ. The outer plate runs forward and joins the premaxillaries. The lower, or horizontal, plate of the palatine is deeply concave just below the heavier median portion, forming a channel which runs as far forward as the anterior end of the choanæ. This channel

\footnotetext{
${ }^{1}$ Huene, F. v., Beiträge zur Kenntnis und Beurtheilung der Parasuchier, Geol. u. Paleont. Abhandlungen, N. F., Bd. $x$, fig. 4, 1911.

${ }^{2}$ Huene, F. v., loc. cit., figs. 5 and 6.
} 
may be somewhat exaggerated by pressure in the specimen, but even in the normal skull it was a prominent feature.

The vomers do not appear upon the lower surface of the skull. This is very different from the condition of the palate as figured by the various authors in the described forms. It seems probable that the interpretation of the vomer as appearing on the lower surface of the skull is due to the condition of the specimens. In the deep V formed by the approximation of the pterygoids in their anterior portions there is evidence of a pair of very slender bones which have the same relations, i. e., they meet below to form a $V$; these are apparently the much-reduced vomers. The position and reduced condition of the vomers, the articulation of the palatine with the anterior bones of the roof of the mouth, in this case the premaxillaries, and the elevation of the pterygoids are very suggestive of the condition in the Crocodilia.

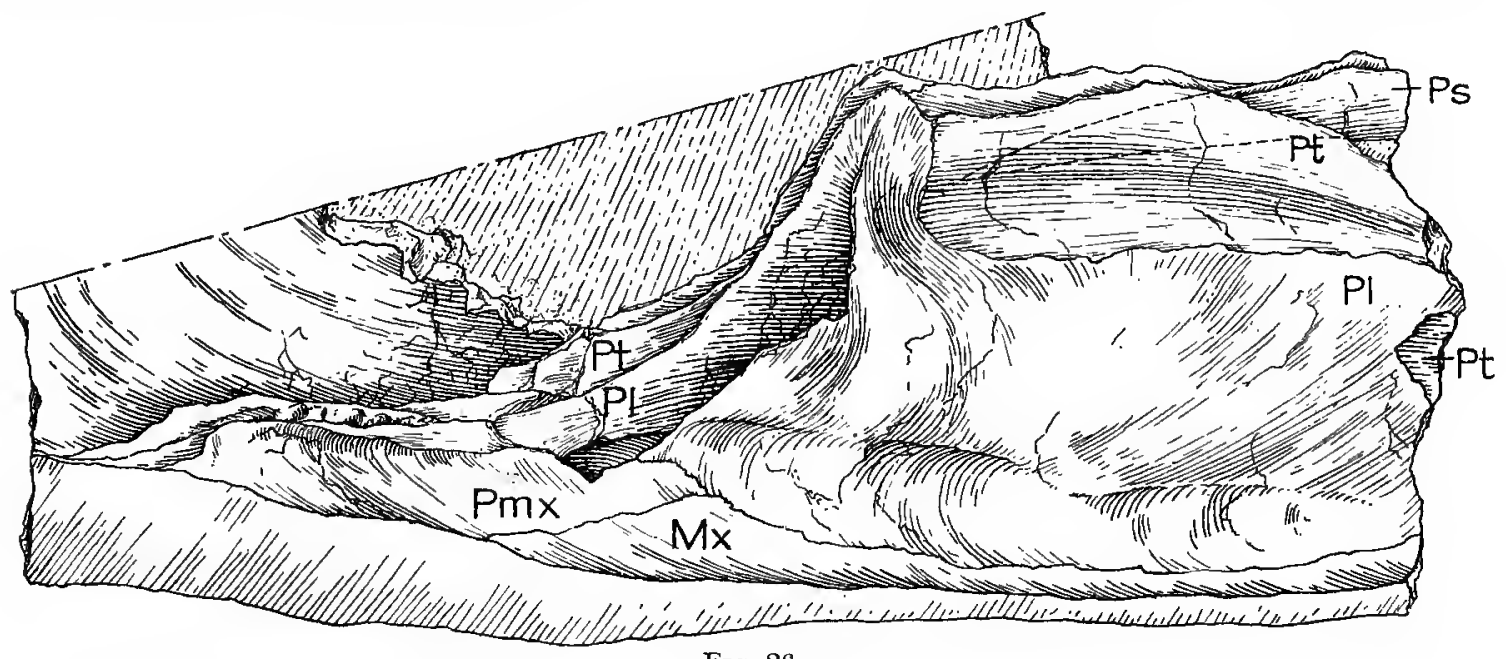

FIG. 26.

Leptosuchus crosbiensis. Left side with outer bones removed to show the structure of internal nares. $\quad \times 0.8$. Lettering as usual.

The choance-- The openings of the internal nares are separated by a bar composed of the palatines, pterygoids, and probably the vomers. There was a distinct space between the internasal septum of the external nares and the septum between the choanæ below. Huene's description of this region is fairly accurate, but he has not recognized the exact relations of the pterygoids, palatine, and vomers, and has not recognized that the palatines extend forward to meet the premaxillaries. The bar between the choanæ is formed by three bones, all paired. The lower pair is the palatine portion. These bones gradually approximate; the posterior portion of the bar is V-shaped, the anterior portion a complete oval bar with a complete upper edge. Between the arms of the $V$ formed by the palatines there is a second $V$ formed by the anterior portion of the pterygoids, which retain this form to the anterior end The lower edge of the pterygoid $V$ rests upon the upper edge of the palatine bar at the extreme anterior end. Between the arms of the $V$ formed by the pterygoids there is evidence of a third $V$, formed by the vomers.

The maxillaries.-The alveolar edge of the maxillaries is supported on the inner side by a strong, horizontal palatine plate. There are 21 sockets in the maxillary, the anterior of. which are rounded in section, but the posterior 10, or more, are oval. The strong median prominences on the premaxillaries gradually die out upon the palatine processes of the maxillary.

The premaxillaries.-The anterior end of the premaxillary is but slightly expanded; it accommodates two enlarged sockets for the tusk-like anterior teeth. Posterior to 
these sockets the premaxillary narrows, and there are three small sockets, rather on the side of the bone than on its lower surface. There are 23 sockets in the premaxillary; in the anterior portion these are rather more on the side of the bone, but by the middle of the series they come to lie entirely on the lower surface. The middle of the snout is occupied by the two prominent rounded ridges which are considered to have acted as buffers to prevent injury to the jaws when they were snapped violently together.

The second skull (Leptosuchus imperfecta, No. 7523, University of Michigan) is much larger than the first, measuring approximately $112 \mathrm{~cm}$. over all. There is a break in the continuity of the snout, and it is impossible to determine the exact length, though only a very small part, if any, can be missing. The whole skull seems proportionately stouter than that of the smaller skull. As certain portions must be restored, it is desirable to designate this as a new species only tentatively, until more detailed study can be made. One very remarkable feature appears in this skull: There is an elevation on the upper surface of the snout, somewhat farther back than in the others in the collection. This elevation is decidedly rugose and its upper surface is excavated by a nearly hemispherical pit with a smooth inner surface. The pit is $5 \mathrm{~cm}$. long and $4 \mathrm{~cm}$. wide, extending into the symphysis of the premaxillary bones. The condition is so remarkable and unexpected that the pit was at first taken for the opening of the external nares, but this is easily demonstrated to be impossible. v. Huene ${ }^{1}$ described a somewhat similar condition in a specimen of $M$. pleiningeri. There is, in his specimen, a rough area near the anterior end, which he attributed to a fracture or injury. In the center of this rough area he found a nodule of matrix. From the evidence cited in this paper it is apparent that an elevation on the premaxillary portion of the snout of members of the Mystriosuchid group of Phytosaurs is a normal thing, but in none of the other specimens is there any evidence of a pit. The region of the snout surrounding the pit is rugose, but without any evidence of fracture or injury. The meaning of this apparent abnormality is at present entirely conjectural.

Paleorhinus:

\section{Contrasting characters in the skulls of the known Phytosaurs. ${ }^{2}$}

1. Post-temporal arcade depressed.

2. Antorbital opening posterior to the external nares rounded.

3. Length of the prenarial portion of skull is to the postnarial portion as $1+: 1$.

4. Post-temporal fenestra small.

5. Posterior bar of parietal short.

6. External nares with elevated rim; internal nares posterior to external.

7. Squamosals not greatly extended behind.

8. Orbits look up and out.

9. Septomaxillary (?).

10. Premaxillary and maxillary teeth 36 , rounded in section.

11. Palatines with inner edge elevated into a ridge. Palatine vacuity anterior to the middle of the transverse.

12. Transverse overlaps the external pterygoid process below.

13. Vomers extend back to interpterygoid vacuity.

14. Parasphenoid process short (?).

15. Interpterygoid vacuity small.

Angistorhinus:

1. Post-temporal arcade at the level of the top of the skull.

2. Antorbital opening with the anterior end even with the anterior end of the external nares. Oval. Anterior end acute, posterior end rounded.

3. Length of the prenarial portion of the skull is to the postnarial as $5: 3$.

4. Post-temporal fenestra largest of any known form.

5. Posterior bar of the parietal very short.

6. External nares with elevated rim, low septum; internal nares a little posterior to the external.

7. Squamosal considerably extended backward and with a strong descending hook; overhangs the bones below. 8. Orbits look upward more than outward.

${ }^{1}$ Huene, F. v., Beiträge zur Kenntnis und Beurtheilung der Parasuchier, Geolog. u. Paleontlg. Abhandlungen, N. F., Bd. x, s. 5, fig. 2, 1911.

2 The same eharacter is described under the same number under each genus. The characters given are as described by the authors. Some of these must be modified by further study. The probable errors are in the deseription of the palatal region. 
9. Septomaxillary present.

10. Premaxillary and maxillary teeth, $41 \pm$, round and oval, with serrate edges.

11. Palatine with inner edge elevated into a ridge. The palatine vacuity between the palatine, pterygoid, and
the anterior half of the transverse.

12. Transverse meets the external edge of the pterygoid. No external process of the pterygoid.
13. Vomers do not appear behind the internal nares.

14. Parasphenoid process long, covered anteriorly by the pterygoids.

15. Interpterygoid vacuity short, narrow.

Phytosaurus (Machoroprosopus):

1. Post-temporal arcade depressed; not visible from above.

2. Anterior end of the antorbital vacuity anterior to the external nares; elongate oval.

3. Length of the prenarial portion of the skull is to the postnarial as $3: 2$.

4. Post-temporal fenestra large.

5. No posterior bar on the parietal; the postorbital takes the place of the parietal on the posterior edge of the skull.

6. External nares without elevated rim, septum at the level of the top.

7. Squamosal region greatly extended posteriorly, with a strong hook.

8. Orbits look outward more than upward; slightly forward.

9. Septomaxillaries large, united in front and form a prominence, "if correctly determined" (Mehl).

10. Premaxillary and maxillary teeth $36-38$; both rounded and oval in section.

11. Palatal surface of the skull unknown.

Mystriosuchus:

1. Post-temporal arcade depressed.

2. Anterior end of antorbital opening anterior to the nares; nares over the middle of the opening.

3 . Length of the prenarial portion of the skull is to the postnarial as $5: 2$.

4. Post-temporal fenestra small.

5. Posterior bar of the parietal depressed, lying on the opisthotic, long.

6. External nares with elevated rim, septum at upper level; internal nares directly under the external nares.

7. Squamosal region extended posteriorly.

8. Orbits look outward more than upward; upward in M. pleiningeri.

9. Septomaxillary present.

10. Premaxillary and maxillary teeth $47-50$, both rounded and oval in section.

11. Inner edge of palatine elevated; palatine vacuity opposite the middle of the transverse.

12. Transverse underlies the external process of the pterygoid.

13. Vomers do not extend posterior to the internal nares, or very little.

14. Parasphenoid process fairly long, anterior end covered.

15. Interpterygoid vacuity small.

Promystriosuchus:

1. Post-temporal arcade at the level of the skull.

2. Anterior end of the antorbital opening opposite middle of external nares; elongate oval.

3. Length of prenarial portion of the skull is to the postnarial portion as $3: 2$.

4. Post-temporal foramen small.

5. Posterior bar of the parietal long.

6. Rim of external nares elevated, septum low; position of the internal nares posterior to external.

7. Squamosal region not greatly extended posteriorly.

8. Orbits look upward, perhaps in part due to crushing.

9. Septomaxillary (?).

10. Premaxillary and maxillary teeth 47 ; both oval and rounded in section.

11. Inner edge of palatine raised and rugose. Palatine vacuity small, near middle of transverse.

12. Transverse underlies the outer process of the pterygoid.

13. Vomers (?).

14. Parasphenoid process long; anterior end probably covered by the pterygoids.

15. Interpterygoid vacuity long.

Leptosuchus:

1. Post-temporal arcade depressed.

2. Antorbital opening with the anterior end even with the anterior end of the nares; oval in outline.

3 . Length of the prenarial portion of the skull is to postnarial portion as $3: 2$.

4. Post-temporal fenestra small.

5. Posterior bar of the parietal long, lying on the opisthotic.

6. External nares without rim, septum at level of the skull. Internal nares directly below the external.

7. Squamosal extended posteriorly with a strong descending process; overhanging the bones below.

8. Septomaxillary present.

9. Orbits look upward and outward.

10. Premaxillary and maxillary teeth 44 ; both rounded and oval in section.

11. Inner edge of palatine strong, a low ridge; palatine foramen small, opposite middle of transverse.

12. Transverse underlies the pterygoid.

13. Vomers do not appear on the palatal surface.

14. Parasphenoid process long, covered anteriorly by the pterygoids.

15. Interpterygoid space short and narrow. 


\section{DESCRIPTION OF ISOLATED BONES OF PARASUCHIANS.}

Many isolated bones were found in the beds in Crosby County, Texas, and a few in the Bad Lands west of San Jon, New Mexico. Some of these are described and figured below:

An interclavicle (No. 7442, University of Michigan) found by Mr. Paul Miller in the Bad Lands 5 miles west of San Jon, New Mexico, resembles in general the interclavicle of Mystriosuchus planirostris, figured by McGregor. ${ }^{1}$ The blade is stouter ard the articular faces for the claricles are deeper and larger. The anterior portion is heavily rugose on the lower side, and the dividing septum between the two articular faces is elevated and strong. The distal end is incomplete, but enough is preserved to show that the whole bone was shorter and wider than in $M$. planirostris. The upper face of the blade is gently convex and covered by fine radiating lines in the posterior half. The lower surface of the bone is gently convex in front, but the posterior half is nearly flat. This portion is marked by rough, radiating rugosities imposed upon a sculpture of very fine lines. The whole bone is $216 \mathrm{~mm}$. long as preserved, and could not have been a very great deal longer when complete (fig. $27 \mathrm{~A}$ ).

A second interclavicle (No. 7313, University of Michigan) was found in the same region; it is very imperfect, but indicates the presence of a very large animal, in which the posterior extension of the interclavicle was much greater than in the one described and figured above.

There are five ilia and partially complete pelves (Nos. 7244, 7266, 7322, 7333, 7470 ), all in the University of Michigan collection. Four of these are so decidedly different that they indicate the presence of different forms of at least specific value. They are described separately below.

No. 7322 is a perfect ilium from the right side, discovered in the breaks of Sand Creek, Crosby County, Texas. It is shown in figure $27 \mathrm{~B}$; plate 13, figure A. The anterior extension of the upper edge is somewhat elongated and down-curved; it extends as far forward as the articulation of the lower anterior edge of the ilium with the pubis. This hook-like extension is rather broad above, but not nearly as broad as in some of the other ilia. The lower edge of the posterior extension of the ilium extends forward at a gentle angle to form the articulation with the ischium. The extreme posterior edge of this slanting surface is curved inward, giving a broad posterior face inclined backward and outward. The cotylus is very deep and the faces for the articulation with the ischium and pubis meet at a gentle angle or on the surface of a broad curve. The upper edge of the blade is moderately broad, and the anterior face of the blade rises almost directly from the upper edge of the cotylus. The inner face is somewhat water-worn and the articulations for the sacral ribs are in part destroyed, but it is apparent that they stood very much lower upon the bone than in other specimens and that the whole blade of the bone was more slender.

No. 7244, also from Sand Creek, Crosby County, Texas, is very different in form from the preceding (fig. $27 \mathrm{c}$; plate 13, fig. B). The anterior process of the blade of the ilium is very short, not reaching halfway to the articulation of the ilium with the pubis. The extremity does not turn downward at all, but is directed slightly upward through its whole length. The upper edge of the blade is relatively thin and slightly rugose on its anterior face. The whole blade is more than twice as thick as in the preceding specimen, for on the inner side of the bone there is a concave area looking inward and upward before the articular faces for the sacral vertebræ begin. The posterior process extends almost directly backward; from the articulation with the ischium the

${ }^{1}$ MeGregor, J. H.. Memoirs American Museum Natural History, vol. Ix, part II, fig. 9, 1906. 

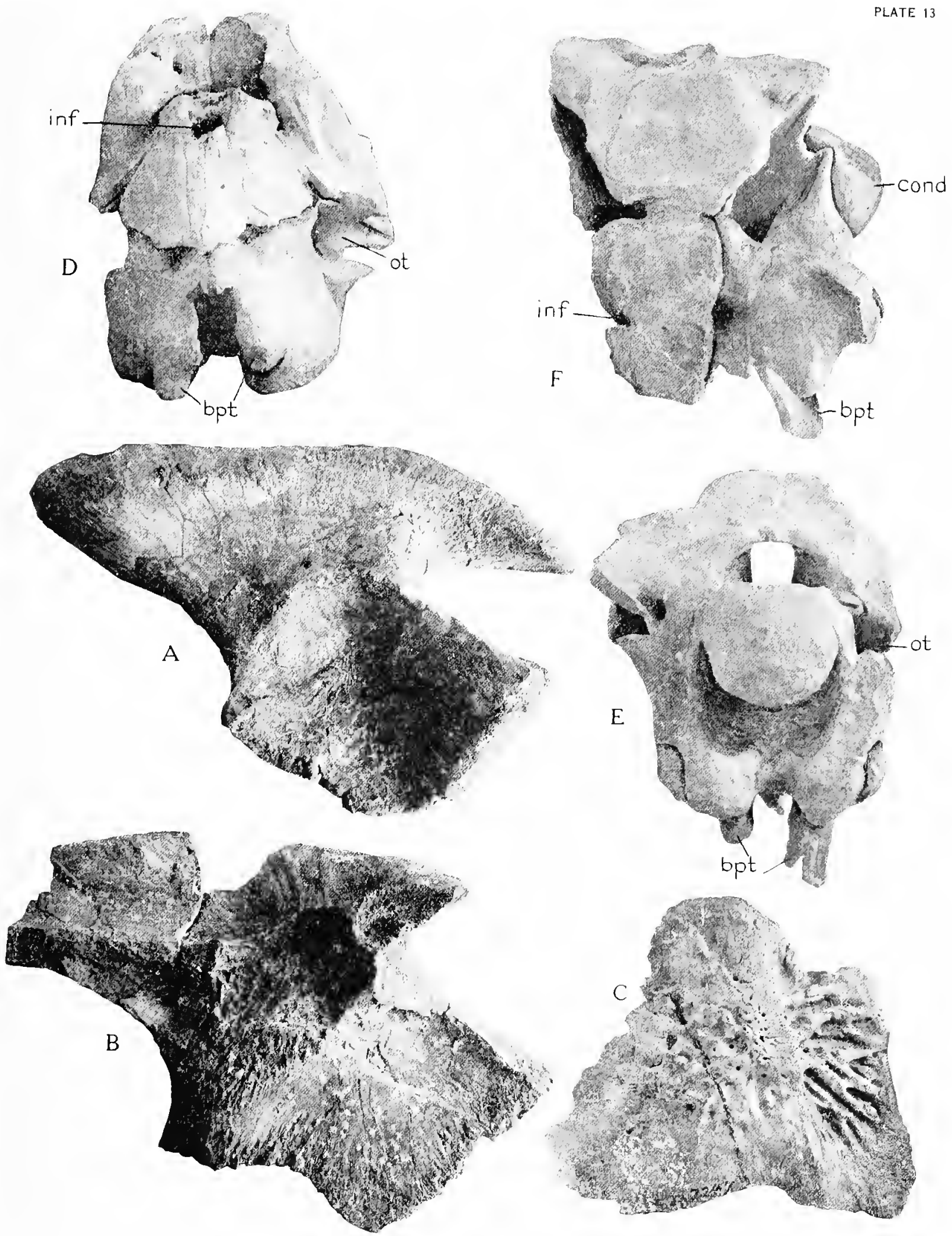

A. Outer surface of ilium of a phytosaur, No. 7322, U. of Mich. $\times 0.54$.

B. Inner surface of ilium of a phytosaur, No. 7244, U. of Mich. $\times 0.45$.

C. A plate of dorsal armor of a phytosaur of the Mystriosuchid group, No. 7247, U. of Mich. $\quad \times 0.8$.

D. The cranial region of skull of a small dinosaur, Coelophysis sp., No. 7473, U. of Mich. $\times 0.9$.

E. Lower view of D. F. Lateral view of D.

inf., cavity for infundibulum; ot., otic region; bpt., basipterygoid process of basisphenoid; cond., occipital condyle. 
lower edge runs upward and forward for a short distance and then turns directly backward. The posterior end is broken away and lost; so the total length of the process is uncertain, but it was evidently quite long. The lower edge of the process is turned inward, as in No. 7322, but in this specimen it looks almost directly downward rather than down and back. The cotylus is not so deep and the faces for the ischium and pubis meet in a sharp angle. On the inner face (see plate 13, fig. B) the upper part of the blade of the ilium is deeply concave; the lower edge of the concavity marks the upper edge of the articular surface for the sacral ribs. Near the anterior end there are two deep,

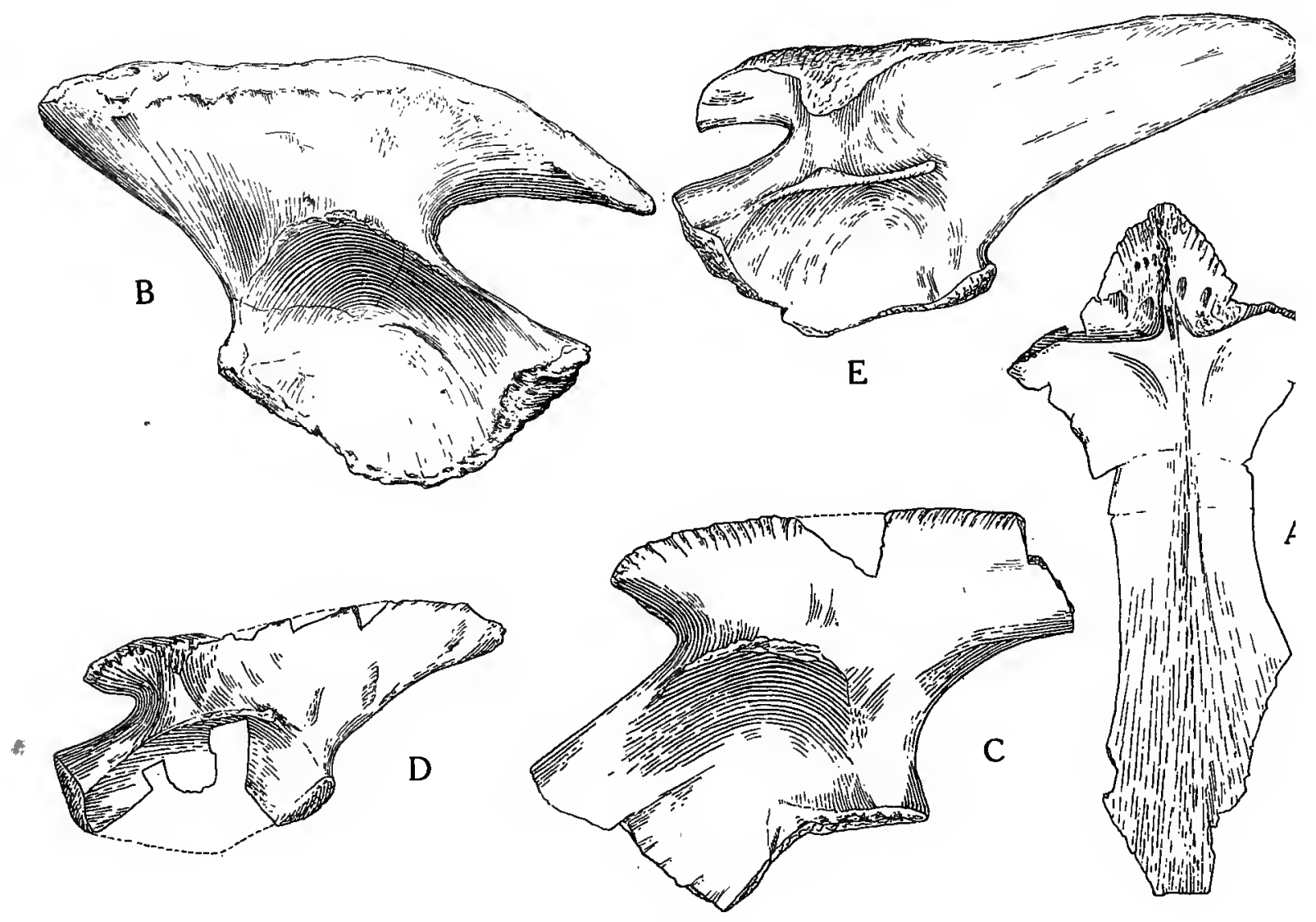

FIG. 27.

A. Lower surface of interclavicle, No. 7442, U. of Mich. $\times 0.3$.

B. Right ilium, outer side, No. 7322, U. of Mich. $\times 0.3$.

C. Left ilium, outer side, No. 7244, U. of Mich. $\times 0.3$.

D. Left ilium, outer side, No. 7333, U. of Mich. $\times 0.3$.

E. Left ilium, outer side, No. 7266, U. of Mich. $\times 0.3$.

rugose pits below this edge, marking the place of insertion of the distal ends of the sacral ribs. Below the posterior pit there is a wide rugose surface which received the posterior half of the distal end of the second rib. Above this surface the lower edge of the concave surface extends back as far as the posterior end of the broken bone; it evidently extended to the extremity in the perfect specimen. The whole bone is much heavier than in No. 7322, the anterior edge just below the anterior process of the upper edge being exceptionally thick.

No. 7333 differs from either of the previously described forms in that the height is much less relative to the length (fig. $27 \mathrm{D}$; plate 12, fig. $\mathrm{F}$ ). The length of the anterior 
process of the crest is intermediate in length between that of Nos. 7322 and 7244, reaching about halfway to the articulation with the pubis. This process is much thinner on the upper edge even than No. 7322, as the outer side is beveled by a rough surface. The posterior process is relatively much longer than in either of the others and extends backward with much the same slant as in No. 7322. The posterior extremity is thickened by the inward curvature of the lower edge, the face thus formed looking almost directly downward. The cotylus is exceptionally deep, as there is a strong buttress developed near its anterior edge which maintains its width to the upper edge of the bone. The upper edge of the cotylus is extended forward on the anterior portion of the bone, forming a sharp ridge and giving the whole region, and the articular face for the pubis, a triangular section. The articular faces for the ischium and the pubis are exceptionally heavy. On the inner side there are no deep cavities for the articulation of the distal ends of the sacral ribs. The upper portion of the blade is smooth and is free above the sacrum for some distance; this surface is only gently concave. The upper edge of the ilium is thickened at the anterior and posterior edges, but the median portion is quite thin and sharp. This is decidedly different from the two other forms described, where the upper edge is thick and heavy throughout its length, the median part being nearly as thick as either of the ends.

No. 7266, discovered near the head of Holmes Creek, in Crosby County, Texas, consists of the two ilia and the sacral vertebræ complete, except for the neural spines. The specimen has been slightly crushed from above downward, but not enough to materially distort the specimen. The ilia are similar in form to No. 7333, but nearly twice as large; they probably belong to an animal of the same species, but of larger size. The anterior process of the blade of the ilium (fig. $27 \mathrm{E}$ ) is relatively slender, reaching a little more than halfway to the articulation with the pubis; its extremity is very slightly down-curved. The posterior process is long, and the lower edge extends backward, almost directly from the articulation with the ischium, at a gentle angle. The cotylus is deep, especially near the anterior end, where there is a strong buttress reaching down from the upper edge of the bone to the upper edge of the cotylus. The articular edges for the ischium and pubis meet in a large angle. The upper edge of the blade is relatively thin, with slight thickenings at the anterior and posterior ends. The articular portions of these edges outside of the cotylus are very heavy. The slight depression of the pelvis has thrown the lower edges of the ilia inward and the upper edges outward, slightly, so there is an apparent flattening of the upper surface. The blade of the ilium on each side rises free from the upper surfaces of the sacral vertebræ, and there is a decided concave area on each bone on the inner upper side. The articulation of the distal ends of the sacral ribs is close and firm, the anterior one being received in deep rugose pits and the posterior one articulating along the length of a rather heavy ridge (fig. $28 \mathrm{~A}$; plate 12, figs. A and $\mathbf{B}$ ).

The sacrum is formed of two heavy vertebræ; the neural spines have been destroyed and the neural arches are pressed downward, almost closing the neural canal, but they were not high even in the undistorted specimen. The two vertebræ were not anchylosed, even in this evidently adult specimen, and the zygapophyses between the two sacral vertebræ are still well formed and distinct, though somewhat injured. The sacral ribs are very wide and strong, giving a powerful attachment of the pelvis to the vertebral column. The ribs originate high upon the sides of the neural arch, almost at the level of the zygapophyses; there is no indication of sutures at the proximal ends. The anterior ribs originate along the full length of the side of the vertebræ, the anterior edges being as far forward as the anterior extremity of the prezygapophysis, and the posterior edges originating relatively as far back. This rib is very heavy at its proximal end and becomes more so as it extends outward in a fan-shape; the distal end is at least 3 centimeters thick 
where it fits into the deep pits on the inner side of the ilium. There is a notch on the posterior side near the proximal end which is in opposition to a similar notch on the anterior side of the proximal end of the second rib, leaving an opening for the escape of the nerves between the two vertebræ. The anterior rib slightly overlaps the posterior rib at the distal end.

The second rib is nearly as large at its origin as the anterior one, but the neck is somewhat narrower, due to the presence of notches on the anterior and posterior edges. Its anterior edge slants somewhat forward, but not at so great an angle as the posterior edge, which extends back to the extremity of the posterior process of the blade of the ilium. The distal end is not so much thickened as in the anterior rib, and the posterior portion of the distal end attaches to the ridge on the inner side of the ilium by an overlap.

Specimen No. 7470 consists of the nearly entire right half of the pelvis, with the two sacral vertebræ and several associated dorsals. It was found by the author near

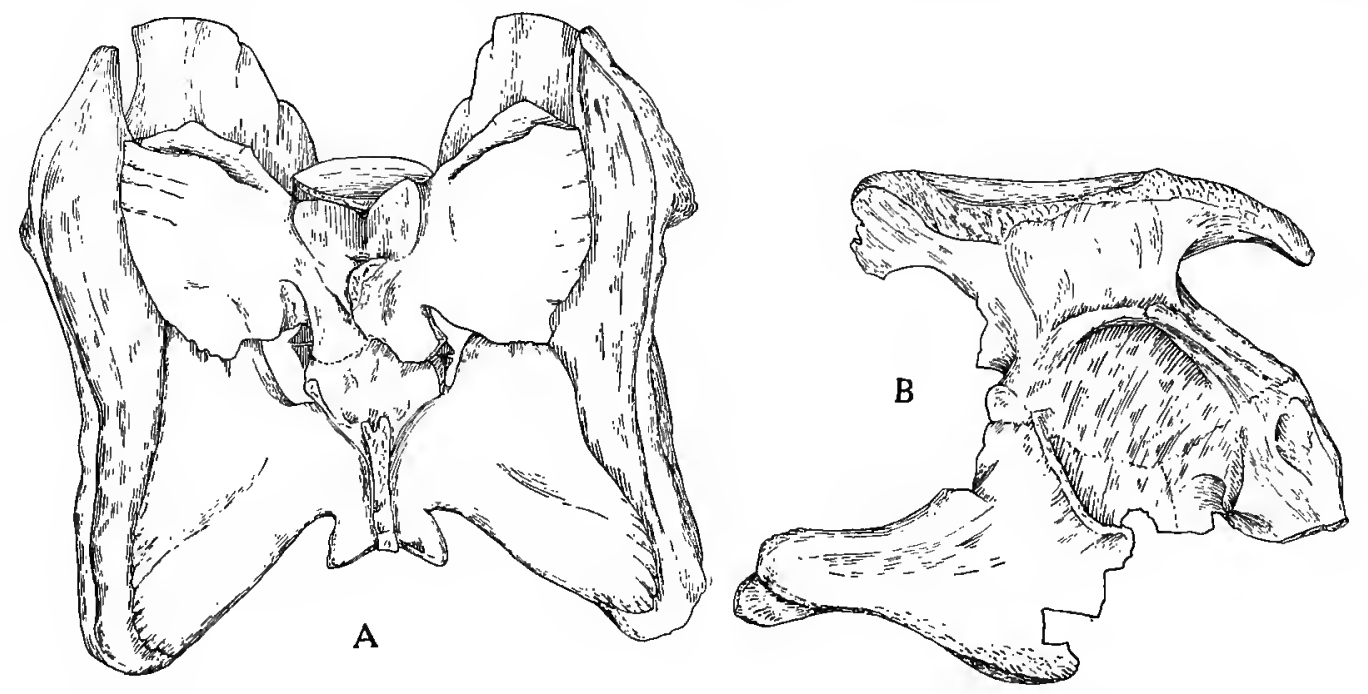

FIG. 28.

A. Upper surface of pelvis and sacrum, No. 7266, U. of Mich. $\times 0.25$.

B. Right side of pelvis, No. 7470 , U. of Mich. $\times 0.25$.

the head of Holmes Creek, Crosby County, Texas. The posterior half of the ilium has been slightly crushed down and out, and the distal portion of the pubis is lacking, but the ischial portion of the symphysis is complete and a part of the ischium of the left side is preserved.

The form of the ilium (fig. $28 \mathrm{~B}$ ) is most like that of No.7322. The anterior process is long, reaching as far forward as the articulation with the pubis, and the distal end is slightly but definitely down-turned. There is no buttress over the anterior portion of the upper edge of the cotylus. The posterior process is somewhat distorted by the crushing described above, but it is apparent that its lower edge rose rather abruptly, much more so than in No. 7322.

The upper edge of the blade of the ilium is decidedly thickened, more at the anterior and posterior ends, but also in the median portion. The top of the anterior process is wide and only slightly convex. Near the extremity of the posterior end there is a very decided thickening of the bone, due to the development on the outer face of a triangular prominence resembling the buttress which is described upon specimens 7333 and 7266, but at the opposite end of the blade of the ilium. The cotylus is very deep in the anterior 
upper portion, but otherwise it is more shallow than in any other of the specimens; this may be in part due to the distortion of the specimen. On the inner side there is a much wider area above the place of the attachment of the distal ends of the sacral ribs; the anterior rib was received into a deep rugose pit, as in specimen 7244 , and the posterior rib was attached along a ridge which ran backward from the pit. The anterior face of the lower part of the ilium descends toward the articulation with the pubis much more directly than in any other of the specimens.

The ischium and pubis are closely anchylosed with the ilium, so that it is difficult to follow the sutures. The anterior edge of the proximal portion of the pubis continues almost directly downward from the articulation with the ilium; just below the articulation there is a large pit near the edge. A little below this, and in the lower part of the cotylus, is the opening of the pubic foramen. The distal portion of the pubis is lost.

The posterior edge of the ischium runs downward and then turns sharply forward, forming the upper edge of a narrow but strong process. The symphysis is preserved forward almost to the juncture of the ischium with the pubis; the union of the bones of the two sides is strong, as they meet in a wide articular face and are firmly fastened together in the specimen. The line of the symphysis, so far as preserved, is sigmoid.

The sacrum of this specimen is complete and resembles that of No. 7266. The anterior rib rises from the level of the zygapophyses and is very heavy; the rib stands with its greatest diameter vertically, which is perhaps the normal position. The distal end was received in a pit on the inner side of the ilium. The two vertebræ are separate and the zygapophyses between them are distinct and well formed. The neural spines of the vertebræ are complete and show an enlargement of the upper end, forming heavy flat tables which overhang the sides of the neural spine. The upper surface of the tabular expansion is marked by a shallow depression which runs antero-posteriorly.

In comparison with the pelvis of Rhytidiodon carolinensis, as figured by McGregor, Nos. 7333 and 7266 are apparently of the same type and are probably Mystriosuchids, but Nos. 7470, 7244, and 7322 are decidedly different. The ischium of No. 7470 resembles that of $R$. carolinensis, but the posterior (upper) edge is perhaps a little more curved, the symphysis is stronger, and the lower edge of the symphysis is sigmoid in outline. There is no suggestion of a space between the ischium and pubis, filled during life with cartilage; the two halves of the pelvis meet at a decided angle, and there could have been little opportunity for a median vacuity. The pubis is largely lost, but the anterior edge is decidedly convex in its upper portion, suggesting a very different contour from that of $R$. carolinensis. These differences, combined with the shape of the ilium, suggest that this pelvis belonged to some member of the Phytosaurid group, a suggestion borne out by the few plates found with the specimen which are typically phytosaurian. The peculiar outline of the upper part of the anterior edge of the pubis, suggesting a more vertical position of the anterior face of the pubis, recalls the peculiar pelvis described by Mehl, ${ }^{1}$ from the Triassic of New Mexico, as Acompsosaurus wingatensis, and even more the condition found in the Pseudosuchians Ornithosuchus and Euparkeria. It is not supposed that the resemblance implies genetic relationships, but so little is as yet known of the Triassic reptiles in North America that note must be taken of suggested resemblances until their value may be correctly estimated. In v. Meyer's paper upon the Reptilia of the Steuben Sandstone of the Upper Keuper ${ }^{2}$ there are figured three phytosaurian ilia. Figure 1 has much the same form as Nos. 7333 and 7266, described and figured above, while figure 5 resembles more closely No. 7244. Von Meyer did not assign the ilia figured by him to any definite genus or species.

\footnotetext{
1 Mehl, M. G., Quarterly Bulletin of the University of Oklahoma, new series, No. 103, p. 33, 1916.

${ }^{2}$ Meyer, H. v., Paleontographica, Bd. 7, Taf. 41, figs. 1, 3, 5.
} 
There is a single left scapula (No. 7472, University of Michigan), in a somewhat imperfect condition, the proximal end being slightly injured by decay. It is impossible to give the exact outline of the anterior edge (see fig. $29 \mathrm{~A}$ ), but there was evidently a much greater extension of the region than in Rhytiodon carolinensis. The wide extension of the anterior lower border recalls that of the Permian Pelycosauria and some of the South African Upper Paleozoic reptiles. The articular face for the coracoid is thick and heavy. The distal end of the blade was broken and the parts somewhat overthrust, but making allowance for this the total length was $277 \mathrm{~mm}$., slightly larger than $R$. carolinensis.
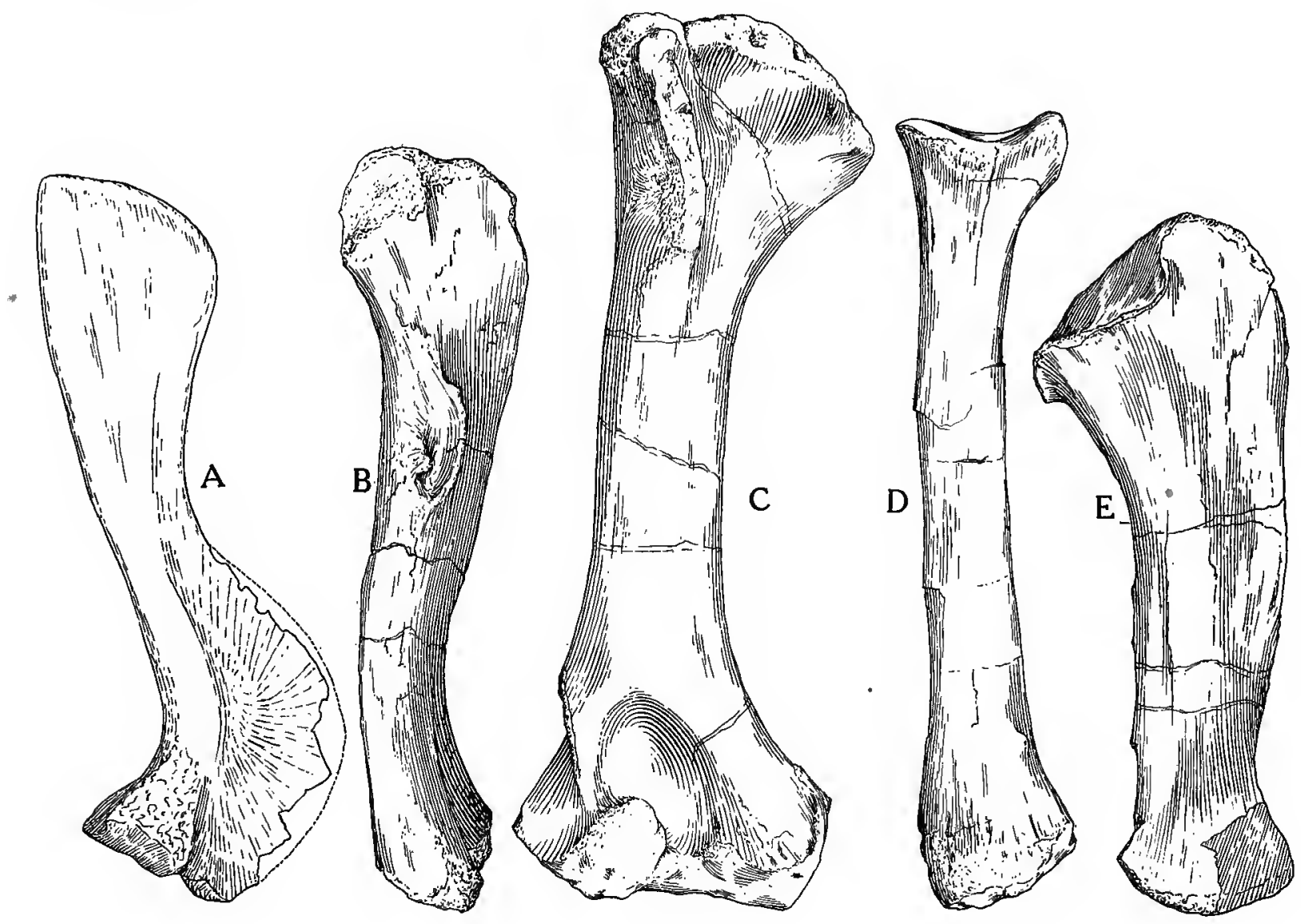

FIG. 29.
A. Right scapula, No. 7472 , U. of Mich. $\times 0.15$.
B. Right femur, No. 3395 , U. of Mich. $\times 0.15$.
C. Right humerus, No. 7312, U. of Mich. $\times 0.15$.
D. Right radius, No. 7312, U. of Mich. $\times 0.15$.
E. Right ulna, No. 7312, U. of Mich. $\times 0.15$.

A single right coracoid (No. 7315, University of Michigan) is too imperfect for figuring or description, but shows the presence of a large notch on the anterior edge.

A very imperfect scapula-coracoid (No. 7471, University of Michigan) shows only the proximal portions and the outlines of the cotylus. Evidently there was in this specimen the same large expansion of the anterior lower portion of the scapula as in No. 7472 , but the size of the preserved portions indicates an animal at least one-half larger. 
There are two femora in the collection (Nos. 7330 and 3395, University of Michigan). The first is a very small femur $73.5 \mathrm{~mm}$. long, apparently of an immature individual. The articular ends are imperfect, as if incomplete ossification had permitted their rapid decay. The trochanter is large compared to that in larger specimens and is well formed. The second femur is from the right side of a fairly large individual. It corresponds in form very closely with that of $R$. carolinensis (fig. 29 в).

In one small spot north of the Spur-Crosbyton road the remains of two or three large Phytosaurs were found in close proximity. Most of the bones were badly weathered, but a humerus, radius, and ulna were collected in close association and in good condition. It has been assumed that these bones belonged to one individual, as they are of the proper size and of the same side. They have been numbered 7312 in the University of Michigan collection.

The humerus (fig. $29 \mathrm{c}$ ) has the two articular ends of nearly equal breadth, with the long axes inclined at a slight angle to each other. The deltoid ridge is broken away in part, but stood nearly at a right angle to the proximal end of the bone. The shaft is nearly cylindrical. The lower end has a well-developed, nearly hemispherical head for the radius and a distinct articular surface for the ulna. There is a distinct ectepicondylar process which is not complete in the specimen. There is no entepicondylar notch or foramen. The total length of the humerus is $28.35 \mathrm{~cm}$.; the breadth of the upper end is $14.2 \mathrm{~cm}$. , and the breadth of the lower end $12.7 . \mathrm{cm}$.

The radius (fig. 29 D) has a nearly straight cylindrical shaft; the upper end has a well-formed concave articular surface; the lower end is but slightly expanded. The total length is $24.6 \mathrm{~cm}$.

The ulna (fig. $29 \mathrm{E}$ ) is very broad proximally and gradually contracts in breadth to the lower end. The shaft is compressed, so that it is much thinner than broad; this may be, in part, due to compression. The articular face is shallow, and there is a very small olecranon process. The out corner of the lower end was broken away and lost and has been restored in plaster. The total length of the ulna is $30 \mathrm{~cm}$.

All of these limb-bones, as well as the femur described above, and the remains of less perfect limb-bones in the collection indicate that the Phytosaurs of the region were relatively long-limbed forms and must have been capable of raising the body from the ground for a time at least, and also that they were capable of relatively rapid progression upon the land.

There are in the University of Michigan collection four basi-cranii of Phytosaurs, Nos. 7257, 7261, 7474, and 7505. The first three show the condyle complete, the last has the condyle broken away and lost. These are all typically phytosaurian in form and correspond closely with Huene's description of $P$. kappfi as opposed to his $P$. rutemeyeri. The general form is shown in figure 30, and plate 12, figure c, of No. 7261. All show clearly the pit in the occipital condyle for the anterior end of the notochord.

No. 7474 is the smallest, and is interesting in that it shows the lower portions of the exoccipitals in position, meeting in the median line and excluding the basioccipital from any part in the foramen magnum. (Plate 12, fig. D.)

No. 7505 is the next largest. The exoccipitals are lost, and it shows clearly the corrugated articular surfaces on the basioccipital for the exoccipital. The floor of the brain-case is eroded and the suture between the basioccipital and the basisphenoid is clearly traceable all round the bone. The edges of the shallow hypophysial cavity are broken away and the entrance of the foramina for the internal carotid arteries into the cavity is very clear. (Plate 12, fig. E.)

No. 7261 is the third largest and the most perfect. The tubera basioccipitalia are seen to be formed by both the basioccipital and the basisphenoid. The tubera are 

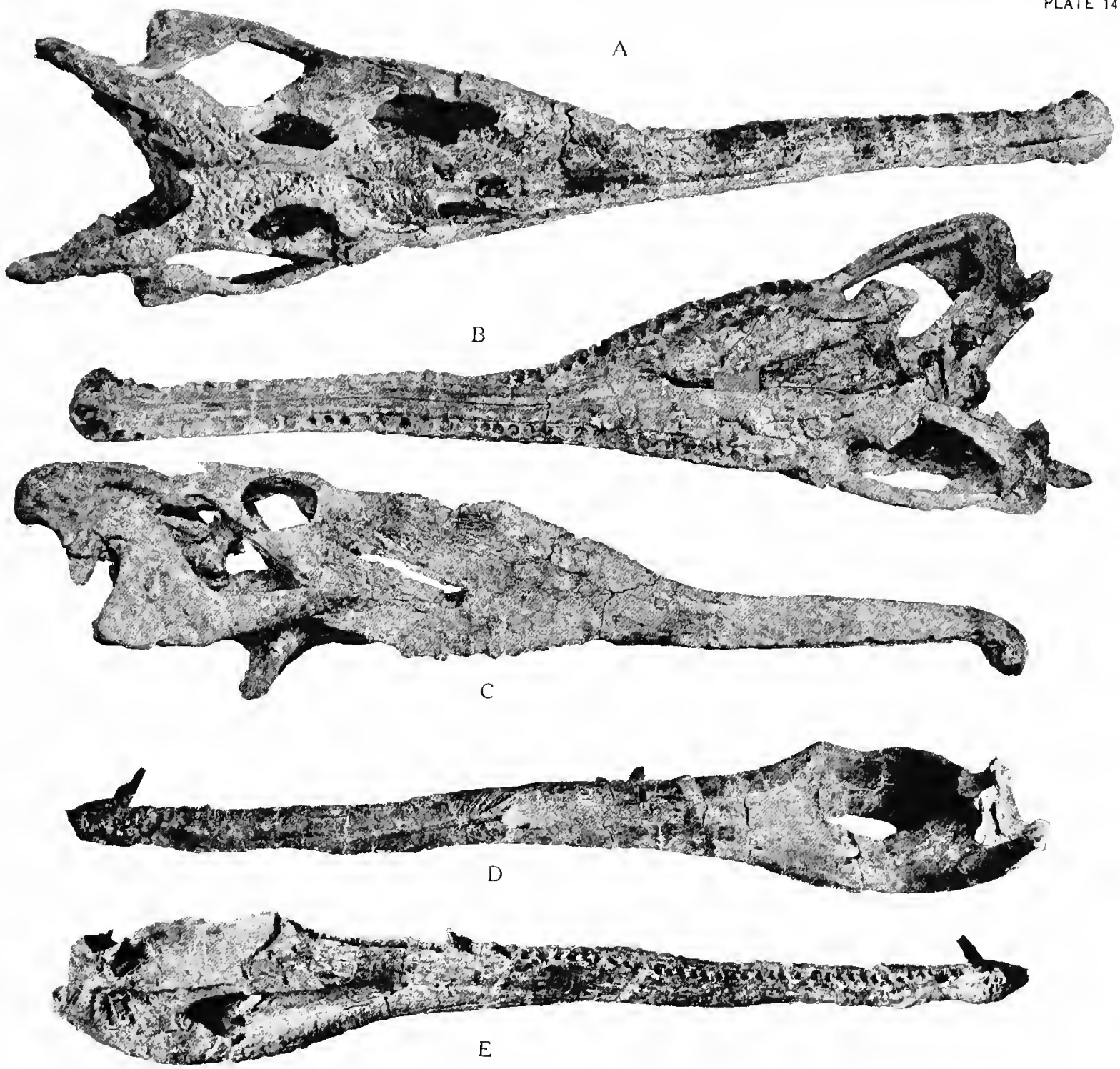

Leptosuchus crosbiensis, University of Michigan. All figures $\times 0.15$.
A. Upper surface of skull.
D. Inner side of the right lower jaw.
B. Lower surface of skull.
E. Outer side of the right lower jaw.
C. Right side of skull. 

prominent and rugose, with a deep, irregular groove marking the position of the suture. Between the tubera is a sharp angulation marking the line between junction of the basioccipital and the basisphenoid, and along this the suture between the two bones is easily traced. On the sides of the basioccipital, just posterior to the basisphenoid suture, there is a shallow groove running upward and backward. Between the tubera and basipterygoid processes on either side are the large openings of the foramina for the internal carotid arteries. These foramina run upward and inward and open a little to either side of the lower end of the hypophysial cavity. The cavity is triangular in section above, but contracts rapidly below; it is surprisingly small and shallow. The basipterygoid processes are well developed and point outward and downward, with a smooth, flat, oval face for the pterygoid. The sphenoidal rostrum is broken away in all of the specimens, but was evidently vertical, narrow, and of great extent. In none of the specimens is there any suggestion of a composite structure, i. e., an upper (presphenoidal) and a lower (parasphenoidal) portion, such as described and figured by Huene.
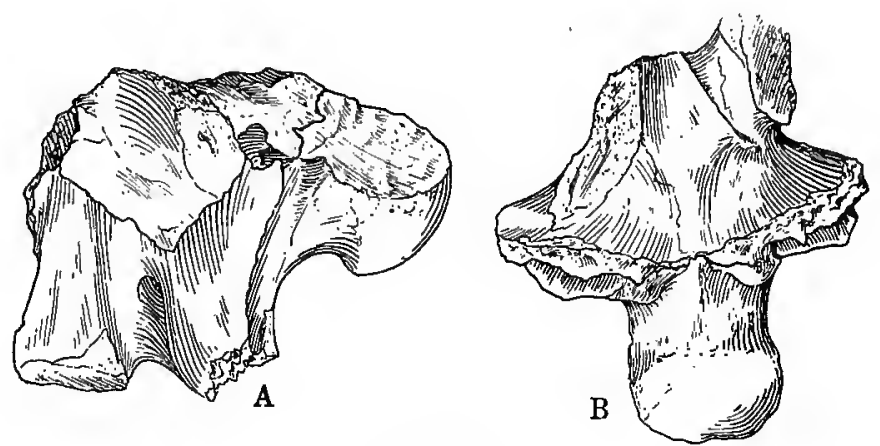

Fig. 30.

A. Basicranial region, left side, No. 7261, U. of Mich. $\times 0.6$.

B. Lower side of same.

No. 7257 is the largest of the specimens, being nearly twice the size of No. 7474 and the least well preserved. It has lost the occipital condyle and parts of the tubera and basipterygoid processes. The anterior lower part of the basioccipital is still in position, and clean breaks show the suture between it and the basisphenoid. The whole basisphenoid is shorter and higher than in the other specimens. The basipterygoid processes are shorter and less well developed; they pointed more directly backward, and on the inner posterior corner of the base of each there is a prominent rugosity, which on the left side has the form of a pit with elevated edges. The space between the basipterygoid processes is marked by two prominent rugose ridges, which converge forward and unite at the origin of the sphenoidal rostrum. It would appear that this space between the processes was almost vertical instead of slanting rather steeply upward and forward, as in the other specimens, but as this would make the sphenoidal rostrum rise vertically in the skull it is probable that the position of the occipital condyle was different from that it occupies in the other specimens. This specimen is so much larger and so different from the others and from any described form that it indicates, in all probability, a new species, but it seems undesirable to give a new name to such imperfect material, especially as the large size suggests the possibility that the peculiar features may be due to advanced age. 


\section{DESCRIPTION OF THE REMAINS OF DINOSAURS.}

Certain specimens collected in Crosby County, in the same beds with the Phytosaurs, indicate the presence of a small Dinosaur. Notable among these are a posterior cranial region (No. 7473, University of Michigan) and a string of cervical and anterior dorsal vertebræ (No. 7507). Both of these specimens were collected on the west side of the Blanco River, north of Cedar Mountain, the first in the breaks to the south of the old Spur-Crosbyton mail-road and the second in the breaks just north of that road.

The cranial region is well preserved in a hard matrix of clay, which has permitted the working out of the smaller details and the foramina of the region. As shown in plate $13 \mathrm{D}$ to $\mathrm{F}$, the basicranial floor is preserved as far forward as the hypophysis. The distal portions of the exoccipital opisthotics are lost. The occipital condyle is nearly hemispherical, with an extremely short neck. The portion of the basioccipital below the condyle descends almost vertically and the posterior edges of the tubera are not in advance of the anterior edge of the condyle. The vertical portion of the basioccipital is deeply concave posteriorly and the lower face of the neck of the condyle is perforated by two small foramina near the middle line, probably for nutrient vessels. The sutures between the basioccipitals, exoccipitals, and supraoccipitals can not be made out. The foramen magnum is depressed oval in outline, with the transverse axis nearly as great as the width of the condyle. The supraoccipital is smooth, slightly concave, and slants upward and forward to the rough, incomplete edge, which must have been very near to the articular surface for the bones above. As described by Huene in Anchisaurus, the exoccipital has three ridges; one runs inward and backward to the upper outer edge of the condyle, one downward on the outer side to the tubera, and one outward and backward to form the lower edge of the opisthotics. In the angle formed by the last two there is the good-sized opening of the foramen for the XII nerve. This foramen can be traced on the broken surface of the bone to its opening on the inner side, not far within the edge of the foramen magnum.

The lateral view of the specimen (plate $13 \mathrm{E}$ ) displays the peculiar characters of the skull most strikingly. The inner portion of the opisthotic and the prootic meet in a smooth concave surface which is inclined to the posterior surface of the supraoccipital, so that the two would meet at a sharp angle. The beginning of the opisthotic shows that that bone extended outward and backward and slightly upward. On its lower side is a deep groove which leads into the surprisingly large otic cavity. Below this cavity the basisphenoid extends downward, terminating in the long and slender basipterygoid processes. The distal ends of these processes are broken away, so that it is impossible to determine the nature of the articulation with the pterygoids. The basipterygoid processes are rounded and heavier behind, but become very thin anteriorly; the anterior edges are broken away, but it appears that the processes of the two sides came together, or very nearly so, in the median line. Between and beneath the anterior portions of the process is a large cavity extending forward as far as the groove on the side of the basisphenoid described below. This cavity is apparently blind; no openings in its wall have been detected, though an artificial opening was made by the needle in the thin anterior portion. The side of the basisphenoid is peculiar. In the broken condition of the specimen it appeared as if the bone were composed of two parts, an anterior overlapping below on to the posterior part, which in turn overlapped in the same way upon the basioccipital; this appearance, however, is less apparent when the upper half of the brain-case is put in place, for the upper part of the apparent groove on the side of the basisphenoid is resolved into a part of a foramen. The anterior portion of the basisphenoid has 
the sides slanting obliquely inward and downward until they meet in a thin edge below; the extreme terminus of this edge is broken away. Posteriorly there is a break between the edge and the anterior portion of the posterior part of the basisphenoid, formed by the approximating edges of the basipterygoid processes. This break emphasizes the apparent bipartite character of the basisphenoid. On the sides of the basisphenoid and marking the line between the two portions is a groove, which is very pronounced below and becomes very shallow in its upper third. A little below the middle of the course of the groove there is a deep extension forward of the cavity which runs a little downward as well as forward. This cavity is so deep that exploration is difficult, but apparently its anterior end communicates by a very small foramen with the hypophysial cavity below. Above this cavity the groove becomes very shallow and finally terminates in a foramen which penetrates the wall of the brain-case. This foramen is the common terminus of two leads, one the groove just described and the other a foramen which in the specimen is first detected on the broken lower outer edge of the opisthotic; the distal termination of the latter is not determinable. From its position on the inner wall of the brain-case the common foramen is evidently the outlet for the VII nerve. The deep vacuities at the middle of the course of the groove are probably the inlets of the internal carotid arteries. Anterior to the grooves the sides of the anterior portion of the basisphenoid contract rapidly into the thin ridge on the lower edge; above this sharp edge and covered by it is a cavity, conical in form, with its posterior end almost a point and the anterior part much larger in diameter. The anterior edge of this opening is apparently coincident with an opening into the brain-cavity and so must be the cavity for the pituitary body. On the sides of the bones, just about opposite the cavity for the pituitary body, there are two small foramina on each side, probably for blood-vessels. On the upper edge, just anterior to the openings of the VII nerves, there is a large foramen on each side which can only be the opening for the $V$ nerve. The anterior portion of the basisphenoid described is in the position of the bone which is called by Osborn the orbitosphenoid.

On the inner side of the brain-case there is visible a decided angulation between the parts of the floor formed by the basioccipital and the basisphenoid; near the middle of the flat floor formed by the basisphenoid, but nearer the anterior than the posterior edge, there is a pair of small foramina in the position usually occupied by the VI nerve. The posterior part of the inner side of the brain-case wall is marked by a decided swelling which sheltered the inner ear. The exact interpretation of this region is impossible, because of the slight injury to the bone on both sides. Beneath the swelling marking the position of the canals of the ear there is an opening of considerable size on both sides, which leads directly into the large cavities on the sides of the skull at the inner end of the opisthotic. This opening in all probability was the outlet for the IX-XI nerves.

Just anterior to the swelling marking the position of the canals there is a shallow notch with an elongate form, its greatest diameter vertical; it is apparent that the bottom of this notch has not been reached in cleaning, and it seems very probable that there is a small foramen leading from it into the region of the otic canals; if this is correct, this notch marks the position of the escape of the VIII nerve; but a similar notch is shown by Osborn, in his figure of Tyrannosaurus, just posterior to the otic region, which he regards as marking an evagination of the dura mater into the cranial wall. Almost directly above these notches and near the anterior edge of the preserved portion of the cranial wall there is a second deep pit on each side which can not be traced through the bone and appear to be blind; these are almost exactly in the position marked by Osborn, in his figure of Tyrannosaurus, as other evaginations of the dura mater.

This fragment of a skull is so radically different from that of the Phytosaurs found in the same beds, and corresponds so well with the figures and descriptions, so far as they have been given, of the same region in the primitive Theropodous Dinosaurs, that there 
can be very little doubt of its subordinal position. Little can be said of its generic position. The only other Dinosaur remains that have been found in the Triassic of the Southwest are the very incomplete remains of forms described by Cope as Colophysis from the Gallina Mountains in New Mexico. These forms are placed in the family Coluridæ, occurring in the Upper Keuper in Europe and in the Upper Triassic in North America. For the present, this fragmentary skull and the few vertebræ described below may be provisionally placed in or near this genus, especially as the remains of Phytosaurs and Stegocephalians which occur in the same beds indicate an Upper Triassic age.

In 1887, Cope ${ }^{1}$ described the remains of a small genus of Dinosaur from New Mexico, which he at first placed in the genus Colurus, later referred to Tanystrophous, and finally placed in a new genus, Cœlophysis. ${ }^{2}$ Three species were described-longicollis, bauri, and willistoni. According to Huene, the type material of the last species has been lost.

During the summer of 1921 the author collected a series of small Dinosaur vertebræ (No. 7507, University of Michigan), a few miles north of Cedar Mountain, in Crosby County, Texas, in the same beds with the Upper Triassic Phytosaurs and Stegocephalians described in this paper. When found the vertebræ were in position, but were fully exposed and badly broken as they lay on the crumbled surface of a light cream-colored clay. The anterior and posterior members of the series and many small fragments of ribs were loosened from the rest of the series and had slipped down the face of a rather steep slope. Because of the crumbled condition of the matrix, it was impossible to collect the specimen in a block; it could only be taken up with as much of the matrix as possible, which was filled with the minute fragments which had been separated from the vertebræ. Reassembling the specimen has been a very long and tedious piece of work and has been only fairly successful as yet, but enough has been accomplished to show the character of the vertebræ. The specimen is of importance, as it is the largest series of Dinosaur vertebræ yet found in a free condition in the Triassic of North America.

The series contains 20 complete vertebræ, with the remains of two very imperfect ones. Of the series, the first four are elongated and very similar to those figured by Huene as characteristic of Anchisaurus colurus and Colophysis. The fifth of the series is shorter and shows for the first time in the series a well-developed transverse process; it is probable that the first four are cervicals and the remainder dorsals. There is no certain indication of the sacrals; the transverse processes of the last two are indicated only by the bases, but these are well formed and not the bases of sacral ribs. In Anchisaurus there are 14 dorsals and probably 9 cervicals. According to Osborn ${ }^{3}$ there are 23 presacrals in Struthiomimus, Allosaurus, and Tyrannosaurus. In Struthiomimus, with 10 cervicals, the first dorsal is indicated by the presence of the first free rib according to Osborn. If we accept this as a criterion, the fifth of the series here described would be the first dorsal and there would be 16 dorsals, a number that seems excessive, but can be questioned only by considering the last two as sacrals, a proceeding that is not warranted by the form of the vertebræ.

The first of the series (sixth (?) cervical) was found a little separated from the series, washed down the bank, and the zygapophyses and the neural arch have not been reassembled. It can be seen, however, that the zygapophyses were elongate, low, and horizontal and that the neural spine was low. The centrum is elongate, the anterior face concave and broader than the posterior; its borders have been injured by decay. The lower face of the centrum is broader anteriorly and nearly flat at the anterior end;

${ }^{1}$ Cope, E. D., American Naturalist, pp. 367-368, 1887.

2 The literature of this genus is given by Hay, Bulletin United States Geological Survey, No. 179, p. 493, 1902, and Huene, Geol. u. Paleont. Abhdlg., N. F., Bd. viri, s. 118, 1906. In the latter paper figures are given of some of the specimens and the species are in part redescribed.

3 Osborn, H. F., Bulletin American Museum Natural History, vol. 35, art. 43, p. 735, 1917. 
posteriorly the lower face becomes rounded from side to side, with no trace of a keel or lateral ridges or angles. The posterior portion of the centrum descends slightly, maintaining its rounded outline. The posterior face has an oval outline, being higher than wide, due to the development of a lip on the lower edge. It is concave, but less so than the anterior face, and slants from above downward and backward. Length of the base of the centrum, $52 \mathrm{~mm}$.

The second of the series (seventh (?) cervical) is much more complete. It lacks the anterior zygapophyses and the neural spine. In this vertebra the anterior face is complete; it is deeply concave and is inclined parallel to the posterior face of the preceding vertebra, i. e., from above downward and backward. On either side of the anterior portion of the centrum there are two processes; the upper begins as a low ridge at about the middle point of the side of the centrum and extends forward to the edge of the anterior face, becoming more prominent during its advance. The second process, below the first, is shorter, not over $12 \mathrm{~mm}$., and heavier; it continues out upon the edges of the anterior face of the centrum, forming a $\mathrm{n}$ ar r ow triangular face which looks downward and outward and slightly forward. These two processes are distinct, as shown by several vertebræ,
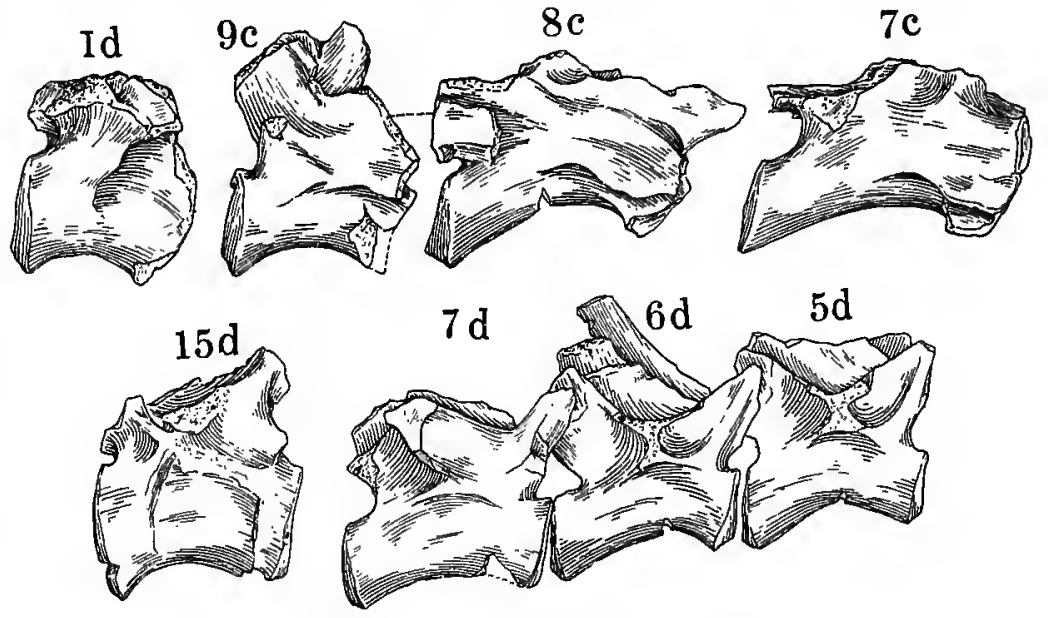

FIG. 31. but are very suggestive of

Cervical and dorsal vertebræ of a small Dinosaur, Coelophysis, sp. No. 7507, U. of Mich. $\times 0.5$.

the complete arch figure by $\mathrm{Marsh}^{1}$ in Colurus and described by Cope and Huene in Calophysis longicollis. It is possible, even probable, that there was such a complete arch in the anterior cervicals, but in the posterior portion of the cervical series the arch has broken into distinct diapophysis and parapophysis. The posterior zygapophyses are depressed and elongate, extending back nearly as far as the upper edge of the posterior face of the centrum. The rest of the vertebra is much like the preceding one. Length of the base of the centrum, $52 \mathrm{~mm}$.

The third of the series (eighth (?) cervical) has the upper process on the side of the centrum stronger and extending outward more than in the second; the process is a little higher on the side of the centrum. The lower process is shorter and has a larger face. The anterior zygapophyses are preserved; they are horizontal, heavy, and extend well forward of the anterior face of the centrum. Length of the base of the centrum, $44 \mathrm{~mm}$.

The fourth of the series (ninth (?) cervical) has the anterior zygapophyses locked with the posterior ones of the third; they are still nearly horizontal, but are slightly inclined upward. The upper process on the side of the centrum is now very strong and stands well out from the vertebra; it is so high upon the centrum that its lower edge is but slightly below the lower face of the neural canal. The anterior edge of the centrum is injured, but it can be seen that the lower process is now but a triangular face on the lower edge of the face. Length of the base of the centrum, $42 \mathrm{~mm}$.

${ }^{1}$ Marsh, O. C., Dinosaurs of North America, Sixteenth Annual Report U. S. Geological Survey, plate vir, figs. 2, 2a, 1896. 
This structure of the posterior cervicals is very similar to the condition found in Sellosaurus hermannianus Huene. ${ }^{1}$

The fifth of the series (first (?) dorsal) has the upper process on the side of the neural arch; only its proximal portion is preserved, but it is apparent that it stood well out from the side of the arch, forming a distinct transverse process. The lower process is a triangular face on the lower edge of the anterior face of the centrum. In this vertebra the zygapophyses and the neural spine have not been replaced. Due in part, but not entirely, to compression, the centrum is notably shorter and heavier than the preceding one and the posterior face of the centrum does not descend lower than the anterior. The faces of the centrum are now vertical and larger than in the cervical series. Length of the base of the centrum, $27 \mathrm{~mm}$.

The sixth of the series has a well-developed transverse process which stands out at right angles from the high neural arch. This process is supported by two ridges running from the upper edges of the anterior and posterior faces of the centrum to its base; between these ridges and on either side of the base of the processes are deep pits. The lower process is still visible as a small facet on the lower edge of the anterior face of the centrum. The neural arch is high and the anterior and posterior zygapophyses rise at a considerable angle instead of lying horizontal. Length of base of centrum, $27 \mathrm{~mm}$.

The seventh of the series has well-developed transverse processes; the extremities are not replaced, but the base shows that they stood out at right angles to the neural arch. The base is supported by four ridges running respectively from the anterior and posterior zygapophyses and from the upper edges of the anterior and posterior faces of the centrum. Between these ridges, on the anterior and posterior faces of the base of the transverse process, there are deep pits. Upon this vertebra appears the last trace of the lower process. The zygapophyses have not been replaced, but it is evident that they rose at a decided angle from the neural arch. The lower edge of the centrum is injured, but its length is approximately $32 \mathrm{~mm}$.

From this point in the series backward the vertebræ do not change radically. The transverse processes increase slightly in length and then decrease; the longest are upon the tenth to the thirteenth. The zygapophyses are very steeply inclined upward on the ninth and tenth and are less steeply inclined in the posterior vertebræ. The centra become gradually heavier toward the posterior end of the series, and the bases of the transverse processes are shorter anterio-posteriorly, due to the atrophy of the supporting ridges. In none of the vertebræ is there any sign of a median keel on the centra or of any lateral ridges. The length of the base of the centrum of each is as follows:

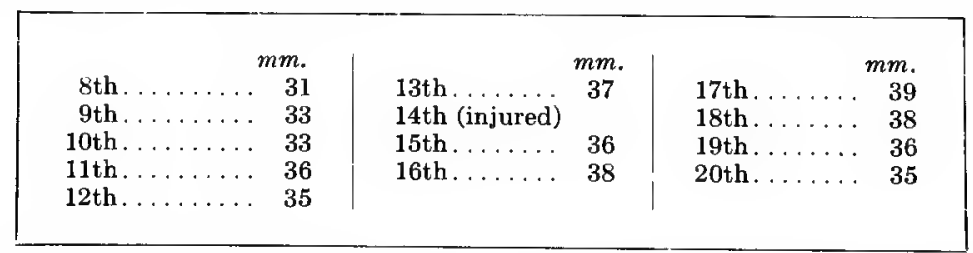

These measurements are as accurate as possible, but are not quite as in nature because of slight compression, breakage, etc., in the specimen.

Fractures in the mid-line of several vertebræ show that the centrum was hollow, but not so thin-walled as in Colurus. The ribs are uniformly single-headed; one attached to the fourteenth vertebra has a thin head $7 \mathrm{~mm}$. wide; other rib-heads not located, but apparently belonging to more anterior vertebræ, are nearly twice as broad." The shaft of the rib in certain parts of the series was T-shaped in section. The ribs are so badly broken and the ends so injured by decay that only portions have as yet been reassembled.

${ }^{1}$ Huene, F. v., Neues Jahrb. f. Geol. Min. u. Pal. Jahrg., 1915, No. 1, Taf. 111. 
These vertebræ must be tentatively assumed to belong to a small Dinosaur, such as bore the skull, the posterior portion of which is described above, as the sizes of the two specimens correspond very closely, and as they were found in the same beds and but 2 or 3 miles apart. Until further evidence is found, the vertebræ may be assigned to the genus Colophysis.

A femur, No. 3396 , University of Michigan (fig. 32), is rather puzzling. It is 42.16 centimeters in length. Compared with a typical phytosaurian femur (No. 3395), it is much heavier at the articular ends and the articular surfaces are better formed. The relation of the long axes of the articular ends is different in the two forms; in No. 3395 the axes are nearly at right angles, so that when the head was in the socket of the pelvis the anterior face of the lower end was presented almost directly forward; in the second femur the axes are at an angle of $60^{\circ}$, so that the anterior face of the lower end was presented inward as well as forward.

In the phytosaurian femur the trochanter has the characteristic form of an oval elevation with a depressed center, and the lower end has a simple articular region obscurely divided into two parts. In the other femur the trochanter is simply a heavy rugose area but little raised above the rest of the bone; the lower end is heavy and divided into two areas, but on the posterior side of the outer part there is a prominent process which is continued upward on the shaft of the bone

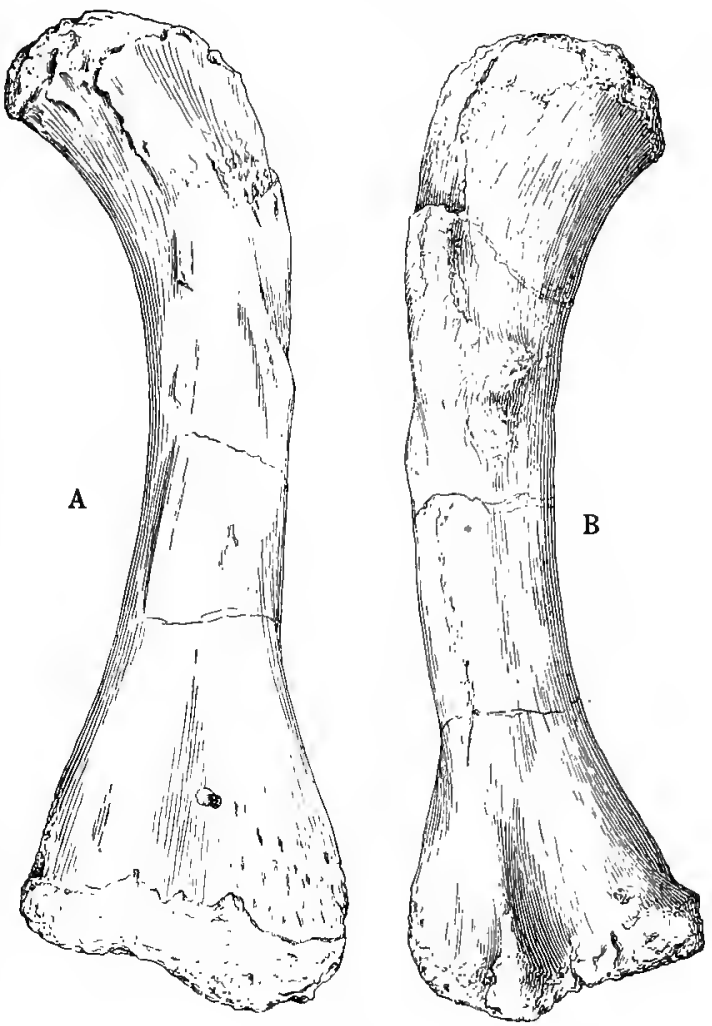

F1G. 32.

A. Left femur of a Dinosaur, front view, No. 3396. U. of Mich. $\times 0.25$.

B. Posterior view of same.

as a ridge for some distance. This femur has a very dinosaurian aspect, resembling in many details the figures of the femora of Plateosaurus and Gressylosaurus from the Triassic of Europe, and, so far as can be determined, the femur of Anchisaurus from the Triassic of North America. No remains of Dinosaurs of the size indicated by this femur have been found in the Triassic of the western portion of North America; Colophysis Cope was decidedly smaller. It is to be hoped that more material revealing the skeleton of this Dinosaur will be found.

\section{COPROLITES.}

There are several types of coprolites contained in the collection. The number found in the Holmes Creek region is very large and the condition of preservation is in most cases very good.

The first type is that which must be assigned to the larger reptiles and stegocephalians. These vary from $5 \mathrm{~cm}$. in length to as much as 15 or $18 \mathrm{cms}$. Theform is generally regular, with smooth surfaces. In none that have been found has it been possible to detect anything, such as comminuted bones or scales, that would indicate the nature of the food. Microscopic sections have not been made of any of the coprolites. 
The second type is small, ranging from $1 \mathrm{~cm}$. to as much as 7 , in extreme cases, in length. They show very perfectly the spiral nature of the coprolite; two very good specimens are shown in figure $33 \mathrm{~A}$ and $\mathrm{B}$. It seems probable that these are the coprolites
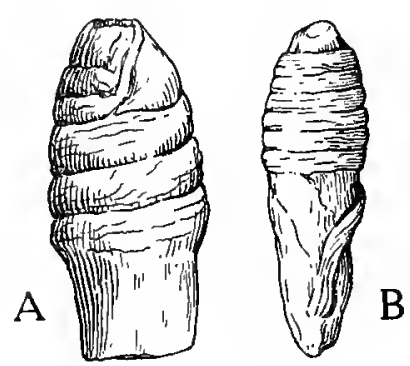

B
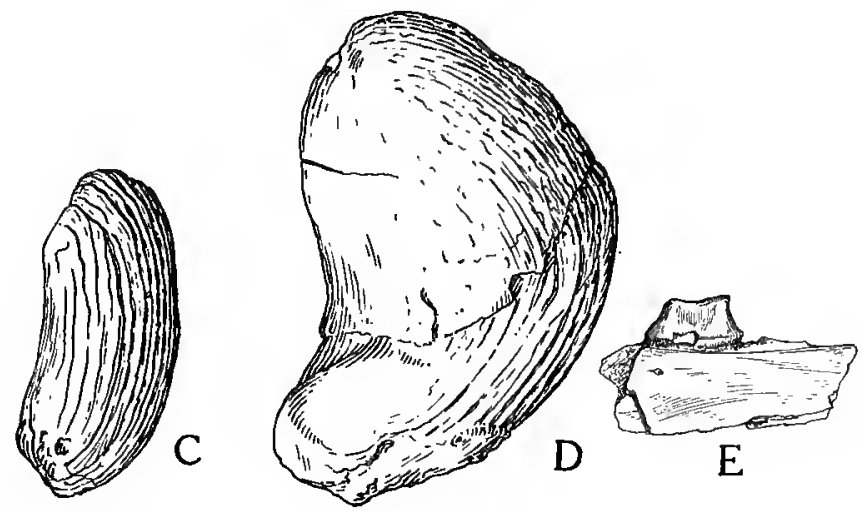

FIG. 33.

A and B. Two coprolites showing trace of the spiral valve. $\times 1$.

$\mathrm{C}$ and $\mathrm{D}$. Two coprolites showing the longitudinal ridges. $\times 1$.

E. Figure of a tooth of an unknown form, No. 7506, U. of Mich. $\times 1$.

of the Dipnoan fish of the region, but in the light of the great number of the coprolites it is strange that not more of the skeleton of the fish has been found; only two teeth and no other parts of the skeleton have been found. ${ }^{1}$

The third type of coprolite is very different from the other two. These range from 2.5 to $7 \mathrm{~cm}$. in length. They are all somewhat curved, sometimes approaching a crescentic form. In many, especially of the smaller coprolites of this type, the outer side of the curve is marked by deep and regular grooves very evenly spaced (fig. $33 \mathrm{c}$ ). This is so striking that when the first fragment of one was found it was suspected that it represented the surface of a Cephalopod shell. In most of the larger coprolites of this type the markings are very obscure or wanting, but the curved form is always characteristic. In the larger forms there is frequently an additional part of the coprolite which fits over the end as a cap or cloak (fig. $33 \mathrm{D}$ ). It is impossible to associate this type of coprolite with any definite group of animals; the only suggestion that can be made is that in many amphibians the distal portion of the rectum is thrown into parallel linear folds-just such an arrangement as would make linear markings upon the fœcal mass.

\section{INCERT 2 SEDIS.}

A small fragment of a jaw contains a very singularly shaped tooth which the author has been unable to identify, or even to determine its relationships. As shown in figure $33 \mathrm{E}$, the tooth is elongate oval in section, with the greatest diameter parallel to the length of the jaw. In general outline it is reminiscent of the teeth of the PermoCarboniferous reptile Diadectes, but the upper edge is contracted, slightly concave anteroposteriorly, and has a narrow, flat surface, slightly inclined toward the outer (?) side. The outer (?) side of the tooth is slightly concave, and there is a swelling at the base and then a sharp contraction. The tooth is without root and attached directly to the bone. The base of a second tooth shows the rather spongy character of the base (fig. $33 \mathbf{~} \mathbf{m}$ ).

\footnotetext{
${ }^{1}$ Casc, E. C., Occasional Papers of the Museum of Zoology, University of Michigan, No. 101, Apr. 9, 1921.
} 





